University of Nebraska - Lincoln

DigitalCommons@University of Nebraska - Lincoln

\title{
Beneath the surface of global change: Impacts of climate change on groundwater
}

Timothy R. Green

USDA-Agricultural Research Service (ARS), tim.green@ars.usda.gov

Makoto Taniguchi

Research Institute for Humanity and Nature

Henk Kooi

VU University

Jason J. Gurdak

San Francisco State University

Diana M. Allen

Simon Fraser University

See next page for additional authors

Follow this and additional works at: https://digitalcommons.unl.edu/usdaarsfacpub

Part of the Agricultural Science Commons

Green, Timothy R.; Taniguchi, Makoto; Kooi, Henk; Gurdak, Jason J.; Allen, Diana M.; Hiscock, Kevin M.; Treidel, Holger; and Aureli, Alice, "Beneath the surface of global change: Impacts of climate change on groundwater" (2011). Publications from USDA-ARS / UNL Faculty. 851.

https://digitalcommons.unl.edu/usdaarsfacpub/851

This Article is brought to you for free and open access by the U.S. Department of Agriculture: Agricultural Research Service, Lincoln, Nebraska at DigitalCommons@University of Nebraska - Lincoln. It has been accepted for inclusion in Publications from USDA-ARS / UNL Faculty by an authorized administrator of DigitalCommons@University of Nebraska - Lincoln. 


\section{Authors}

Timothy R. Green, Makoto Taniguchi, Henk Kooi, Jason J. Gurdak, Diana M. Allen, Kevin M. Hiscock, Holger Treidel, and Alice Aureli 


\title{
Review papers
}

\section{Beneath the surface of global change: Impacts of climate change on groundwater}

\author{
Timothy R. Green ${ }^{\mathrm{a}, *}$, Makoto Taniguchi ${ }^{\mathrm{b}}$, Henk Kooi ${ }^{\mathrm{c}}$, Jason J. Gurdak ${ }^{\mathrm{d}, 1}$, Diana M. Allen ${ }^{\mathrm{e}}$, \\ Kevin M. Hiscock ${ }^{\mathrm{f}}$, Holger Treidel ${ }^{\mathrm{g}}$, Alice Aureli ${ }^{\mathrm{g}}$
}

a USDA, Agricultural Research Service (ARS), Fort Collins, CO, USA

${ }^{\mathrm{b}}$ Research Institute for Humanity and Nature (RIHN), Kyoto, Japan

${ }^{\mathrm{c}} \mathrm{VU}$ University, Amsterdam, The Netherlands

${ }^{\mathrm{d}}$ San Francisco State University, CA, USA

e Simon Fraser University, Burnaby, BC, Canada

${ }^{\mathrm{f}}$ University of East Anglia, Norwich, UK

${ }^{\mathrm{g}}$ UNESCO, International Hydrological Programme (IHP), Paris, France

\section{A R T I C L E I N F O}

\section{Article history:}

Received 18 October 2010

Received in revised form 5 April 2011

Accepted 3 May 2011

Available online 7 May 2011

This manuscript was handled by P. Baveye, Editor-in-Chief

\section{Keywords:}

Adaptation

Climate change

Global change

Groundwater

Soil water

Vadose zone

\begin{abstract}
S U M M A R Y
Global change encompasses changes in the characteristics of inter-related climate variables in space and time, and derived changes in terrestrial processes, including human activities that affect the environment. As such, projected global change includes groundwater systems. Here, groundwater is defined as all subsurface water including soil water, deeper vadose zone water, and unconfined and confined aquifer waters. Potential effects of climate change combined with land and water management on surface waters have been studied in some detail. Equivalent studies of groundwater systems have lagged behind these advances, but research and broader interest in projected climate effects on groundwater have been accelerating in recent years. In this paper, we provide an overview and synthesis of the key aspects of subsurface hydrology, including water quantity and quality, related to global change.

Adaptation to global change must include prudent management of groundwater as a renewable, but slow-feedback resource in most cases. Groundwater storage is already over-tapped in many regions, yet available subsurface storage may be a key to meeting the combined demands of agriculture, industry, municipal and domestic water supply, and ecosystems during times of shortage. The future intensity and frequency of dry periods combined with warming trends need to be addressed in the context of groundwater resources, even though projections in space and time are fraught with uncertainty. Finally, potential impacts of groundwater on the global climate system are largely unknown. Research to improve our understanding of the joint behaviors of climate and groundwater is needed, and spin-off benefits on each discipline are likely.
\end{abstract}

Published by Elsevier B.V.

\section{Contents}

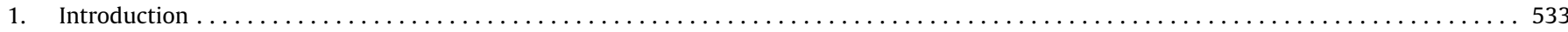

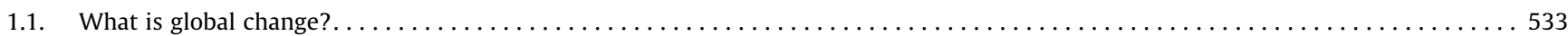

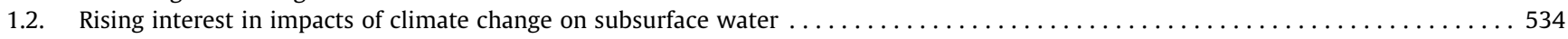

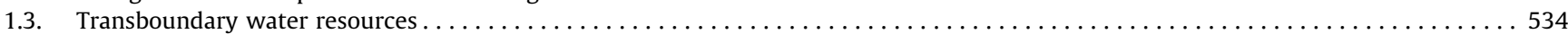

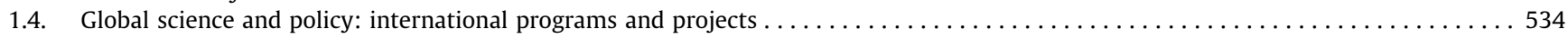

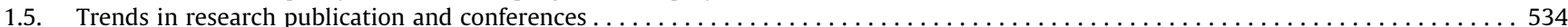

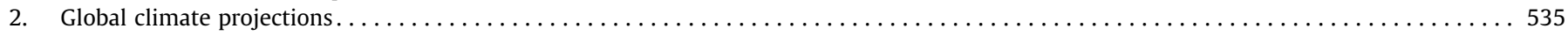

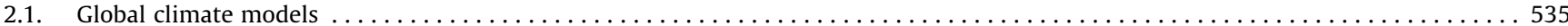

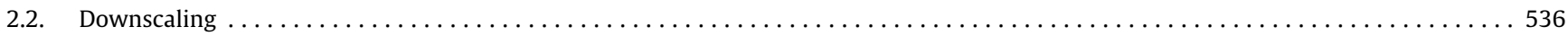

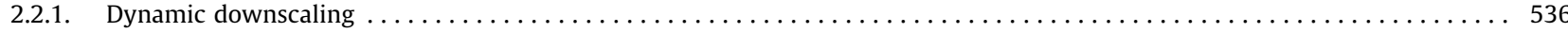

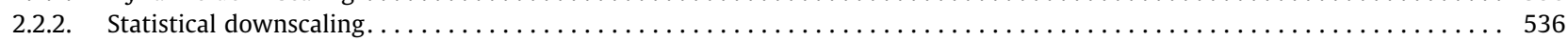

\footnotetext{
* Corresponding author. Tel.: +1 9704927335; fax: +1 9704927310.

E-mail address: tim.green@ars.usda.gov (T.R. Green).

1 Formerly USGS, Denver, CO, USA.
} 


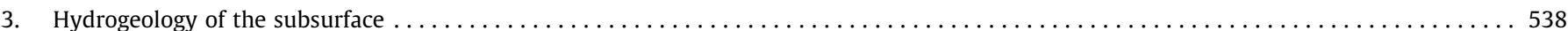

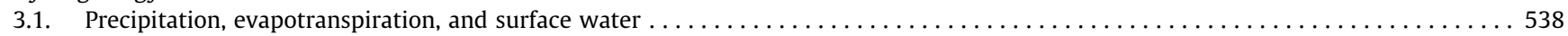

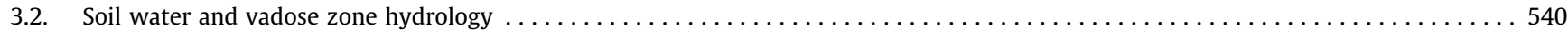

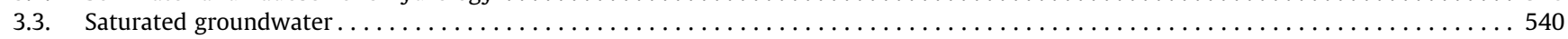

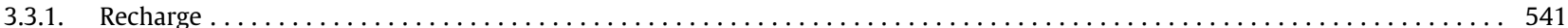

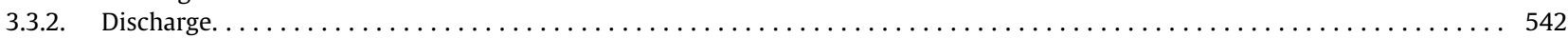

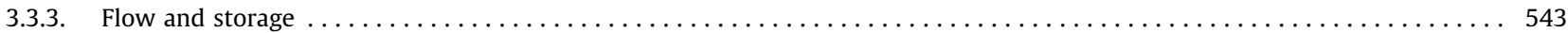

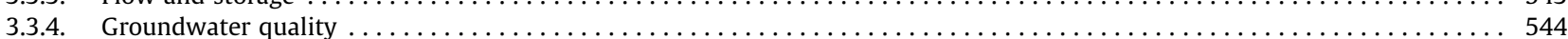

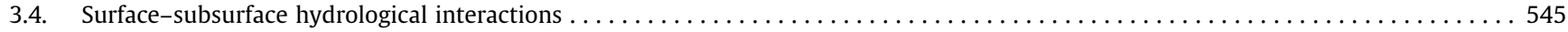

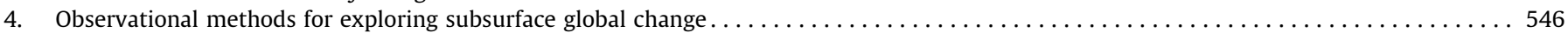

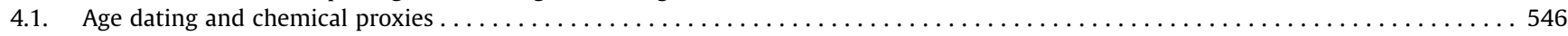

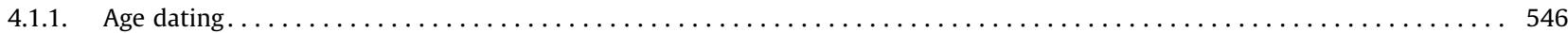

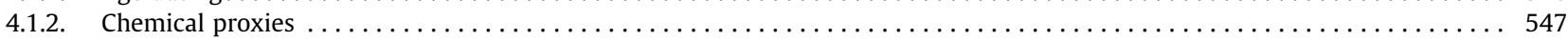

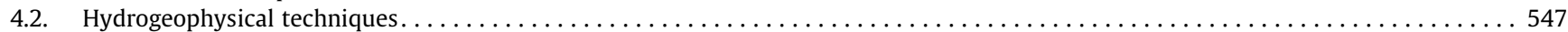

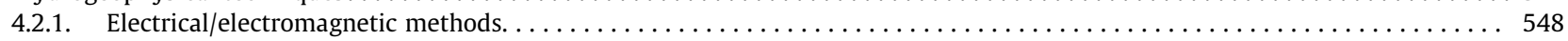

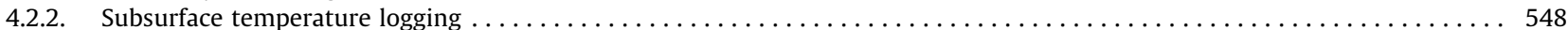

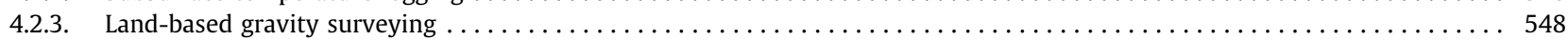

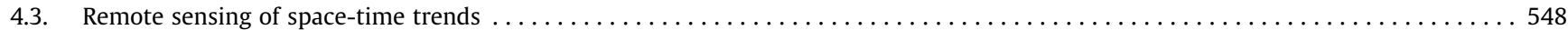

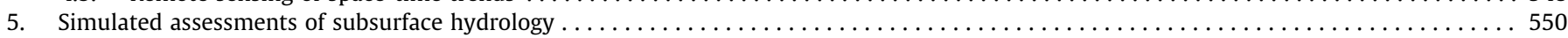

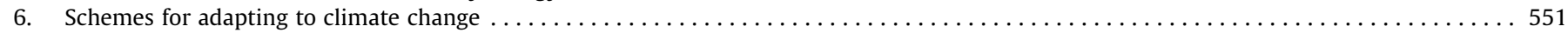

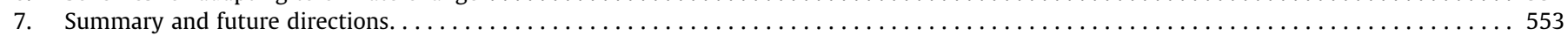

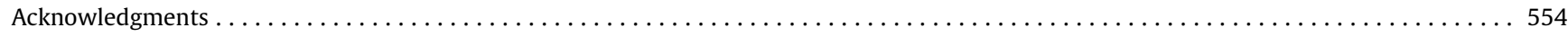

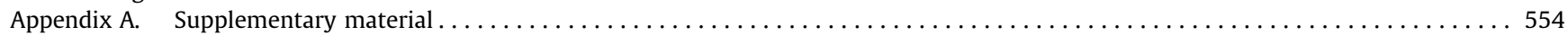

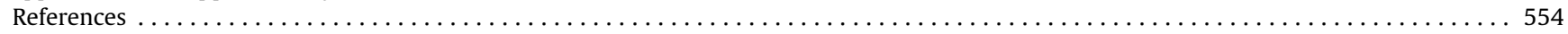

\section{Introduction}

Global change affects water resources around the world in generally unknown ways. Potential impacts of global change on surface water, particularly projected regional climate patterns and trends (i.e., climate variability and change) have been studied in some detail. Yet, little is known about how subsurface waters will respond to climate change coupled with human activities (Holman, 2006; Green et al., 2007b; Bovolo et al., 2009). For convenience, we refer to all subsurface water as "groundwater", including soil water, deeper vadose zone water, and unconfined and confined aquifer waters. Distinctions can be made between these components of groundwater, noting interactions between them and surface water.

The challenges of understanding climate-change effects on groundwater are unprecedented because climate change may affect hydrogeological processes and groundwater resources directly and indirectly, in ways that have not been explored sufficiently (Dettinger and Earman, 2007). The IPCC (2007a) stated that a lack of necessary data has made it impossible to determine the magnitude and direction of groundwater change due solely to climate change (Kundzewicz et al., 2007).

Observational data and climate predictions provide abundant evidence that freshwater resources (both surface and groundwater resources) are vulnerable and have the potential to be strongly affected by climate change, with wide-ranging consequences for society and ecosystems (Bates et al., 2008). According to Jorgensen and Yasin al-Tikiriti (2003) the effect of historical climate change on groundwater resources, which once supported irrigation and economic development in parts of the Middle East, is likely ${ }^{2}$ the primary cause of declining cultures there during the Stone Age. Today, climate change may account for approximately $20 \%$ of projected increases in water scarcity globally (Sophocleous, 2004). Thus, there is a need to evaluate and understand climatic variability over the long term to better plan and manage groundwater resources well into the future, while taking into consideration the increasing stresses on those resources from population growth and industrial, agricultural, and ecological needs (Warner, 2007).

\footnotetext{
2 Terms such as "likely" are strictly defined and used by the IPCC. In this paper, we use such terms more loosely without intending to quantify likelihood.
}

In this paper, we appraise the state of the science of global change related to all components of groundwater. Scientific issues and methods are placed in the context of global programs aimed at assessment of groundwater resources and adaptation to climate change. The current emphasis is on regional case studies with the potential for global analogues to inform decisions where detailed studies are not presently feasible. In this synthesis of results to date, we provide the type of soft information needed to generalise scientific knowledge and the controlling factors specific to each case study.

\subsection{What is global change?}

Global change may include natural and anthropogenic influences on terrestrial climate and the hydrologic cycle. Greenhouse gases are assumed to drive much of the contemporary climate change, and global atmospheric $\mathrm{CO}_{2}$ concentration is the primary indicator of greenhouse gases, as well as a primary regulator of global climate (Petit et al., 1999). Atmospheric $\mathrm{CO}_{2}$ concentration has been measured in the middle of the Pacific Ocean atop Mauna Loa, Hawaii at the National Centre for Environmental Prediction (NCEP) since 1958 (e.g., Keeling et al., 1976, 2004; Thoning et al., 1989). Both $\mathrm{CO}_{2}$ concentration and its rate of change have increased continuously over most of our lifetimes, based on a simple power-law fit to the data (Fig. 1). Seasonal and multi-decadal variations appear to explain most of the remaining short-term variability. Forward extrapolation of the fitted curve is avoided, and projections of future greenhouse gas concentrations are based on complex "storylines" (IPCC, 2007a). Projected climate change is based primarily on simulated responses to these storylines of emissions and resulting greenhouse gases.

Atmospheric scientists are exploring complex interactions and causative factors using available data and climate models. Ice-core data have shown long-term correlation between atmospheric $\mathrm{CO}_{2}$ and (surrogate) temperature (Petit et al., 1999); however, the temporal cross-correlation lag is not what might be expected from a greenhouse model. Instead of temperature changes lagging behind $\mathrm{CO}_{2}$ changes, it is the other way around by approximately 1300 years (Mudelsee, 2001). The Earth's orbit and “Milankovitch cycles" seem to explain the apparent paradox, possibly working in tandem with global greenhouse warming and ocean circulation 


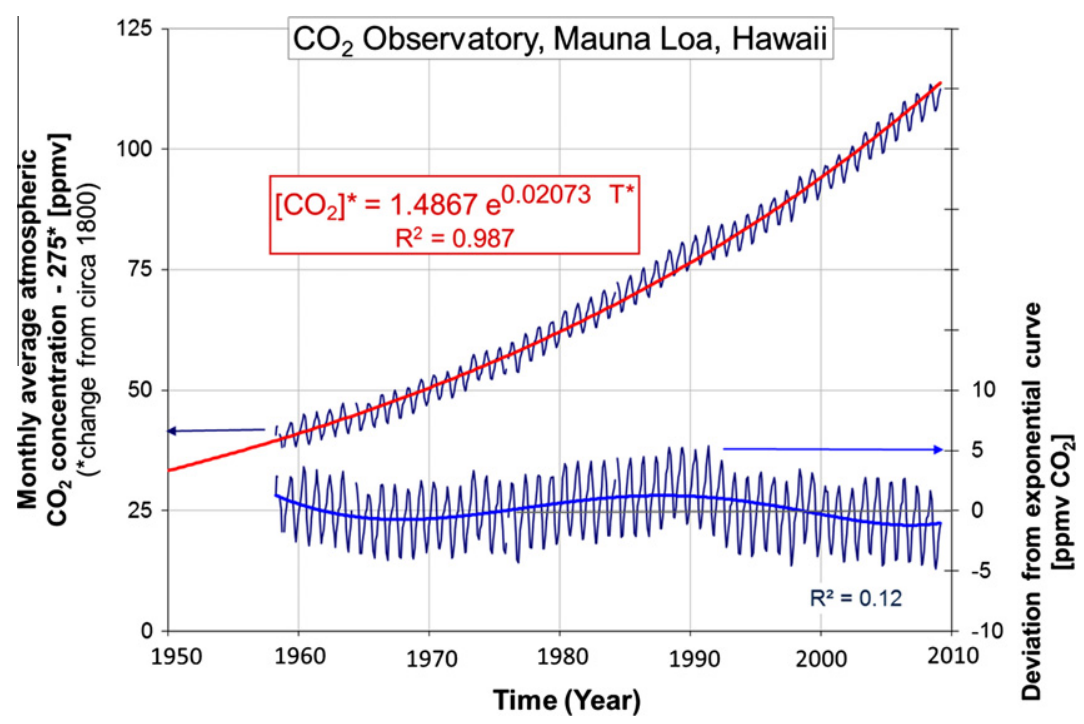

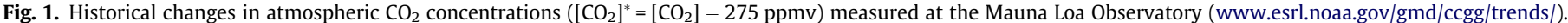

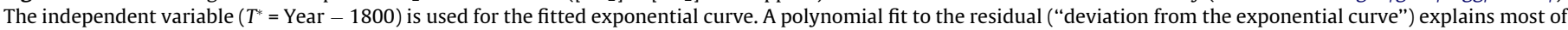
the residual decadal-scale oscillation, with the remainder being seasonal fluctuations in monthly $\left[\mathrm{CO}_{2}\right]$.

(Monnin et al., 2001). Loaiciga (2009) provided a concise and cogent discussion of several factors in the debate over dominant drivers of climate as it relates to (ground)water resources. To our knowledge, these types of issues in the theory and prediction of climate have not been fully resolved, but science tends to fill in gaps and self-correct over time. Therefore, we take the current state of atmospheric science as our best available knowledge, expecting incremental and possibly fundamental improvements to climate projection in the near future. The current level of confidence in climate projections is discussed further in Section 2.

\subsection{Rising interest in impacts of climate change on subsurface water}

In recent decades, a wide array of scientific research has been carried out to better understand how water resources might respond to global change. However, research has been focused dominantly on surface-water systems, due to their visibility, accessibility and more obvious recognition of surface waters being affected by global change. Only recently, water resources managers and politicians are recognising the important role played by groundwater resources in meeting the demands for drinking water, agricultural and industrial activities, and sustaining ecosystems, as well as in the adaptation to and mitigation of the impacts of climate change and coupled human activities.

Projections from the Intergovernmental Panel on Climate Change (IPCC) show significant global warming and alterations in frequency and amount of precipitation from year 2000 to 2100 (Hengeveld, 2000; Le Treut et al., 2007, Fig. 1.3; Mearns et al., 2007). These changes in global climate are expected to affect the hydrological cycle, altering surface-water levels and groundwater recharge to aquifers with various other associated impacts on natural ecosystems and human activities. Although the most noticeable impacts of climate change could be changes in surfacewater levels and quality (Winter, 1983; Leith and Whitfield, 1998), there are potential effects on the quantity and quality of groundwater (Zektser and Loaiciga, 1993; Bear and Cheng, 1999).

\subsection{Transboundary water resources}

Climatic zones cross international political boundaries, as do surface-water and groundwater resources. Surface-water rights have been set historically, and changes in supply have obvious implications for surface-water management and allocation. Groundwater basins face similar issues. Groundwater may also provide critical storage for prolonged periods of shortages in water resources. Withdrawals from transboundary aquifers have important regional management and political implications. Issues associated with transboundary aquifers have been addressed in more detail (Puri and Aureli, 2005), including a global map of such transboundary groundwater resources (IGRAC, 2009).

\subsection{Global science and policy: international programs and projects}

A number of international programs and projects have been established to facilitate and financially support research activities aimed at improving our understanding of groundwater resources under the pressures of global change. Platforms, fora and networks enhance communication among scientists, and channel the results and recommendations derived from scientific research into the political process. Appendix A (electronic supplement) provides a review of groundwater-related international programs and projects, their specific areas of intervention, and the institutions and organisations engaged. Links to relevant organisational web-based materials may be found therein. This resource is provided to help fill a common knowledge gap between researchers, implementing ("action") agencies and policy makers.

Political decision makers around the world are becoming increasingly aware of the opportunities that sustainable use of groundwater resources may offer in the face of the uncertain consequences related to climate change. Likewise, the challenges posed to groundwater resources, and their vulnerability to contamination and over-exploitation, are being increasingly recognised. Thanks to the efforts of groundwater-related scientific research and the transfer of science-based and policy-relevant key messages into the political process, groundwater and climate change related issues are now among the priorities on the political agenda in many regions. However, continued support by international programs and projects in terms of both research and implementation will be required to advance this progress.

\subsection{Trends in research publication and conferences}

Of more than 300 articles cited in this paper, we have synthesized over 200 publications directly related to climate change 


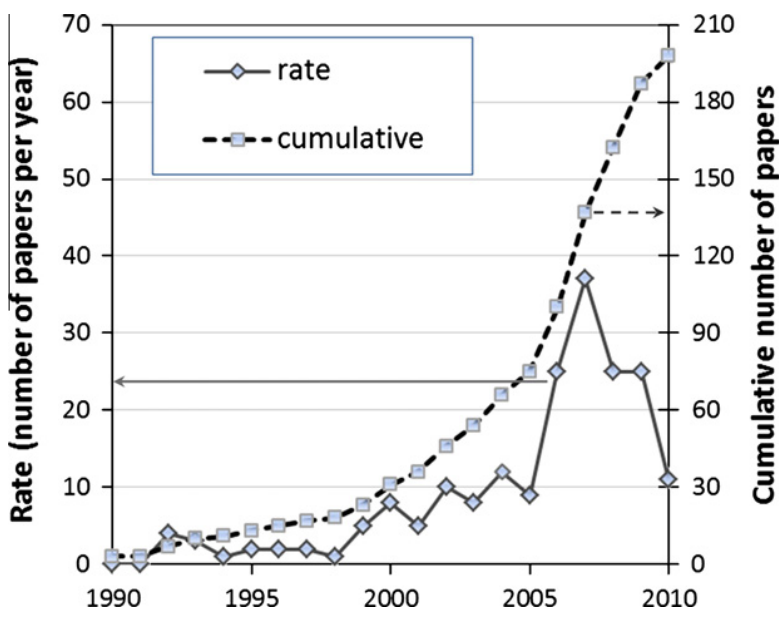

Fig. 2. Rate of peer-reviewed journal paper publications addressing groundwater and climate change from 1990 to $2010^{*}$. A total of 198 papers addressing subsurface water and climate change are included. ${ }^{*}$ Final references were compiled in February 2011, so some papers published late in 2010 may be missing.

and groundwater. Fig. 2 shows the rate of journal publications per year and cumulative number of papers from 1990 through 2010. Most work on the subject has been conducted in the last two decades. Although some key work started in the 1980s, there was some hesitation followed by a resurgence of interest in climate change in all fields, including subsurface hydrology. To date, the rate peaked in 2007, and more than half of the cumulative papers were published after 2005.

Another indication of global interest in this topic is evinced by the number of meetings focused on climate and groundwater internationally (Kundzewicz and Döll, 2009). It is difficult to gauge the scope and impact of different conferences and special sessions focused on climate change and groundwater. Most groundwateroriented conferences and society meetings now include sessions on climate change. To a lesser extent, groundwater is working its way into climate conferences (e.g., World Climate Conference-3, $2009^{3}$; UN Climate Conference $2009^{4}$ ). The combination of publications and meetings indicates a strong increase in interest and research activity.

\section{Global climate projections}

As will be discussed in Section 3, aquifers are recharged mainly by precipitation or through interaction with surface-water bodies. Ultimately, groundwater systems are affected by climate change influences on surface water and precipitation (as well as other climate variables). In order to quantify potential effects of climate change on groundwater systems, future projections of climate are needed at the scales of application.

\subsection{Global climate models}

Climate models are tools for studying local, regional or global climate behavior and its variability over changing conditions on the Earth. They come in different forms, ranging from simple climate models (SCMs) of the energy-balance type to Earth-system models of intermediate complexity (EMICs) to comprehensive three-dimensional (atmosphere-ocean) general circulation models or global climate models (GCMs).

GCMs are the most sophisticated tools available for simulation

\footnotetext{
3 http://www.wmo.int/wcc3/page_en.php.

${ }^{4}$ http://unfccc.int/meetings/cop_15/items/5257.php.
}

of the current global climate and future climate scenario projections. Their formulation usually takes into account the behavior and interaction of flow systems in the biosphere, hydrosphere, cryosphere, atmosphere and geosphere in the climate system. Since the very early GCMs were developed in the 1960s and 1970s, there has been considerable growth in knowledge of climate processes and in the complexity of climate research. Over the last decades, not only has the spatial resolution of GCMs increased, but the physical processes incorporated into these models has increased from simple rain and $\mathrm{CO}_{2}$ emissions to complex biogeochemical (including water vapor) feedbacks (Le Treut et al., 2007, Fig. 1.2). The dominant terrestrial processes that affect large-scale climate over the next few decades are included in current climate models. Some processes important on longer time scales (e.g., global glaciation), however, are not yet included. Development of the oceanic component of these newer GCMs continues. They model freshwater fluxes, improved river and estuary mixing schemes, sea ice, etc. (Randall et al., 2007, Table 8.1). GCMs are able to simulate extreme warm temperatures, cold air outbreaks and frost days reasonably well. However, simulation of extreme precipitation is dependent on resolution, parameterisation and the thresholds chosen. In general, models tend to produce too many days with weak precipitation $\left(<10 \mathrm{~mm} \mathrm{~d}^{-1}\right)$ and too little precipitation overall in intense events (>10 $\mathrm{mm} \mathrm{d}^{-1}$ ) (Randall et al., 2007).

Considerable advances in model design have not reduced the variability of model results, because climate predictions are intrinsically affected by uncertainty and deterministic chaos (Lorenz, 1963). Lorenz (1975) defined two distinct kinds of prediction problems: (1) prediction of actual properties of the climate system in response to a given initial state due to non-linearity and instability of the governing equations and (2) determination of responses of the climate system to changes in the external forcings. Estimating future climate scenarios as a function of the concentration of atmospheric greenhouse gases is a typical example of predictions of the second kind (Le Treut et al., 2007).

Uncertainties in climate predictions (of the second kind) arise mainly from model uncertainties and errors. A number of comprehensive 'model intercomparison projects' (MIPs) were set up in the 1990s under the auspices of the World Climate Research Programme to undertake controlled conditions for model evaluation (e.g., Taylor, 2001). By far the most ambitious organised effort to collect and analyze GCM output from standardised experiments was undertaken in the last few years. The Multi-Model Data set (MMD) hosted by the Program for Climate Model Diagnosis and Intercomparison (PCMDI) has allowed hundreds of researchers from outside the modelling groups to scrutinise the models from a variety of perspectives. Randall et al. (2007, Table 8.1) compared the features of a wide range of GCMs related to the atmospheric, oceanic, land surface, sea ice, and coupling components of each model. Use of multiple simulations from a single model (i.e. Monte Carlo, or ensemble, approach) has proved a necessary and complementary approach to assess the stochastic nature of the climate system. Such single-model ensemble simulations clearly indicated a large spread in the climate projections (Le Treut et al., 2007).

The ability of any particular GCM to reproduce present-day mean climate and its historical characteristics with respectable realism and good overall performance in comparison with the other models are presumed to indicate that it can be used to project credible future climates (i.e., up to the 2080s). The IPCC (2007a) states, "There is considerable confidence that climate models provide credible quantitative estimates of future climate change, particularly at continental scales and above. This confidence comes from the foundation of the models in accepted physical principles and from their ability to reproduce observed features of current climate and past climate changes. Confidence in model estimates is higher for some climate variables (e.g., temperature) than for others (e.g., precipita- 
tion)." The atmosphere-ocean coupled climate system shows various modes of variability that range widely from intra-seasonal to inter-decadal time scales (e.g., Northern Annular Mode (NAM); Interdecadal Pacific Oscillation (IPO), etc.). Successful simulation and prediction over a wide range of these phenomena increase confidence in the GCMs used for climate predictions of the future (Randall et al., 2007). In addition, the IPCC (2007a) assessment of the recent scientific literature shows that the global statistics of the extreme events in the current climate, especially temperature, are generally simulated well by the current models. These models have been more successful in simulating temperature extremes than precipitation extremes (Randall et al., 2007).

However, there remains uncertainty with respect to what the future "picture" of global climate will be. GCMs are forced with concentrations of greenhouse gases and other constituents derived from various emissions scenarios ranging from non-mitigation scenarios to idealised long-term scenarios. The IPCC (2007b) Fourth Assessment Report considered six scenarios for projected climate change in the 21st century. These included a subset of three IPCC Special Report on Emission Scenarios (SRES; Nakićenović and Swart, 2000) non-mitigation emission scenario simulations: B1, A1B and A2, representing 'low', 'medium' and 'high' scenarios, respectively. Additionally, three climate change commitment experiments were performed: one where concentrations of greenhouse gases were held fixed at year 2000 values (constant composition commitment) and the models were run to 2100 (termed 20th century stabilisation), and two where concentrations were held fixed at year 2100 values for A1B and B1, and the models were run for an additional $100-200$ years.

The projected warming by 2100 is largest in the high greenhouse gas growth scenario $\mathrm{A} 2$, intermediate in the moderate growth A1B, and lowest in the low growth B1 (Meehl et al., 2007). The close agreement of warming for the early century, with a range of only $0.05^{\circ} \mathrm{C}$ among the SRES cases, shows that the warming is similar for all non-mitigation scenarios over the next decade or two (Meehl et al., 2007, Table 10.5). Increases in precipitation at high latitudes in both summer and winter seasons are very consistent across models. The increases in precipitation over the tropical oceans and in some of the monsoon regimes (e.g., South Asian and Australian seasonal monsoons) are notable, and while not as consistent locally, considerable agreement is found at the broader scale in the tropics (Neelin et al., 2006). There are widespread decreases in mid-latitude summer precipitation, except for increases in eastern Asia. Decreases in precipitation over many subtropical areas are evident in the multi-model ensemble mean, and consistency in the direction of change among the models is often high (Wang, 2005), particularly in some regions like the tropical Central American-Caribbean (Neelin et al., 2006).

Meehl et al. (2007, Fig. 10.12) showed global changes in mean annual precipitation, evaporation, soil water content, and runoff for the model ensemble for the SRES A1B scenario for the period 2080-2099. Overall, precipitation over land was projected to increase by about $5 \%$, while precipitation over ocean increased $4 \%$, but with both positive and negative regional changes (Meehl et al., 2007). Emori and Brown (2005) predicted increases of over $20 \%$ at most high latitudes, as well as in eastern Africa, central Asia and the equatorial Pacific Ocean. Substantial decreases, reaching $20 \%$, may occur in the Mediterranean region (Rowell and Jones, 2006), the Caribbean region (Neelin et al., 2006) and the subtropical western coasts of each continent. Annual average evaporation was projected to increase over much of the ocean, with spatial variations tending to relate to those in the surface warming. Over land, rainfall changes tend to be moderated by both evapotranspiration and runoff. Runoff is notably reduced in southern Europe and increased in Southeast Asia and at high latitudes, where there is consistency among models in the direction of change. Mean an- nual decreases in projected soil water content (SWC, derived from land-surface schemes within GCMs) were indicated for the subtropics and the Mediterranean region. While the magnitudes of change in SWC are quite uncertain, there is good consistency in the direction of change in many regions of the world.

Although such broad generalisations of projected climate change may be useful for comparing responses at a global scale, GCMs cannot provide information at scales finer than their computational grid (typically of the order of $200 \mathrm{~km}$ ), and processes at these unresolved scales are important. Thus, the usefulness of the raw output from a GCM for climate change assessment in specific regions is limited. To bridge the spatial resolution gaps for GCMs to produce realistic local climate projections, downscaling techniques are usually applied to the GCM output.

\subsection{Downscaling}

Downscaling addresses the disparity between the coarse spatial scales of GCMs and observations from local meteorological stations (Wilby and Wigley, 1997; Hewitson and Crane, 2006). GCMs do not accurately predict local climate, but the internal consistency of these physically-based climate models provides most-likely estimates of ratios and differences (scaling factors) from historical (base case) to predicted scenarios (Loaiciga et al., 1996) for climatic variables, such as precipitation and temperature.

Improvements to climate projections will likely come by developing regional and GCMs that couple groundwater and atmospheric processes (Gutowski et al., 2002; Cohen et al., 2006). The primary challenge is the difference in scale between the large (continental) scale of GCMs and the local scale of groundwater or surface-water models, the latter requiring daily data, with higher spatial resolution of a few square kilometers (Loaiciga et al., 1996; Bouraoui et al., 1999).

Downscaling techniques are grouped into two main types: (a) dynamic climate modelling and (b) empirical statistical downscaling. Downscaling methods have matured since the Third Assessment Report (IPCC, 2001) and have been more widely applied. Nevertheless, large-scale coordination of multi-model downscaling of climate change simulations has been achieved only in some regions (Christensen et al., 2007). A clearer picture of the robust aspects of regional climate change is emerging due to improvement in model resolution, the simulation of processes of importance for regional change and the expanding set of available simulations (Christensen et al., 2007).

\subsubsection{Dynamic downscaling}

This technique involves nesting a higher resolution Regional Climate Model (RCM) within a coarser resolution GCM. RCMs use the GCM to define time-varying atmospheric boundary conditions around a finite domain from which the physical dynamics of the atmosphere are modeled using horizontal grid spacing of about $20-50 \mathrm{~km}$ or less. The main limitation of RCMs is that they are computationally demanding (much like the GCMs) and, therefore, place constraints on the feasible domain size, the duration of simulations, and the number of experiments that can be performed. RCMs are attractive to those seeking process understanding and causative simulation, but most downscaling is currently empirical.

\subsubsection{Statistical downscaling}

Statistical downscaling techniques combine existing and past empirical knowledge to address the disparity between coarse spatial scales of GCMs and point meteorological observations. This methodology uses a statistically-based model to determine a relationship between regional or local climate variable(s) (known as predictands) and large-scale climate variables (referred to as predictors). The derived relationships between the predictors and 
predictands are applied on similar predictors from GCM simulations in the statistical model to estimate the corresponding local or regional climate characteristics. Available statistical downscaling models can be grouped as:

- Synoptic weather typing, which involves grouping local meteorological data in relation to prevailing patterns of atmospheric circulation, and constructing future climate scenarios either by re-sampling from observed data distributions, or by generating synthetic sequences of weather patterns using combined Monte Carlo and Markov chain techniques and re-sampling from observed data.

- Stochastic weather generation, which involves modifying parameters of conventional Markov chain weather generators scaled in direct proportion to corresponding parameters in GCMs to generate local climate data.

- Regression-based models, which use different mathematical transfer functions and a statistical fitting procedure to derive empirical relationships between local predictands and regional scale predictors. Individual downscaling schemes differ according to the choice of predictor variables of statistical fitting procedures.

Examples of statistical downscaling methods include the Statistical DownScaling Model (SDSM) (Wilby et al., 2002), and principle component $K$-nearest neighbor (PCA $K$-nn) (Bates et al., 1994; Schnur and Lettenmaier, 1998; Zorita and von Storch, 1999; Yates et al., 2003). Newer methods, blending the attributes of each downscaling technique described above have recently been developed (e.g., multivariate statistical downscaling) (Cannon, 2008, 2009). Groves et al. (2008) conditioned $K$-nn climate sequences to generate a set of biased, ranked (wet to dry) sequences for resampling.

The statistical downscaling models are computationally inexpensive, easily applied to output from different GCMs (Stoll et al., 2011), and can be used to provide local information most often needed in many climate change impact applications. In addition, they offer a framework for testing the ability of physical models to simulate the empirically-found links between large-scale and small-scale climate (von Storch et al., 1993; Noguer, 1994; Osborn et al., 1999). However, the model's basic assumption (i.e., statistical relationships developed for present day climate also hold under different forcing conditions of future climates) may not be valid, and model calibration requires high quality data.

As discussed in Section 5 on assessments, downscaled daily temperature generally compares well with observed data, but daily precipitation amounts often do not, particularly seasonal amounts, wet spell length, etc. This is due to the generally low predictability of daily precipitation amounts at local scales by regional forcing factors. Khan et al. (2006) compared SDSM, Long Ashton Research Station Weather Generator (LARS-WG) model (Semenov and Barrow, 1997; Semenov et al., 1998) and an Artificial Neural Network (ANN) model with respect to various measures of uncertainty in the downscaled results of daily precipitation, daily maximum and minimum temperatures. The study used 40 years of observed and downscaled daily precipitation, daily maximum and minimum temperature data using National Centre for Environmental Prediction reanalysis predictors starting from 1961 to 2000. The uncertainty assessment results indicated that SDSM reproduced various statistical characteristics of observed data with 95\% confidence, the ANN was the least capable in this respect, and the LARS-WG was in between SDSM and ANN.

To overcome the discrepancy between downscaled and observed precipitation, shifts in climate projected by a GCM or through downscaling can be used as input to a stochastic weather generator (Wilks and Wilby, 1999) (represented as the alternative route in Fig. 3). This shift factor or "delta" approach for downscal- ing starts with preparation of coincident predictor and predictand data sets. The predictor data set is obtained from the GCM output in the grid corresponding to the local study area, whereas the predictand is a long series of observed daily weather information (e.g., temperature, precipitation, solar radiation, sunshine hours, etc.) at the meteorological station representing the local area. The calibration dataset is a climate re-analysis dataset (e.g., National Centre for Environmental Prediction (NCEP); Kalnay et al., 1996) for the historical period. A set of parameters are derived using multiple linear regressions relating the predictors to the predictands based on the output of the GCM time periods. These parameters are then used as input for stochastic weather generation of data for different future time periods (Fig. 3).

Scibek and Allen (2006b) compared the results for temperature and precipitation downscaled from a GCM (CGCM1) (Flato et al., 2000) using two methods for a small valley in south-central British Columbia, Canada. The two downscaling methods (SDSM and principal component $K$-nearest neighbor - PCA $K$-nn) yielded comparable estimates of mean monthly temperature, and small calibration bias (Fig. 4a and b). Precipitation was found to have variable seasonal/monthly predicted changes, and results varied somewhat between downscaling methods (Fig. $4 \mathrm{c}$ and $\mathrm{d}$ ). The SDSM downscaled precipitation series were too low in the late spring to summer months, especially June, but fit the observed normals reasonably well in other months. Thus, precipitation was underestimated by roughly $40 \%$ compared to observed during the summer, even after downscaling with a well-calibrated model. Overall, PCA $K$-nn downscaling of the same dataset yielded worse results than SDSM downscaling. Other variables used in calibration, such as precipitation variability (standard deviation), number or percentage of wet days, wet spell length and dry spell length, gave similar results for both methods, although the standard deviation was notably better for SDSM. Both downscaling methods underestimated number of wet days by about 30\% in May and June, underestimated wet spell length by about 1 day, and underestimated dry spell length by about $30 \%$ in all months except June and July. To overcome the discrepancy in downscaling accuracy, Scibek and Allen (2006b) assumed that the relative and/or absolute changes in precipitation and temperature, respectively, between present and future climate scenarios have strong physical basis and meaning. Thus, change factors were computed using SDSM (relative for precipitation, and absolute for temperature), and these factors were used in LARS-WG to generate daily time series. Climate data series were applied to a spatially-distributed recharge model and, ultimately, into a groundwater flow model. A similar approach was used by Scibek and Allen (2006a) for a different study area in southwestern British Columbia, Canada, and by Candela et al. (2009) in Majorca, Spain. Additionally, Allen et al. (2010) used state-of-the-art downscaling methods to predict variations in recharge for the trans-national Abbotsford-Sumas aquifer in Canada and the United States. They found that the variability in recharge predictions indicates that the seasonal performance of the downscaling tool is important, and that a range of GCMs should be considered for water management planning.

Finally, Yang et al. (2005) developed statistical models for generating sequences of potential evaporation (PE), possibly conditioned on rainfall, and applied to data from southern England. Daily PE data were used to develop a downscaling procedure. The authors noted that sufficient PE data are rarely available to identify long term trends. Thus, they made use of limited daily data to study sub-weekly structure, and used this information to downscale weekly sequences. In this way the dual objectives of downscaling weekly data and simulating daily PE sequences could both be achieved, since daily sequences can be simulated by generating a weekly sequence and then downscaling it in time. 


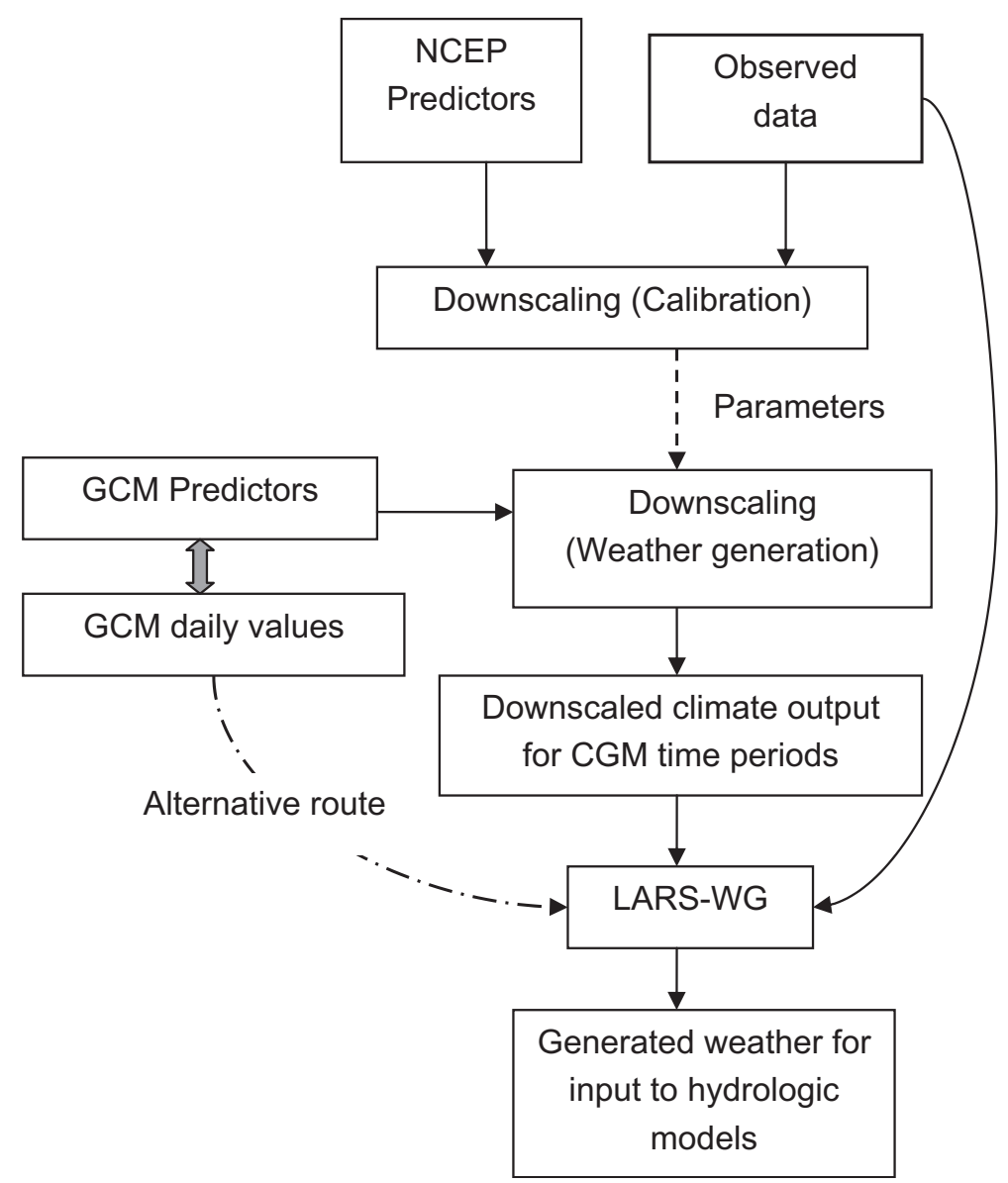

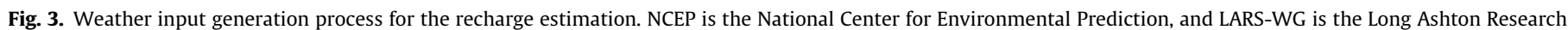
Station Weather Generator.

\section{Hydrogeology of the subsurface}

This section outlines current research and understanding of climate-change effects on subsurface hydrology and surface-subsurface hydrologic interactions. Climate change, including anthropogenic-global warming and natural climate variability, can affect the quantity and quality of various components in the global hydrologic cycle in the space, time, and frequency domains (Loaiciga et al., 1996; Sharif and Singh, 1999; Milly et al., 2005; Holman, 2006; IPCC, 2007b). The components of the surface hydrologic cycle affected by climate change include atmospheric water vapor content, precipitation and evapotranspiration patterns, snow cover and melting of ice and glaciers, soil temperature and SWC, and surface runoff and stream flow (Bates et al., 2008). Such changes to the atmospheric and surface components of the global hydrologic cycle will likely result in changes to the subsurface hydrologic cycle within the soil, vadose zone, and aquifers of the world (Van Dijck et al., 2006). However, the potential effects of climate change on groundwater and groundwater sustainability are poorly understood. Alley et al. (1999) define groundwater sustainability as development and use of groundwater resources in such a manner that can be maintained for an indefinite time without causing unacceptable environmental, economic, or social consequences. The relation between climate variables and groundwater is considered more complicated than with surface water (Holman, 2006; IPCC, 2007a). This understanding is confounded by the fact that groundwater-residence times can range from days to tens of thousands of years, which is likely to delay and disperse the effects of climate change, and challenge efforts to immediately detect responses in the groundwater (Chen et al., 2004).

\subsection{Precipitation, evapotranspiration, and surface water}

Scientists who study the Earth's climate generally concur that human activities are enhancing the Earth's natural greenhouse effect and that these activities will likely lead to an increase in global warming. Because the capacity of the atmosphere to hold water increases exponentially with temperature, global precipitation is expected to increase. However, spatial variability in projected precipitation indicates both positive and negative changes in regional precipitation, as well as changes in seasonal patterns (IPCC, 2007a). Any changes in precipitation patterns can affect surfacewater processes and resources. Warming trends may also affect global evapotranspiration patterns, which have direct implications for the sustainability of surface- and subsurface-water resources. There is little agreement on the direction and magnitude of predicted evapotranspiration patterns (Barnett et al., 2008). However, higher air temperatures are likely to increase evapotranspiration, which may result in a reduction in runoff and SWC in some regions (Chiew and McMahon, 2002). Precipitation and evapotranspiration are particularly important because they directly affect groundwater recharge and indirectly affect human groundwater withdrawals or discharge. Even small changes in precipitation may lead to large changes in recharge in some semiarid and arid regions (Woldeamlak et al., 2007). For example, Sandstrom (1995) showed that a $15 \%$ reduction in precipitation, with no change in 

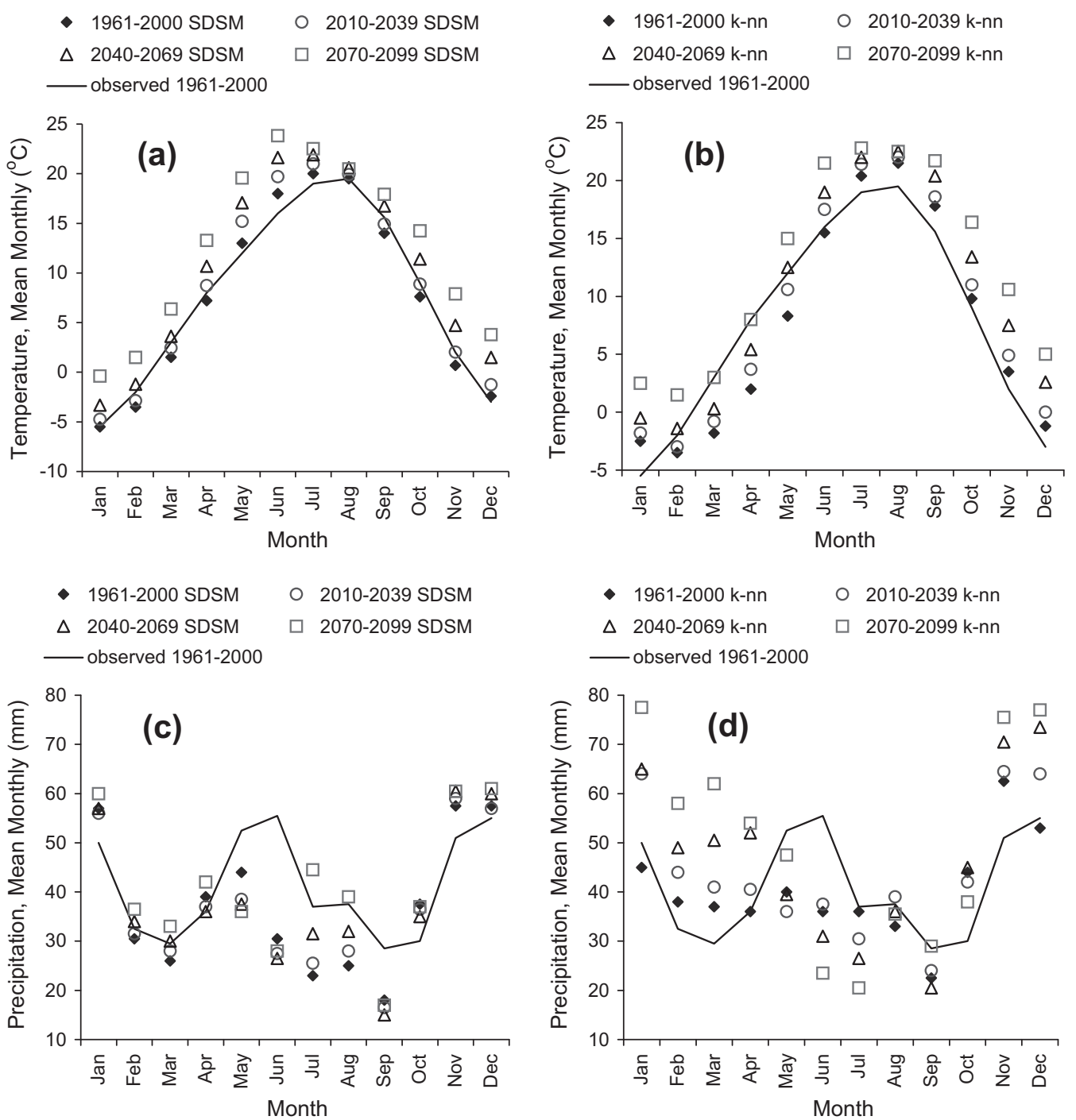

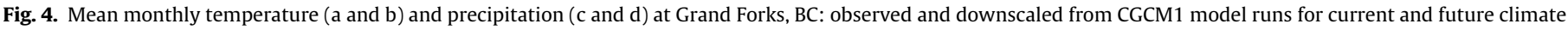
scenarios using SDSM (a and c) and K-nn (b and d) (Scibek and Allen, 2006a).

temperature, resulted in a $40-50 \%$ reduction in recharge. The forecasted changes in the global spatiotemporal patterns of evapotranspiration and precipitation and resulting responses to surfacewater systems are not discussed in detail here. The current section describes recent research findings regarding how atmospheric and surface-water changes will generally affect subsurface hydrologic processes in the soil and vadose zone that control infiltration and recharge to groundwater resources.

Predicted increased precipitation intensity and variability will likely increase the risks of flooding and drought in many regions (Bates et al., 2008). The increased frequency of heavy precipitation events increases the risk of rain-generated floods. In seasons of above average precipitation, recharge is likely to increase (relative to seasonal average conditions), and water demand, such as for irrigated agriculture, will decline because of lower temperature and solar radiation and higher humidity in such periods (Rosenberg et al., 1999). In contrast, the proportion of land surface in extreme drought is predicted to increase under future climate change, as is a tendency for drying in continental interiors during summer, especially in the sub-tropics, low and mid-latitudes (IPCC, 2007a; Bates et al., 2008). Miller et al. (2009) showed that light to severe drought in the Central Valley, California, USA might result in a decrease in surface water diversions by as much as $70 \%$ and significant declines in the water table for much of the Central Valley aquifer that do not recover within the 30-year simulation period.

The increased variability in precipitation, temperature, and evapotranspiration that is predicted under many climate-change scenarios will likely have varied effects on different aquifers and different locations within an aquifer depending on spatial variability in hydraulic properties and distance from the recharge area(s). For example, Chen et al. (2002) observed that groundwater level responses to precipitation variability in a mid-continent carbonate-rock aquifer are different from well to well because of the spatial differences in permeability of overlying sediments and recharge characteristics. Additionally, groundwater levels at some locations of the aquifer responded to high-frequency precipitation events while groundwater levels in other areas did not respond. High-frequency events are buffered in some areas because of the long distance to the recharge area or by slow infiltration rates in low permeability materials. The groundwater-level response to high-frequency events may indicate the existence of highly permeable channels or preferential-flow paths from land surface to the water table (Chen et al., 2002).

Other studies indicate that even modest increases in nearsurface air temperatures, predicted under most IPCC scenarios, will 
substantially alter the hydrologic cycle in snowmelt-dominated regions via seasonal shifts in streamflow because of the fundamental ability of the snowpack to act as a reservoir for water storage (Cayan et al., 2001; Stewart et al., 2004; Mote et al., 2005; Barnett et al., 2008; Tague et al., 2008). For example, Eckhardt and Ulbrich (2003) predicted a smaller proportion of the winter precipitation will fall as snow due to warming trends in mountainous regions of central Europe and that the spring-snowmelt peak will likely be reduced while the flood risk in winter will probably increase. Unless additional reservoir storage is created to account for the earlier snowmelt runoff, the use of groundwater may increase, where available, to offset the lack of surface water later in the season when water demands are typically higher.

Spatial differences in groundwater dynamics in mountainous regions also can play a substantial role in determining streamflow responses to warming (Tague et al., 2008; Tague and Grant, 2009). Tague et al. (2008) suggested that groundwater dynamics, such as subsurface drainage, are as important as topographic differences in snow regimes in determining the response of mountain landscapes to climate change. The changes in streamflow, shifting spring and summer streamflow to the winter, will likely increase competition for reservoir storage and in-stream flow for endangered species (Payne et al., 2004) and lead to summer water shortage throughout the western United States (Tague et al., 2008) and other similar semiarid and arid regions globally.

Most studies of climate-change effects on surface-water basins, particularly in mountainous regions (Viviroli et al., 2011), do not explore subsurface hydrologic responses. How will forecasted changes to the surface hydrologic regime affect infiltration, evapotranspiration, SWC distribution, and ultimately recharge? Singleton and Moran (2010) noted that recharge mechanisms, storage capacity, and residence times of high elevation aquifers are poorly understood. Moreover, the net change in recharge in mountain aquifers due to changes in the timing of snowpack melting is generally not known in sign (positive or negative) or magnitude, making it difficult to predict the response of mountain groundwater systems to climate change (Singleton and Moran, 2010). How will mountain-front recharge (MFR) and recharge in other types of mountainous systems be affected by predicted changes in the snowmelt-dominated regions where MFR is very important? A negative feedback between early timing of snowmelt and evapotranspiration may exist in snowmelt-dominated watershed (Barnett et al., 2008). Earlier snowmelt results in increased SWC in the season when potential evapotranspiration is relatively low (Barnett et al., 2008), which may increase infiltration and recharge in mountainous regions. When potential evapotranspiration is greater later in the year, the shift in snowmelt timing may reduce SWC and increase evaporative resistance, which again reduces the effect of evapotranspiration change (Barnett et al., 2008) but has an unknown effect on net infiltration and recharge. These and other questions remain regarding subsurface hydrologic responses to climate-change effects on surface-water hydrology.

\subsection{Soil water and vadose zone hydrology}

Climate change and variability are expected to have profound effects on soil water and temperature (Jasper et al., 2006; Jungkunst et al., 2008). Soil water content and temperature are important factors in terrestrial biogeochemical reactions, landatmosphere interactions, and a critical determinant of terrestrial climate. Variability in vadose-zone hydrology, shallow water tables that support soil-moisture content, and ultimately the water resources in many aquifers are also affected by SWC and temperature (Cohen et al., 2006; Fan et al., 2007). Spatial variations in SWC also influence atmospheric processes, such as the cumulus convective rainfall (Pielke, 2001). Jungkunst et al. (2008) noted that some soil types, such as hydromorphic soils, will likely exhibit a higher climate-change feedback potential than other, well-aerated soils because soil organic matter losses in hydromorphic soils are predicted to be much greater than those from well-aerated soils.

Climate-related variables that have a substantial control on SWC include spatiotemporal patterns in precipitation, evapotranspiration, and surface-water conditions. Land use, soil texture, slope, and other biological, chemical, and physical characteristics also are known to affect SWC (Jasper et al., 2006) with associated effects on groundwater and baseflow to streams (Wang et al., 2009). Seneviratne et al. (2010) provided an extensive review of interactions and feedbacks between SWC and climate, specifically atmospheric temperature and precipitation.

The vadose zone is the region between the land surface and saturated zone through which recharge can occur, and represents complex interactions between thermal-hydrologic-geochemical processes that can affect groundwater quantity and quality (Glassley et al., 2003). The vadose zone of some semiarid and arid regions has slowly evolving, dynamic characteristics that pose important challenges for long-term understanding of the effects of climate change and variability on the vadose zone and (or) subsequent processes affecting the groundwater (Phillips, 1994; Glassley et al., 2003). For example, Glassley et al. (2003) showed that vadose-zone pore-water chemistries in the southwestern United States are likely to be in a continuously evolving state, in the process of chemically and thermally adjusting to relatively recent, post-glacial climate changes, and are not at a steady state (Phillips, 1994).

\subsection{Saturated groundwater}

Groundwater in the saturated zone is an important component of the global water balance comprising approximately $30 \%$ of the Earth's freshwater resources and approximately 96\% of liquid freshwater (excluding icecaps and glaciers) (UNESCO, 2008). The use of groundwater can mitigate droughts, because many aquifers have a large storage capacity and are potentially less sensitive to climate change than surface-water bodies, which often rely on groundwater discharge to maintain baseflow conditions (Dragoni and Sukhija, 2008). However, the ability to use groundwater storage to buffer rainfall deficits that affect surface-water resources will be constrained by the need to protect groundwater-dependent environmental systems (Skinner, 2008).

Groundwater has and will continue to respond to changes in climate. Paleoclimate-change conditions and subsequent responses in recharge, discharge, and changes in storage are preserved in the records of groundwater major and trace-element chemistry, stable and radioactive isotope composition, and noble gas content (Fan et al., 1997; Bajjali and Abu-Jaber, 2001; Edmunds and Milne, 2001; Castro et al., 2007; Hendry and Woodbury, 2007). Other important components of hydrogeological systems include groundwater-fed lakes in some arid and semiarid regions (Gasse, 2000), pore-water chemistry of the vadose zone (Zuppi and Sacchi, 2004), and subsurface-thermal regimes (Taniguchi, 2002; Miyakoshi et al., 2005; Uchida and Hayashi, 2005; Taniguchi et al., 2008).

Groundwater archives act as low-pass filters and provide lowresolution time-series of reconstructed temperatures and information on atmospheric-moisture transport patterns (Gasse, 2000). Hiscock and Lloyd's (1992) paleohydrogeologic reconstruction of the North Lincolnshire Chalk aquifer in England revealed that recharge during the late Pleistocene (approximately the last 140,000 years) has been restricted to periods when the climate and sea-level position were similar to those of the present day. Forest clearance since about 5000 years ago is likely to have resulted in increased recharge rates and enhanced the rate of Chalk permeability development (Hiscock and Lloyd, 1992). Falling global-sea levels during the last five glacial periods of the Pleistocene Ice Ages 
likely resulted in increased hydraulic heads in inland aquifers relative to those in the continental shelf, enhancing groundwater flow toward the coast (Faure et al., 2002). Faure et al. (2002) suggested that the resulting "coastal oases" that formed from the groundwater discharge as springs along the exposed continental shelf had profound effects on biodiversity, human evolution, and carbon storage during periods of severe climatic stress. At present sea levels, submarine groundwater discharge is a well established phenomenon that contributes substantial mass flux to oceans (Burnett et al., 2006). Gasse (2000) recommended that future paleohydrological research needs to develop solid chronologies, but also to analyze the mechanisms of water storage and losses in aquifers, obtain quantitative reconstructions of hydrological cycles, and identify atmospheric-moisture transport patterns at regional scales that affect groundwater resources.

Groundwater resources have been affected by a number of nonclimatic forcings, especially since the 1950 s, such as contamination, reduction in streamflow (reduction in recharge), and lowering of the water table and loss of storage due to groundwater mining (primarily for irrigated agriculture). As Kundzewicz et al. (2007) noted, climate-related changes to groundwater to date have been relatively small compared with non-climate drivers. Additionally, groundwater systems often respond more slowly and have a more substantial temporal lag to climate change than surface-water systems (Chen et al., 2004; Hanson et al., 2004, 2006; Gurdak et al., 2007; Kundzewicz et al., 2007; Gurdak, 2008). Persistent and severe dry periods have altered the hydraulic properties of aquifers, such as the transmissivity of a regional karst aquifer in France (Laroque et al., 1998). Current vulnerabilities in water resources are strongly correlated with climate variability, due largely to precipitation variability, especially for semiarid and arid regions (Kundzewicz et al., 2007; Ouysse et al., 2010). Such regions are particularly vulnerable to climate change if groundwater reservoirs are not available. Even if groundwater resources are currently available, communities become more vulnerable to climate change if the ratio of stored groundwater volumes to recharge is smaller and if there are no other local water resources, such as in the isolated alluvial aquifers of Yemen (van der Gun, 2010). The IPCC also noted that groundwater levels correlate more strongly with precipitation than with temperature, but temperature becomes more important for shallow aquifers (Kundzewicz et al., 2007). The complexity is exacerbated because predictions of global precipitation spatiotemporal patterns are less certain than are predicted temperature patterns due to climate change. As a result, the IPCC (2007b) stated that there is no evidence for ubiquitous climate-related trends in groundwater.

The following sections outline what is known about climatechange effects on components of the groundwater system, including recharge, discharge, flow and storage, groundwater quality, and surface-subsurface hydrological interactions.

\subsubsection{Recharge}

Understanding the dynamics and processes interactions affecting recharge over time is fundamental to assessment of groundwater quality and quantity, and requires a reliable prediction of critical climate variables (Jyrkama and Sykes, 2007; Gurdak et al., 2008; Herrera-Pantoja and Hiscock, 2008). Aquifer recharge is most frequently considered to be the vertical, volumetric flux of water across the water table, but also includes interaquifer flow from underlying or adjacent hydrogeologic formations. The former component of recharge occurs via two general pathways in many environments: diffuse recharge to the water table and focused recharge that occurs at locations where surface-water flow is concentrated at land surface, including stream channels, lakes, topographic depressions, irrigated-agricultural land, and (or) other macropore, preferential-flow pathways (Small, 2005). Thus, recharge is a sensitive function of the climate (precipitation and temperature regimes), local geology and soil, topography, vegetation, surface-water hydrology, coastal flooding, and land-use activities (such as urbanisation, woodland establishment, crop rotation, and irrigation practices) (de Vries and Simmers, 2002; Holman, 2006; McMahon et al., 2006; Green et al., 2007a; Candela et al., 2009). Understanding of the controls on recharge is improving (Scanlon et al., 2002, 2006), but knowledge of recharge rates and mechanisms is often poor (Kundzewicz et al., 2007).

Excess rainfall or runoff that is not used or stored in reservoirs ultimately becomes part of the soil or groundwater system or flow to oceans (Sherif and Singh, 1999). Recharge will be affected under forecasted changes in precipitation patterns. For the purposes of understanding climate-change effects on recharge and groundwater resources, Sherif and Singh (1999) divided groundwater resources into four categories:

1. Confined aquifers with upper impermeable layers where recharge only occurs from precipitation where the water-bearing formations outcrop at land surface.

2. Unconfined (phreatic) aquifers in wet regions where rainfall is high and evapotranspiration is low. These aquifers are highly renewable because precipitation exceeds evapotranspiration throughout much of year and are not expected to face substantial threats to climate change.

3. Unconfined aquifers in semiarid and arid regions that are likely to have shifting annual balances between precipitation and evapotranspiration and a general drying trend under most climate-change forecasts. Sherif and Singh (1999) suggested that recharge may be less to these aquifers, resulting in less groundwater availability but an increase in demand from growing population and less reliable surface-water resources.

4. Coastal aquifers vulnerable to rising sea levels (Döll, 2009) and salt-water intrusion.

Climate change and variability will likely have numerous effects on recharge rates and mechanisms (Vaccaro, 1992; Green et al., 2007a; Kundzewicz et al., 2007; Aguilera and Murillo, 2009). Many climate-change studies have predicted reduced recharge (Herrera-Pantoja and Hiscock, 2008); however, the effects of climate change on recharge may not necessarily be negative in all aquifers during all periods of time (Jyrkama and Sykes, 2007; Döll, 2009; Gurdak and Roe, 2010). For example, Dettinger and Earman (2007) concluded that it is unknown whether the overall recharge will increase, decrease, or stay the same at any scale in the western United States. While many studies have shown a predicted decrease in recharge rates under future climate, other studies have shown an increase in recharge rates. Kruger et al. (2001) predicted as much as a $30 \%$ reduction in recharge of a lowlands aquifer in Germany, while nearby mountainous regions are predicted to have negligible changes to recharge rates. Jyrkama and Sykes (2007) showed that climate change will likely result in increased recharge rates and a shifting spring melt from spring toward winter, allowing more water to infiltrate and possibly become recharge across a watershed in Ontario, Canada. Kovalevskii (2007) showed that many regions of Russia would likely have increased recharge rates under future climate, resulting in improved groundwater resources in some regions while other regions will be adversely affected by waterlogged soils, more swampy lands and landslides, and a decrease in soil productivity. Allen et al. (2004) and Scibek and Allen (2006a) showed that predicted climate change would likely result in only moderate changes in recharge and associate water-level changes in two aquifers in western Canada. Yusoff et al. (2002) found that recharge in aquifers of eastern England is likely to decrease under 'medium-high' greenhouse gas emission but increase under 'medium-low' 
greenhouse gas emissions. Finally, Green et al. (2007a) simulated highly variable recharge depending upon the combination of soil and vegetation types. Recharge tended to increase in the subtropics, while remaining relatively unchanged or reduced in a Mediterranean climate of Australia.

Climate variability, especially variability in precipitation, can have substantial effects on recharge and groundwater levels. For example, Thomsen (1989) noted that recharge in most of western Denmark at the end of the nineteenth century was only half of the recharge during the period 1964-1983 because of much greater winter rainfall. A similar study of recharge sensitivity in Western Australia by Sharma (1989) concluded that a $\pm 20 \%$ change in rainfall would result in a $\pm 30 \%$ change in recharge beneath natural grasslands and $\pm 80 \%$ change in recharge beneath a pine plantation, indicating that recharge is greatly influenced by land use and precipitation variability. Subsequently, Green et al. (2007a) demonstrated the potential importance of changes in the timing of rainfall regimes. Eckhardt and Ulbrich (2003) predicted that mean monthly recharge and streamflow will be reduced by up to $50 \%$ under change precipitation regimes, that may lead to issues of local water quality, groundwater withdrawals, and hydropower generation.

Groundwater recharge and corresponding vulnerability indices have been mapped globally (Döll, 2009). As noted above, estimates of recharge vary spatially with vegetation, soils and land use, and change in time depending upon the emissions scenario. For the 2050s time period, Döll (2009) estimated that approximately $18 \%$ of the global population would be affected by decreased recharge of at least $10 \%$, up to a third of the population may experience increased recharge of at least $10 \%$. The latter increases may have pronounced effects in areas with already shallow water tables, which may be more significant than sea level rise in coastal aquifers (Kundzewicz and Döll, 2009).

Temperature-depth profiles in deep boreholes are useful for estimating ground-surface temperature history and recharge, because climate change at the ground surface is stored in the subsurface thermal regime (Taniguchi, 2002; Miyakoshi et al., 2005). This method and its development are covered in greater detail in Section 4.2.2. In the context of estimating recharge, Taniguchi (2002) showed that subsurface thermal profiles near Tokyo, Japan reveal that recharge rates increased from the 1890s to 1940s and decreased from the 1940 s to 1990 s, in large part, for climatic variations in precipitation regime. The spatiotemporal response of recharge to precipitation variability may affect the aquifer yield, discharge, and groundwater flow networks, such as gaining streams may become losing streams and groundwater divides may move position (Dragoni and Sukhija, 2008). For example, Winter (1999) showed that climatic conditions affect the direction of groundwater flow and the relation between surface-water bodies and subsurface-water resources. Cambi and Dragoni (2000) showed that forecasted decreases in precipitation and recharge will result in a decrease in the discharge of the Bagnara spring, Italy and a decrease in the regional groundwater flow.

Permafrost-groundwater dynamics respond to climate change at many scales, particularly in sub-permafrost groundwater that is highly climate dependent (Haldorsen et al., 2010). Recharge is likely to increase in areas of Alaska that experience permafrost thaw (Kitabata et al., 2006; Dragoni and Sukhija, 2008). Additionally, Walvoord and Striegl (2007) proposed that long-term ( $>30$ year) streamflow records of the Yukon River in Alaska indicate a general upward trend in groundwater contribution to streamflow, which is caused by climate warming and permafrost thawing than enhances infiltration and supports deeper groundwater flow paths. In the Qinghai-Tibet Plateau of China, groundwater flow may play a more important role in permafrost degradation than climate change (Cheng and $\mathrm{Wu}, 2007$ ), where degrading perma- frost caused regional lowering of the groundwater table, which has resulted in falling lake levels, shrinking wetlands, and degenerating grasslands. Additionally, SWC may decrease as permafrost degrades, increasing the likelihood of desertification in the region (Cheng and $\mathrm{Wu}, 2007$ ). Climate change is expected to reduce snow cover and soil frost in boreal environments of Finland, which will increase winter floods and cause the maximum recharge and water levels to occur earlier in the year in shallow unconfined aquifers (Okkonen et al., 2009; Okkonen and Klove, 2010). In a national assessment of flooding in Finland, Veijalainen et al. (2010) found some evidence of reduced surface-water availability, but warned about spatially variable hydrologic conditions.

Climate parameters that affect recharge, groundwater, and pore-pressure fluctuations can often trigger slope instability and landslide activity (Dehn et al., 2000). Dehn et al. (2000) explained that changes in precipitation patterns and air temperature have substantial control on future landslide activities. Additionally, changes in recharge, which ultimately affect groundwater levels, have implications for slope stability, geomorphology, and other engineering considerations. Areas that experience increases in recharge may have increased slope instability (Dragoni and Sukhija, 2008). For example, Soldati et al. (2004) identified relationships between climate change and the temporal distribution of landslides, which in some cases is caused by rising groundwater levels.

Groundwater is a crucial component of the hydrologic cycle and many water-resource projects. Thus, potential effects of climate change on recharge deserve more attention than have been received to date (Dettinger and Earman, 2007). Scientists currently lack the necessary tools and data, such as long-term continuous monitoring of recharge processes, to confidently predict recharge responses to future climate change in most environments. To date, it is unknown in many regions of the world whether recharge will increase or decrease under predicted climate change. Given the many complexities assumed within the paleoclimate-analogue approach, uncertainties exist, as with any approach to make future predictions, and scenarios from the analogue approach may not be valid beyond 20 years (Dragoni and Sukhija, 2008). Furthermore, the uncertainty that is inherent to the spatial and temporal variations in temperature and precipitation from any given climate-change scenario is translated to the uncertainties of predicted evapotranspiration, runoff, and recharge (Strzepek and Yates, 1997). It is clear that the changing conditions of the location and timing of recharge and associated effects on groundwater supplies are insufficiently understood under future climate change and variability (Sophocleous, 2004; Gurdak et al., 2007). However, there is abundant evidence that water resources, especially in many semiarid and arid regions, are particularly vulnerable to the effects of climate change, especially if recharge conditions change or worsen (Aguilera and Murillo, 2009; Barthel et al., 2009; Novicky et al., 2010). The use of groundwater to offset declining surface-water availability will be hampered by declining recharge rates, especially in the most water-stressed regions (Kundzewicz et al., 2007).

\subsubsection{Discharge}

Groundwater discharge is the loss of water from an aquifer to a surface-water body, the atmosphere, or abstraction for human uses. Groundwater depletion occurs when rates of groundwater recharge are less than rates of discharge. Over the last 50 years, groundwater depletion from direct or indirect effects of climate change and (or) human activities, such as groundwater pumping for irrigated agriculture or urban centers (Bouraoui et al., 1999; Dams et al., 2007), has expanded from a local issue to one that affects large regions in many countries throughout the world (Brouyere et al., 2004; Alley, 2007; Hsu et al., 2007; Martin-Rosales et al., 2007; Moustadraf et al., 2008). Changing global groundwater 
discharge has even contributed to sea-level rise during the past century. In particular, the rise in sea level would have been even greater if substantial quantities of water had not been stored in land-surface reservoirs or channeled into aquifers by irrigation return-flow (Sahagian et al., 1994).

Some groundwater resources could be substantially affected by climate change even if the present groundwater pumping rates are not increased, such as in the Edward aquifer in Texas, USA (Loaiciga et al., 2000) and the Chalk aquifer in eastern England (Yusoff et al., 2002). Direct or indirect effects of climate change on groundwater discharge include soil degradation, changes in water demand, and changes in irrigation or land-use practices (Brouyere et al., 2004).

The notable increase in groundwater depletion beginning in the mid-1900s is consistent with the increase in population in many regions and the development of high-capacity well pumps that are used to support agricultural industries and public and private drinking-water supplies. The High Plains (or Ogallala) aquifer in the United States, as with many aquifers worldwide, has had substantial water-level declines since the 1950s that range from 3 to more than $50 \mathrm{~m}$ depending on the relative magnitudes of discharge and recharge in the aquifer (McMahon et al., 2007). Declining baseflow in the Sand Hills of Nebraska, USA has also been correlated with soil texture (Wang et al., 2009).

Alley (2006) suggested that the effects of discharge and groundwater development often take many years to become evident and thus, there is a tendency to neglect the data collection and analysis that is needed to support informed groundwater management until the problems materialise. This type of reactionary stance to groundwater management is flawed in many ways because, although some groundwater systems are renewable, many groundwater resources contain "fossil" groundwater, especially in arid and semiarid regions, and thus are non-renewable natural resources. For example, the groundwater that is removed from storage in many arid regions was recharged during wetter periods under paleoclimate conditions (Alley, 2007).

Under some climate scenarios, many regions may receive more precipitation. Woldeamlak et al. (2007) showed that under wetclimate scenarios, runoff was the most sensitive component, and when combined with the predicted increases in groundwater discharge, may result in rising groundwater levels and winter precipitation that increase the risk of flooding. Under dry-climate scenarios, recharge was the most sensitive component and decreases in all seasons, resulting in annual groundwater level declines by as much as $3 \mathrm{~m}$. This could have adverse effects on local aquatic life in local wetlands and riverine ecosystems that rely on groundwater discharge to support baseflow (Woldeamlak et al., 2007).

Submarine groundwater discharge (SGD), or the net groundwater discharge that occurs beneath the ocean, is a large component of the global hydrologic cycle, accounting for as much as $12,000 \mathrm{~km}^{3}$ per year (Speidel and Agnew, 1988) and may otherwise provide fresh water for human needs (Taniguchi, 2000; Burnett et al., 2006). Quantifying submarine groundwater discharge and the biogeochemical effects on the ocean has important implications for understanding climate-change effects on oceanic processes (Windom et al., 2006). For example, high dissolved nitrogen-phosphorus ratios in SGD relative to surface waters may drive the coastal oceans toward phosphorus limitation within the coming decades, perhaps changing the present nitrogenlimited coastal primary production (Slomp and Van Cappellen, 2004; Taniguchi et al., 2008).

\subsubsection{Flow and storage}

Alley (2001) noted the critical importance of groundwater storage in successfully dealing with climate change and variability. In particular, changes in groundwater storage and agricultural groundwater pumping in active semiarid basins are substantial, yet little understood, components of the water balance (Ruud et al., 2004). The use of groundwater storage to modulate the effects of drought increases in importance as surface-water storage becomes more limited, especially during drought periods (Alley, 2001).

Prior to development, the water in storage of most aquifers worldwide was based on local-climate conditions, ecological demands, and interactions with surface water. Water-table declines and loss of storage worldwide during the second half of the twentieth century were consistent with the development of highcapacity well pumps, aquifer development for human use, and a warming climate (Kertesz and Mika, 1999). Although some regions of the world, including parts of Russia (Dzhamalov et al., 2008), may have sufficiently reliable groundwater storage under future climate change and variability, the rate of global groundwater depletion was approximately $1.6 \times 10^{11} \mathrm{~m}^{3} /$ year during the second half of the twentieth century (Brown, 2001). Postel (2001) estimated that if this rate of groundwater depletion (loss of storage) continues, the number of people globally that will live in waterstressed countries will increase from 500 million to 3 billion over the next 25 years. This problem will likely be compounded by future global-population growth, which correlates with higher groundwater pumping rates that further threaten the groundwater sustainability of many aquifers at the global scale (Loaiciga, 2003). Taniguchi et al. (2008) showed that population growth and the associated increase in demand for water resources, groundwater pumping, and temporary loss of groundwater storage, have resulted in substantial land-subsidence problems for many Asian urban centers. In response to land subsidence, regulation and groundwater management in Tokyo and Osaka, Japan has reduced groundwater pumping and stopped land subsidence (Taniguchi et al., 2008). However, other problems have arisen, including damage to underground infrastructures caused by the buoyant forces of the rising groundwater levels. Bultot et al. (1988) simulated changes in groundwater storage of three aquifers in Belgium in response to climate change (a doubling of $\mathrm{CO}_{2}$ in their study) that were largely dependent on aquifer specific hydrogeologic properties, such as transmissivity, presence of perched lens, or confining units. Changes to infiltration rates also affected groundwater storage and may increase groundwater storage if infiltration rates are high.

The water-table declines and loss of groundwater storage in the High Plains aquifer in the United States were consistent from about the 1940s, when aquifer development became widespread across the aquifer, until about the early 1980s when rates of water-table drawdown diminished (Rosenberg et al., 1999). Rosenberg et al. (1999) noted that this turn-around occurred despite a very large increase in the total acreage of irrigated agriculture between the early 1980s and mid-1990s, which should have worsened watertable declines. Dugan and Sharpe (1996) attributed the changes in water tables over this period to a number of technological (i.e., more efficient irrigation methods) and economic factors, but also in large measure to the fact that precipitation in the High Plains was well above normal between 1980 and 1999 (Garbrecht and Rossel, 2002).

The responsiveness of the High Plains aquifer, and other similar aquifers, is strongly suggestive that natural and human-induced changes in climate, including temperature, precipitation, humidity, and solar radiation can profoundly affect the availability and future sustainability of groundwater resources (Rosenberg et al., 1999). The above normal precipitation across the High Plains aquifer region between 1980 and the late-1990s can be attributed to teleconnections from natural variations in sea-surface temperatures and atmospheric pressures across the Atlantic and Pacific Oceans (Garbrecht and Rossel, 2002). During the 1980s and early 1990s, 
the Pacific Decadal Oscillation (PDO) (Mantua and Hare, 2002) was in the positive phase of variability and the Atlantic Multidecadal Oscillation (AMO) (Kerr, 2000) was in the negative phase of variability, which generally results in wetter conditions and lower frequency of drought for the High Plains region (McCabe et al., 2004).

Natural-climate variability, as represented by effects from the PDO or AMO, occurs on all time scales, from annual to decadal, centennial, and millennial time scales. Ghil (2002) noted that the complex nature of climate variability on multiple time scales is a major obstacle to the reliable characterisation of global climate change resulting from human activities. Anthropogenic effects on aquifers, such as groundwater pumping and resulting loss of storage, are often on the same time scale as some natural-climate variabilities, which confound analyses and make it difficult to distinguish between the two (Hanson et al., 2004; Gurdak et al., 2007; Mayer and Congdon, 2008). These natural variations in climate, when combined, can have profound effects on the surface-hydrologic cycle largely because of the magnitude and phase relation that can cause average or extreme climate forcings (Hanson and Dettinger, 2005), such as drought, low flow in streams, changes to water quality, and adverse effects on stream ecosystems (Caruso, 2002). As a result, recent research efforts have characterised subsurface hydrologic and geochemical responses to climate variability on interannual to multidecadal time scales because variability on these time scales has the most tangible implications for water-resource management (Chen et al., 2002, 2004; Hanson et al., 2004, 2006; Hanson and Dettinger, 2005; Gurdak et al., 2007). Climate forcings on these timescales, such as the PDO, AMO, and the El Niño/Southern Oscillation (ENSO), have been identified as having substantial control on recharge and water-table fluctuations of the High Plains aquifer (Gurdak et al., 2007, 2008; McMahon et al., 2007), other aquifer systems of the southwestern United States (Hanson et al., 2004, 2006; Barco et al., 2010), and a number of other aquifers worldwide (Ngongondo, 2006), including those in many small, tropical islands in the Pacific, Indian, and Atlantic oceans (White et al., 2007). A number of studies have relied on long-term historical hydrologic time series to identify climate-variability effects on groundwater levels (Chen et al., 2004; Gurdak et al., 2007; White et al., 2007). Many of these studies have identified quasi-periodic variations in hydrologic time series that reflect a range of natural and anthropogenic climate forcings (Hanson and Dettinger, 2005). For example, groundwater levels in the Santa ClaraCalleguas Basin of coastal Southern California reflect climate forcings on time scales that range from days to decades and represent teleconnections between recurrent and persistent climatic patterns over large parts of the Earth's surface, such as ENSO (Hanson et al., 2003).

Many questions remain with regard to the control of natural climate forcings on subsurface hydrologic processes and how anthropogenic global warming may affect the frequency and magnitude of these forcings, which, in turn, affect the hydrologic cycle of the surface and subsurface (Gurdak et al., 2009). For example, what is the confidence in predictions of future subsurface-hydrologic response to climate forcings on interannual to multidecadal timescales in light of anthropogenic warming of Earth and the likely effects on the magnitude and frequency of the known climate forcings (such as ENSO, PDO, or AMO)? Hanson and Dettinger (2005) suggested that GCMs have the ability to simulate and transmit climate-variability processes, such as precipitation, streamflow, and changes in groundwater levels that are consistent with ENSO and PDO variability, and that these models hold promise for predicting natural-climate variability and anthropogenic-climate change effects on groundwater. Additional research on the climate variability may help advance water-management practices especially in communities that rely more on groundwater during dry periods (e.g., during the La Niña phase of ENSO variability in the southwestern US) or prolonged climate change, and in those communities that rely more on surface water during wet periods (e.g., during the El Niño phase in the southwestern US) (Alley, 2001).

One of the key findings by the IPCC is that past processes within the hydrologic cycle may not provide a reasonable guide to future climate conditions and hydrologic processes (IPCC, 2007a; Bates et al., 2008). Groundwater is an essential component of the hydrologic cycle and the future climate conditions may have substantial consequences for groundwater management and infrastructure (Ludwig et al., 2010). The assumption that the hydroclimatic system will fluctuate within an unchanging envelope of variability, termed stationarity, is a fundamental and inherent concept in the training and practice of most hydrologists and water-resource engineers (Milly et al., 2008). However, stationarity of the hydroclimatic system is not a reasonable assumption under naturalclimate variability that has low-frequency and internal variability (such as ENSO, PDO, or AMO (McCabe et al., 2004)) or under substantial anthropogenic change of the Earth's climate that we currently face. Milly et al. (2008) have suggested that stationarity assumptions must be replaced by non-stationary conceptual and statistical models for relevant variables in the hydroclimatic system to optimise water systems and management.

\subsubsection{Groundwater quality}

Most studies of the effects of climate change and variability on groundwater have focused on processes that affect recharge, discharge, changes in storage and the associated physical processes that govern subsurface-water flow. Relatively few studies of climate change and variability effects on groundwater have focused on processes that will affect groundwater quality. Groundwater quality is a function of the chemical, physical, and biological characteristics of the resource. Thus, groundwater quality can be expected to respond to changes in climate and linked human activities because of the influences of recharge, discharge, and land use on groundwater systems. Groundwater quality is a value-specific concept because the quality of water is related to specific water-use standards. The protection and enhancement of groundwater quality has been a high-priority environmental concern because of the direct implications for drinking-water health standards (Alley, 1993). Also, if groundwater becomes too saline because of rising sea levels, for example, the water quality may be a limiting factor for other uses of groundwater, such as agriculture, industry, or ecosystem needs. Therefore, sustainability of water supplies under future climate change and variability is not only dependent on the quantity and quality of groundwater resources, but also on the physical hydrogeologic characteristics of the aquifer, laws, regulations, and socioeconomic factors that control the demand and use of groundwater (Reilly et al., 2008).

Global change may affect the quality of groundwater in many ways (Alley, 2001; Dragoni and Sukhija, 2008). Changes to recharge rates, mechanisms, and locations can affect contaminant transport, which may lead to erroneous conclusions about temporal trends in groundwater quality, particularly if only a few samples have been collected over time (Alley, 2001). For example, recharge during relatively dry periods may have a greater concentration of salts and total-dissolved solids (TDS), while recharge during relatively wet periods may have a relatively lower TDS concentration (Sukhija et al., 1998). Climate variability on interannual to multidecadal timescales also has been linked with changes in spatiotemporalprecipitation patterns that can result in substantial infiltration events that mobilise large, pore-water chloride and nitrate reservoirs in the vadose zone of aquifers in semiarid and arid regions (Gurdak et al., 2007; Gurdak, 2008). Groundwater quality may deteriorate substantially if these large chemical reservoirs reach the water table. 
Coastal regions support approximately one-quarter of the global population, but contain less than $10 \%$ of the global-renewable water supply and are undergoing rapid-population growth (Kundzewicz et al., 2007). The IPCC has a very high confidence that sea-level rise, spatiotemporal changes in precipitation and evapotranspiration, which affect recharge, and increased groundwater pumping will result in more groundwater salinisation in many coastal regions (Oude Essink, 1996, 2001, 2004; Klein and Nicholls, 1999; Sharif and Singh, 1999; Pierson et al., 2001; Beuhler, 2003; Ranjan et al., 2006a,b; IPCC, 2007a; Kundzewicz et al., 2007; Moustadraf et al., 2008; Barrocu and Dahab, 2010; Oude Essink et al., 2010; Yechieli et al., 2010). For example, Vandenbohede et al. (2008) simulated a likely $15 \%$ increase in recharge across a Belgian coastal aquifer over the next 100 years. Simulations showed that a $0.4 \mathrm{~m}$ sea-level rise resulted in an increased groundwater flow of fresh water toward low-lying inland areas and a decreased groundwater flow toward the sea, while the increase in recharge resulted in more groundwater flow toward both low-lying inland areas and the sea (Vandenbohede et al., 2008). Therefore, brackish and salt water present in low-lying areas will be pushed back, and salt-water intrusion may occur from the lowlying areas into dunes, which could affect the ecology of the dunes and the drainage system used in most low-lying areas (Vandenbohede et al., 2008). Lambrakis and Kallergis (2001) showed that over-pumping, combined with a dry period, has led to a substantial decline in groundwater quality of many Greek coastal aquifers. Factors included abstraction from great depths, a lack of reliable water-resource management, and salt-water intrusion resulting in a rise of the fresh/salt-water interface. When simulated groundwater pumping was discontinued, the reverse process of groundwater freshening was a relatively long process in those Greek coastal aquifers, ranging from 15 to 10,000 years depending on the local geochemical conditions and flow regime (Lambrakis and Kallergis, 2001). Such long periods of groundwater freshening highlight the importance of minimising the initial saltwater intrusion to maintain fresh groundwater resources in coastal environments. The salinisation of groundwater may, in turn, affect the water quality in many rivers and estuaries (Burkett et al., 2002). Due to increasing concentration of human settlements, agricultural development and economic activities, the shortage of fresh groundwater for domestic, agricultural, and industrial purposes becomes more striking in coastal low-lying deltaic areas like the Mississippi, Nile, Mekong, Ganges, Po, and Rhine-Scheldt deltas (Oude Essink, 1996). The rising water levels of the Mediterranean Sea and falling levels of the Dead Sea will likely cause water levels to rise and fall, respectively, in adjacent coastal aquifers in Israel, with local coastal topography, recharge rates, and permeability also having an important effect on future water levels (Yechieli et al., 2010)

Climate change may also affect groundwater quality by causing a decline of fresh groundwater through reduced recharge and (or) increased pumping. This may disrupt the current balance of the freshwater/saline water boundary, resulting in saline water intrusion in not only coastal basins, but inland aquifers as well, such as the carbonate rock aquifer in the Winnipeg region of Canada (Grasby and Betcher, 2002; Chen et al., 2004). An indirect effect of climate change is increased groundwater pumping, which could affect hydraulic heads in many aquifers, allowing upward leakage of groundwater with poorer-water quality, such as in the High Plains aquifer (McMahon et al., 2007). Alley (2001) also noted that the combined effects of groundwater development and climate change may lead to less dilution of contaminants in streams during low flow than was assumed in setting streamdischarge permits.

A wide range of additional climate-change effects on groundwater quality are possible. Kovalevskii (2007) showed that under projected climate change, many regions of Russia will likely have increased rates of recharge that may increase rates of contaminant transport and groundwater vulnerability to various types of nonpoint- and point-source contamination. The combination of the heat-island effect from urbanisation and global warming on subsurface temperatures has implications for groundwater quality because of changes to subsurface biogeochemical reactions (Knorr et al., 2005; Taniguchi et al., 2008). Future research is needed to better understand the full range of effects on groundwater quality from changes in the subsurface thermal regime and various biogeochemical reactions (Aureli and Taniguchi, 2006). Climate change and the global trend of increasing urbanisation may also increase flood vulnerability (Aureli and Taniguchi, 2006). Flooding in urban areas could increase loading of common urban contaminants like oil, solvents, and sewage to groundwater.

Nutrient transport rates, particularly nitrogen $(\mathrm{N})$ and phosphorus $(P)$, beneath agricultural lands may also be sensitive to climate change. A study of N and P in Sweden (Destouni and Darracq, 2009) illustrated subsurface controls on nutrient loading to coastal areas that were relatively insensitive to projected climate due to a lagged response to historical nutrient inputs. On the other hand, subsurface feedback to the climate system is likely due to emissions of greenhouse gases such as $\mathrm{N}_{2} \mathrm{O}$, which Destouni and Darracq (2009) noted as a neglected feedback mechanism.

Relatively few studies have explored climate-change effects on pesticide fate and transport in the subsurface. Using a source-pathway (or transport)-receptor conceptual framework, Bloomfield et al. (2006) identified that the main climate drivers for changing pesticide fate and behavior are changes in rainfall seasonality and intensity, and increased temperatures. However, indirect impacts, such as land-use change are likely to have a more substantial effect on pesticides in surface water and groundwater than the direct effects of climate change on pesticide fate and transport. Bloomfield et al. (2006) noted the overall effect of climate change on pesticide fate and transport is likely to be highly variable and challenging to predict because of the uncertainties associated with climate predictions.

Long-term monitoring efforts will likely provide the necessary data to observe and understand climate-related spatiotemporal trends in groundwater quality (McMahon et al., 2007; Dragoni and Sukhija, 2008). Groundwater-remediation practices may consider climate-change prediction in site design. Warner (2007) noted that climate change, including shifting rainfall patterns, rising sea levels, and fluctuating river levels may be a future cause for concern with regard to the potential failure of a fixed-in-place remediation strategy, such as in situ permeable reactive barrier (PRB), to capture its intended plume because of the climate-induced shifts in hydraulic gradients. The relatively short-life expectancy of most engineered groundwater-remediation systems do not currently include the development of economically viable remediation systems for the long-term and uncertain nature of climate predictions. Warner (2007) suggested that flexibility in design of remediation systems, such as increasing the length of a PRB, may account for future shifts in the hydraulic gradient caused by climate change, or more likely, from human activities and groundwater pumping.

\subsection{Surface-subsurface hydrological interactions}

Climate change has substantial implications for surface-water processes (Gosling et al., 2010), including groundwater/surfacewater interactions. Some studies suggest that climate change will result in less surface-water availability, which will likely increase the need for groundwater development (Chen et al., 2004; Hsu et al., 2007). For example, climate change may extend the dry season of no or very low flows in some semiarid and arid regions, which can have a substantial effect on the overall water resources 
of the region if no deep and (or) reliable groundwater resources are available (Giertz et al., 2006). Surface-water storage structures can play a vital role in augmenting groundwater recharge, especially in semiarid and arid regions (Sharda et al., 2006). Accurate low-flow stream measurements are important for groundwater-fed streams to assess the potential effects of climate change and variability, and to assess in-stream flow requirements and the nature of groundwater-surface interactions (Berg and Allen, 2007). Cohen et al. (2006) showed that the responses in surface-water bodies to climate change were controlled in part by groundwater hydrodynamics and position within the watershed; water-table fluctuations were consistent and had larger-amplitude fluctuations with lake levels within the upland portions of a watershed in central Minnesota, USA. Cohen et al. (2006) also noted that groundwatersupported evapotranspiration varied with topography and aquifer-hydraulic conductivity, and indicated that small yet important feedbacks exist between groundwater and atmospheric processes on decadal and longer time scales. Moreover, Ferguson and Maxwell (2010) demonstrated that the hydrologic sensitivity of a watershed to climate change depends on feedbacks between groundwater, overland flow, and land-surface water and energy balance. The magnitude and seasonality of groundwater feedbacks to surface hydrologic processes is highly sensitive to climate change (Ferguson and Maxwell, 2010).

An increased frequency of droughts has implications for surface-groundwater interactions. For example, the summer of 2003 was the hottest in Europe in more than 500 years, linked to an estimated 500 deaths in the Netherlands alone, and could become a close-to-normal summer by about 2050 (Kabat et al., 2005). The extremely low freshwater discharge by the river Rhine in 2003 resulted in groundwater seepage of seawater to the low-lying delta, which threatened substantial areas of Dutch agriculture and horticulture. As a result, studies are underway to develop freshwater canals and additional summer water storage facilities for the region. Across regions of the High Plains aquifer in Kansas, USA, streamflow declines are historically caused by high rates of groundwater pumping, but also correlate with climate variability since the mid1980s (Brikowski, 2008). Brikowski (2008) showed that projected climate change for the region will likely continue streamflow declines at historical rates, resulting in severe consequences for surface-water supply and the strong possibility of unsustainable surface storage of water resources in the region, which will likely create even more pressure on the groundwater resources of the already-stressed High Plains aquifer. Similar findings have been identified in other climate regions, including humid, tropical and arctic catchments. For example, Kingston and Taylor (2010) demonstrated that warming scenarios will increase evapotranspiration and lead to reductions and changes in the seasonality of groundwater contributions to discharge of the River Mitano catchment in Uganda. Both observations and modelling suggest that climate-warming induced permafrost degradation will markedly increase baseflows of arctic and subarctic rivers and streams (Walvoord and Striegl, 2007; Bense et al., 2009; St. Jacques and Sauchyn, 2009).

Because natural-climate variations often play an important role in successful conjunctive management of groundwater and surface-water resources (Hanson and Dettinger, 2005), understanding future climate change (natural variability and anthropogenic change) effects will be crucial, especially for groundwater/surface-water resources already close to the limits of sustainability and under forecasted drought conditions. It is clear that groundwater withdrawals can strongly affect streamflow during dry periods (Lee and Chung, 2007). Therefore, it is critically important to accurately understand the links between climate change and variations and the cycles of supply and demand that drive recharge and withdrawal of water resources. Accurate projections of climate change and variations and simulations of the responses in the water-resources system are required (Hanson and Dettinger, 2005).

\section{Observational methods for exploring subsurface global change}

Methods available to detect temporal changes in subsurface parameters, notably groundwater quantity and quality, are numerous and range markedly in observation scale and "directness" of observation. The most direct, but also smallest-scale observations are obtained from head measurements in piezometers and water quality measurements of water samples obtained in wells. Environmental tracers and age dating provide invaluable means to constrain processes, in particular on relatively long timescales ( $>50$ year). While in situ measurements arguably provide the most accurate, reliable and a very valuable means to detect change, the small observation scale brings about issues of representativeness for large spatial domains. Most investigations are specific to the site or region of study, because regional stakeholders want information, and it is most feasible to assess well-defined physiographical systems. Moreover, observation networks do not exist across large parts of the globe and installing and maintaining measurement systems is expensive and labor intensive. To bring to light temporal trends at regional to global scale and to study their relationship to change in regional to global climate and human activities, studies of extensive data sets (monitoring networks) of such "point-data" are required. Hydroclimatically similar regions can be explored using a global database of historical climate data. Similarity between historical climates in different regions is a necessary starting point but may not be sufficient to constitute analogous climate change scenarios.

Most hydrogeophysical methods have the advantage that they allow detection of change over larger volumes of the subsurface, but at the expense of detail, notably regarding water chemistry. Remote sensing allows detection of systematic change in the recent past and future on truly large scales, but has limited ability to "see" groundwater. The major benefit of remote sensing technologies is their ability to access spatial information in remote areas where in situ monitoring is sparse or non-existent. Furthermore, conjunctive use of well data, hydrogeophysics and remote sensing is essential.

\subsection{Age dating and chemical proxies}

Tracer methods are standard tools of hydrologists to obtain constraints on the age of groundwater and on processes and conditions water samples experienced during recharge and upon transit in the groundwater system (Plummer, 1993; Clark and Fritz, 1997; Cook and Herczeg, 2000; Hinsby et al., 2001; Loosli et al., 2001; Kooi, 2008a). In the following, key methods are summarised, and their potential for detecting temporal change in groundwater systems is discussed, focusing on relatively short time scales (less than 100 years).

\subsubsection{Age dating}

Age dating refers to methods that aim to constrain the timing of recharge, often via the time since recharge. Evidently, these methods are extremely valuable to address changes in groundwater systems. Groundwater ages can be obtained using

- radioactive isotopes with well-known, stable source concentrations (e.g., ${ }^{14} \mathrm{C}$ ),

- radioactive isotopes with variable source concentration and a daughter isotope that can be fairly uniquely linked to the mother species (e.g., ${ }^{3} \mathrm{H} /{ }^{3} \mathrm{He}$ ), or 


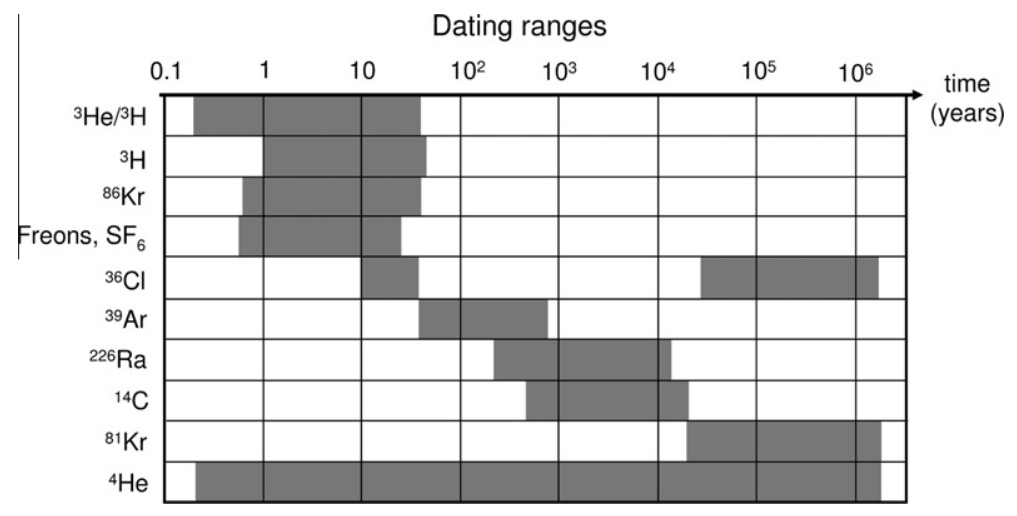

Fig. 5. Isotopic tools potentially available for dating of groundwater that is up to $10^{6}$ years old (after Loosli et al., 2001).

- conservative chemical species which exhibit negligible decay and which have a well-known, systematically changing source concentration (e.g., ${ }^{85} \mathrm{Kr}, \mathrm{CFC}$ 's, $\mathrm{SF}_{6}$ ).

These "direct methods" of age dating (Fig. 5), in principle, allow construction of a continuous record of water age with distance along a flow path, thereby potentially revealing temporal changes in recharge. Such changes have primarily - or perhaps solely been documented for the relatively distant past ( $>2000$ year BP) from inferred gaps in the ${ }^{14} \mathrm{C}$ age record. In northern latitudes, the lack of recharge is mostly attributed to glacial or permafrost conditions during the Late Glacial Maximum (Edmunds, 2001), while similar gaps encountered in Africa have been linked to Late Pleistocene and Holocene periods of prolonged drought (Beyerle et al., 2003; Guendouz et al., 2003). Similar uses of ${ }^{3} \mathrm{H} /{ }^{3} \mathrm{He},{ }^{85} \mathrm{Kr}$, CFC's, $\mathrm{SF}_{6}$ to infer relatively subtle changes in recharge for the last five decades are appealing, but also non-trivial as this requires detailed knowledge of the two- or even three-dimensional nature of local groundwater flow systems and mixing processes. Accuracy of age-dating methods covering time scales of $100-500$ years is low, such that temporal changes in this age-range still are hard to resolve.

Several "indirect" age-dating methods provide additional useful constraints on groundwater age. These methods generally determine whether the water sample is recharged before or after a known event. Only when water is sampled which corresponds to the event marker can an absolute age be assigned to the water. The nuclear bomb test peaks in ${ }^{3} \mathrm{H},{ }^{14} \mathrm{C}$ and ${ }^{36} \mathrm{Cl}$ are key examples. Presence of ${ }^{3} \mathrm{H}$, nitrate and pesticides in groundwater has been used extensively to distinguish relatively old from "modern water" which carries an anthropogenic signature. These indirect methods are most useful to study spatial variability in groundwater flow systems.

\subsubsection{Chemical proxies}

Several chemical proxies are used to trace changes in groundwater flow and, notably, changes in recharge conditions associated with climate change and surface environmental change in general. Key proxies are the stable isotopes of water (Clark and Fritz, 1997) and noble gases dissolved in groundwater (Stute and Schlosser, 1993; Porcelli et al., 2002). Also, chloride content of groundwater and, in particular in vertical SWC profiles collected in thick vadose zones in desert areas, have been exploited to infer changes in recharge conditions (e.g. Edmunds and Tyler, 2002).

Stable isotopes of $\mathrm{H}$ and $\mathrm{O}$ in the water molecule are sensitive to evaporation and condensation processes occurring in the hydrological cycle (Clark and Fritz, 1997). The isotopic composition of groundwater formed by local infiltration and recharge is intimately coupled to the composition of precipitation. When precipitated water partly evaporates before being recharged, this can often be recognised in the isotopic signature of groundwater samples through a deviation from the (local) meteoric water line. Temporal changes in recharge conditions can, therefore, also be potentially gleaned from isotope studies of groundwater. Temporal trends in meteoric conditions may also cause spatial variations of isotopic signatures along groundwater flow paths through changes in the input signal of precipitation (e.g., Allen, 2004). Over long time scales (thousands of years), studies have inferred changes in atmospheric circulation patterns and the vapor source area (often sea/ ocean) of precipitation intensity and amount, and changes in air temperature (Kreuzer et al., 2009). Within shorter time scales, the latter changes may be inferred more directly from the fairly extensive network of meteorological stations for which isotopes are measured in precipitation and other more direct methods to monitor weather and climate variables. Furthermore, studies of regional/global change in recharge conditions via comparison of groundwater and precipitation isotopic signatures should provide valuable information for changes of groundwater resources.

Analysis of noble gas concentrations ( $\mathrm{Ne}, \mathrm{Ar}, \mathrm{Kr}$, and $\mathrm{Xe}$ ) in groundwater along a flow path (or with depth) can be used to study changes in recharge temperature (NRT) (Stute and Schlosser, 1993; Kipfer et al., 2002). The method exploits the fact that the solubility of these gases is temperature dependent and this dependence increases strongly with atomic mass and, hence, is different for the different species. Xe has the highest sensitivity to temperature, whereas Ne solubility only shows a very minor temperature effect. Accuracy of the technique has been shown to be $1{ }^{\circ} \mathrm{C}$ or better when all four gases are used. NRT records are usually interpreted to closely track changes in surface air temperature. However, systematic differences between annual ground surface and air temperature occur in association with vegetation and SWC conditions, which could potentially also be responsible for some of the changes recorded in NRT reconstructions. Recent studies have shown that noble gas contents can also be used to detect water provenance such as recharge from lakes. High excess air content (gas content in excess of solubility equilibrium with the atmosphere) are interpreted to provide a proxy for large water table fluctuations and, hence, strong variability (intermittency) of recharge (Ingram et al., 2007). Although noble gases have been applied primarily in paleohydrological reconstructions of long time scales (Kooi, 2008a), they should also provide valuable constraints regarding changes in groundwater systems on timescales of decades to centuries.

\subsection{Hydrogeophysical techniques}

Of the numerous hydrogeophysical methods available, three are particularly relevant to the study of groundwater and the 
consequent changes that arise from climate variability and change: electrical/electromagnetic methods, subsurface temperature logging, and land-based gravity surveying.

\subsubsection{Electrical/electromagnetic methods}

A wide range of electrical/electromagnetic imaging and logging methods can be used to study groundwater systems and their responses to climate-related phenomena. This group of methods includes spontaneous/self potential (SP), electrical resistivity, induced polarisation (IP), a range of time and frequency domain electromagnetic methods, and ground-penetrating radar (GPR). These techniques take advantage of differences in two important properties of subsurface materials; electrical resistivity and dielectric constant. Water has a low resistivity (or high electrical conductivity) and high dielectric constant relative to mineral grains and air. Saline water has a high electrical conductivity relative to fresh water. Therefore, where there are either spatial or temporal changes in water content or water salinity, these techniques can be applied. Their advantage over point sampling is that large areas can be covered either in land-based surveys or airborne surveys. Borehole logging methods can be used in a similar fashion to provide vertical profiles of these properties with depth and to constrain survey data.

Climate change is expected to alter groundwater recharge and discharge, changing both their timing and magnitude. Some examples of applications targeting recharge and discharge phenomena include time lapse resistivity imaging to monitor snowmelt infiltration (French and Binley, 2004), VLF (very low frequency) EM for mapping water seepage from a lake in Egypt (Khalil et al., 2009), and a combination of SP, temperature and electrical conductivity logging to characterise hydraulically active fractures in a carbonate aquifer (Suski et al., 2008). To date, however, there have been relatively few studies applied to groundwater recharge and discharge under variable climate conditions.

Perhaps the most common application of these methods is to studies of saline water in aquifers (Dent, 2007). Saline water can occur, for example, in coastal regions in association with seawater intrusion (Koukadaki et al., 2007; Zouhri et al., 2008), in arid areas due to salinisation from over-irrigation (Guérin et al., 2001), as a consequence of road salt application in cold climate regions, near contaminated sites (such as landfills), and as a result of mixing of connate or fossil water with freshwater. Climate change is expected to result in higher sea levels, posing an even greater threat to coastal aquifers. Thus, these hydrogeophysical methods are ideally suited for monitoring changes in groundwater salinity over large coastal areas due to the effects of sea level rise. Higher groundwater use due to pumping will likely exacerbate coastal salinisation problems (Cimino et al., 2008). Greater demand for irrigation under warmer and drier conditions will also potentially lead to increased regional scale salinisation. These techniques may prove invaluable for detecting changes in salinity over broad agricultural areas.

\subsubsection{Subsurface temperature logging}

Subsurface temperature can be used to reconstruct climate change and land cover change, because the signal of surface temperature change is preserved in subsurface environment (e.g., Chapman et al., 1992; González-Rouco et al., 2009; Davis et al., 2010). Development of this method dates back to early paleoclimatic work (Birch, 1948; Čermák, 1971). Changes in surface temperature associated with changes in air temperature (Smerdon et al., 2009) can propagate into the subsurface, and can be detected by measuring ground temperatures either in the shallow subsurface or to greater depths (up to several hundred meters) (Čermák et al., 1992; Beltrami and Mareschal, 1995). Temperature-depth profiles collected in boreholes can reveal and be used to help reconstruct the surface temperature changes due to climate change and land cover change during a few to several hundred years (Huang et al., 2000; Beltrami, 2002; Roy et al., 2002). Lewis and Wang (1998) identified ground temperature anomalies and associated these with deforestation in Canada. Taniguchi et al. (1999) also examined these effects in Western Australia. Analyses of temperature profiles continue to be refined with regard to the hydrodynamics of groundwater (Kukkonen et al., 1994; Smerdon et al., 2004; Bodri and Cermak, 2005). Although time-lapse temperature logging may also reveal changes in groundwater flow conditions (Taniguchi et al., 1999; Kooi, 2008a), this has not been exploited much. The human impacts on subsurface temperatures, such as the "heat island effect", can also be detected from subsurface temperature (e.g., Ferguson and Woodbury, 2007; Taniguchi et al., 2007, 2009; Kooi, 2008b; Huang et al., 2009; Yamano et al., 2009). Effects of global warming on subsurface temperature subsequently affect the ecology and water quality.

\subsubsection{Land-based gravity surveying}

Land-based gravity measurements have been used to detect changes in groundwater storage. Pool and Eychaner (1995) conducted a temporal gravity survey to measure changes in aquifer storage and documented water-level variations in an aquifer and associated gravity variations. Changes in storage reflect variations in the volume of water stored in the subsurface. Pool and Eychaner (1995) observed that measured gravity changes of about 13 microgal represented storage changes of about $0.30 \mathrm{~m}$ of water level. Although this study was undertaken over a large area with station spacing on the order of kilometers, the details of the survey demonstrated that gravity meters are now sufficiently precise to measure variations in the gravitational attraction on the order of a few tens of microgals. As such, smaller study areas have become suitable for use of gravimetric methods. For example, Krause et al. (2009) used new-generation superconducting gravity meters to collect gravimetric data in a small (approximate to $2 \mathrm{~km}^{2}$ ) catchment. The site was also instrumented with soil moisture and groundwater probes at various locations as well as additional precipitation gauges and a climate measurement station for monitoring of climatological and hydrological parameters in high spatial and temporal resolution. The gravimeter records contain noticeable influence due to variations of groundwater, soil water content and snow coverage. Gravity measurements have also been used to detect the changes in groundwater storage in situ (gravity profiling) and using the GRACE satellite data as discussed next in Section 4.3.

\subsection{Remote sensing of space-time trends}

Satellite remote sensing (RS) undoubtedly represents the most powerful method for detection and monitoring of environmental and climate change on a truly global scale. At the same time, however, capabilities of RS to "look below the ground surface" and to detect properties that directly bear on groundwater conditions are extremely limited. Notable exceptions to this are satellitebased observations of the gravity field which contain key information of changes in groundwater storage. RS further provides essential constraints on "surface components of the hydrological cycle" which indirectly influence the subsurface-water balance.

Remote sensing and earth observation technologies provide an important means of collecting groundwater-related data on a regional scale and to assess the state of the resource, which in turn allows for predictions of the possible responses of groundwater resources to climate change. Satellite remote sensing has drawbacks, but it offers the advantages of global coverage, availability of data, metadata, error statistics, and the ability to provide meaningful spatial averages. In cooperation with the European Space Agency 
(ESA), and other partner institutions, UNESCO-IHP launched the TIGER initiative, focusing on the use of satellite data for water resource management in Africa (European Space Agency, 2009).

Aerial thermal infrared imaging is being used increasingly for mapping groundwater discharge zones in estuaries, rivers and oceans. Peterson et al. (2009) used aerial thermal infrared imaging to reveal that submarine groundwater discharge (SGD) along the western coast of the Big Island of Hawaii is often focused as point-source discharges that create buoyant groundwater plumes that mix into the coastal ocean.

Several satellite and airborne remote sensing technologies can contribute to groundwater monitoring activities. Landsat, the Moderate-resolution Imaging Spectroradiometer (MODIS), the Advanced Very High Resolution Radiometer (AVHRR), and certain other instruments can resolve the location and type of vegetation, which can be used to infer a shallow water table. Landsat imagery can also provide geological clues where not obscured by vegetation. Altimetry measurements and Interferometric Synthetic Aperture Radar (InSAR) over time can show where subsidence is occurring, which is often an indicator of groundwater depletion. Microwave radar and radiometry measurements can be used to estimate snow and surface soil water, which further constrain groundwater assessments. But perhaps the most valuable remote sensing technology for groundwater investigations is high-precision satellite gravimetry, as enabled by the NASA/GFZ Gravity Recovery and Climate Experiment (GRACE) - a satellite gravimetry technology that may be used to assess groundwater storage changes.

Since its launch in 2002, the GRACE satellites have been employed to detect tiny temporal changes in the gravity field of the Earth (Ramillien et al., 2008). Temporal changes in measured gravity are primarily caused by changes in total water (mass) storage (TWS) in the atmosphere, ocean and at and below the surface of the continents. GRACE is being used to generate time series of total terrestrial water variations (Tapley et al., 2004), which can be used to assess groundwater storage changes. Wahr et al. (2006) presented the first technique for deriving terrestrial water storage variations from global gravity field solutions delivered by GRACE. Rodell and Famiglietti (2002) showed in a pre-GRACE-launch study that interannual variations and trends in the High Plains aquifer water storage would be detectable by GRACE, pointing to new opportunities for groundwater remote sensing. Rodell et al. (2007) developed time series of groundwater storage variations averaged over the Mississippi River basin and its four major subbasins using in situ data, and used these to verify GRACE-based estimates in which SWC and snow water equivalent fields output from a sophisticated land surface model were used to isolate groundwater from the GRACE terrestrial water storage data. At the smaller spatial scale of Illinois $\left(145,000 \mathrm{~km}^{2}\right)$, Swenson et al. (2006) showed that GRACE captures the signal of changes in total water storage very well, while Yeh et al. (2006) showed that GRACE-based estimates of groundwater storage variations compared well with borehole observations on seasonal timescales. Swenson et al. (2008) used Oklahoma Mesonet data and local groundwater level observations to further refine methods to remove the SWC signal from the total water storage change signal recorded by GRACE. Strassberg et al. (2007) followed up on the work of Rodell and Famiglietti (2002) by presenting a post-launch assessment of GRACE capabilities to monitor groundwater storage variations within the High Plains aquifer. Famiglietti et al. (2011) recently used GRACE to estimate groundwater depletion rates of $31.0 \pm 2.7 \mathrm{~mm} /$ year in the Central Valley aquifer, USA.

Post-launch studies using GRACE data have demonstrated that when combined with ancillary measurements of surface water and SWC, GRACE is capable of monitoring changes in groundwater storage with reasonable accuracy (temporal resolution 10 days to monthly, spatial resolution $400-500 \mathrm{~km}$, mass change $\sim 9 \mathrm{~mm}$ water equivalent). Validation studies have found acceptable agreement between GRACE-derived changes in continental water mass storage and independent inferences from global hydrology models and surface data. Seasonal correlations of $0.8-0.9$ were found by comparing GRACE and piezometer-network data for different parts of the USA. GRACE-data were recently used to monitor drought impacts of the Murray-Darling basin in Southeastern Australia (Leblanc et al., 2009). Syed et al. (2008) also found agreement between the storage changes estimated by GRACE and the Global Land Data Assimilation System (GLDAS), where GLDAS was used to disaggregate terrestrial water storage between soil, vegetation canopy and snow. Using combined groundwater modelling and GRACE data, Rodell et al. (2009) recently documented a $4 \mathrm{~cm} /$ year equivalent water height decline for aquifers covering much of northwest India.

In recent years, the need to better quantify potential changes in the water cycle associated with climate change (IGOS- ${ }^{5}$; WATCH program $^{6}$ ) has provided a major stimulus for improvement of techniques to monitor key variables and components of the hydrological cycle using space-based platforms. Advances and new developments in monitoring of soil moisture (de Jeu et al., 2008; Liu et al., 2009), precipitation, and evapotranspiration (Anderson and Kustas, 2008; Kalma et al., 2008) provide crucial elements to help constrain space-time trends in groundwater recharge. Future research will undoubtedly focus on the further integration of these multi-platform and multi-parameter observations, including GRACE data, in extensive hydrological models. Recent and upcoming dedicated hydrological missions for improved monitoring of soil moisture (2009: SMOS/ ESA; 2011: SMAP/NASA) and precipitation (2012: GPM/NASA), will therefore, also enhance RS capabilities of groundwater resources assessment.

GRACE has not yet been used fully by the hydrological community, due to its low spatial resolution and lack of information on the vertical distribution of observed water storage changes. GRACE can measure variations in equivalent height of water over regions about $200,000 \mathrm{~km}^{2}$ or larger, with uncertainties on the order of a few centimeters (Wahr et al., 2006). Accuracy degrades rapidly as the spatial resolution increases. While this is sufficient for many large scale hydrological investigations, most water resources, meteorological, agricultural, and natural hazards applications require higher resolution data. Furthermore, GRACE was launched in 2002 with an expected lifetime of 9 years, while climate variability assessments require a longer, nearly continuous record. This emphasizes the importance of developing a follow-on gravimetry mission with advanced technology to increase spatial resolution while decreasing uncertainty.

The monthly temporal resolution of GRACE is an issue for many applications, but it should be sufficient for regional groundwater assessments. To address such scale issues, Zaitchik et al. (2008) used an advanced data assimilation approach to incorporate GRACE data into a land surface model, and hence merge them with other datasets and knowledge of physical processes as represented in the model. In simulations over the Mississippi River basin, the GRACE-assimilation groundwater storage output fit observations better than output from the open loop, and they were of much higher spatial and temporal resolution than GRACE alone. Yamamoto et al. (2008) reported the larger difference, in particular at low latitude regions, between current terrestrial water models of global river basins and GRACE data. This technique may be the key to maximising the value of GRACE data for groundwater resources studies (e.g., Fukuda et al., 2009).

\footnotetext{
${ }^{5}$ http://www.gewex.org/igosreport.htm.

${ }^{6}$ http://www.eu-watch.org/templates/dispatcher.asp?page_id=25222705.
} 


\section{Simulated assessments of subsurface hydrology}

Mathematical groundwater models play a central role, both for interpreting and integrating data and for generating general insight to the response of groundwater systems to climate change and other forcings on multiple spatial and temporal scales. While observations are essential to explore and document subsurface global change, numerical models provide key tools, not only to assist in developing a comprehensive understanding of observed changes (i.e., hindcasting), but also predict the future response of the subsurface parameters to climate change, land-use change and water management scenarios (forecasting). Distributed groundwater models simulate flow in the subsurface, both in saturated and unsaturated conditions, as well as for porous and fractured media. Specialised codes are used to simulate chemical processes, such as solute transport and reactions, heat transport, and densitydependent flow (e.g., for coastal regions). In addition to groundwater models, which form the basis for groundwater assessment, other potential models include coupled land surface-atmospheric models, biogeochemical models, surface-water hydrological models, coupled surface-water/groundwater models, and coupled land surface and variable-saturated groundwater models (Maxwell and Miller, 2005) to name a few.

Differences in how the physical and chemical processes are represented along with the degree of complexity in subsurface and surface conditions control, to a major extent, the scale at which the codes can be realistically applied, as well as the type and scale of data required for driving or validating the models. Lumped models use spatially distributed climate forcing data that is aggregated over the entire basin, while semi-distributed models aggregate data over sub-basins. Distributed models typically consider distributed climate forcing data and spatially-varying (two- and three-dimensions) land-surface and subsurface properties. The advantages and disadvantages of these various approaches require further investigation in respect of climate change impacts modelling.

Process-based continental or global-scale hydrological models are rare, if not absent, at present. Thus, most studies develop smaller-scale models, which are better constrained by available data and, thus, more easily calibrated. However, there remain challenges for coupling GCM predictions with hydrological models (Xu, 1999; Scibek and Allen, 2006b; Toews and Allen, 2009b), including issues discussed in the section Global Climate Projection.

A number of different approaches have been used to derive climate data series for hydrogeological studies. Studies range in application from predicting changes in groundwater recharge, evapotranspiration, runoff/streamflow, groundwater levels, and groundwater/surface-water interactions. The complexity of approaches for obtaining the climate data series appears to have increased in the past several years, ranging from the use of global averages (Zektser and Loaiciga, 1993; Loaiciga et al., 1996) to the use of regional "bulk" projections (Vaccaro, 1992; Yusoff et al., 2002; Allen et al., 2004; Brouyere et al., 2004) to the direct application of downscaled climate data (Scibek and Allen, 2006b; Jyrkama and Sykes, 2007; Scibek et al., 2007; Serrat-Capdevila et al., 2007; Toews and Allen, 2009a) to the use of regional climate models (van Roosmalen et al., 2007, 2009; Rivard et al., 2008). Some of the early efforts to assess potential hydrologic impacts were reviewed by Gleick (1986). Most of these hydrologic models used daily weather series generated stochastically, with climate change shifts applied for future climate scenarios. Ideally, several different GCMs (or model ensembles) and a range of downscaling methods should be used and compared to assess uncertainty. Many studies have considered a range of GCMs or the average projection from several GCMs, and a few studies have considered different downscaling methods.
Zektser and Loaiciga (1993) used a global water balance approach coupled with a projected global change in precipitation (assumed $10 \%$ ) to predict shifts in runoff, baseflow, and discharge of groundwater to the oceans. Vaccaro (1992) considered two GCM scenarios: an average of conditions for three different GCMs with $\mathrm{CO}_{2}$ doubling, and a most severe "maximum" case to examine the sensitivity of recharge under different land use cases. Also considered was the sensitivity of recharge to the variability of climate within the historical and adjusted historical records.

Rosenberg et al. (1999) applied HUMUS, the Hydrologic Unit Model of the US to the Missouri and Arkansas-White-Red water resource regions that overlie the Ogallala aquifer. They imposed three GCMs (GISS, UKTR and BMRC) projections of future climate change on this region and simulated the changes that may be induced in water yields (runoff plus lateral flow) and groundwater recharge. Each GCM was applied to HUMUS at three levels of global mean temperature (GMT) to represent increasing severity of climate change (a surrogate for time). HUMUS was also run at three levels of atmospheric $\mathrm{CO}_{2}$ concentration in order to estimate the impacts of direct $\mathrm{CO}_{2}$ effects on photosynthesis and evapotranspiration.

Loaiciga et al. (2000) used historical climatic time series in periods of extreme water shortage (1947-1959), near-average recharge (1978-1989), and above-average recharge (1975-1990). These historical values were scaled to $2 \times \mathrm{CO}_{2}$ conditions to create aquifer recharge scenarios in a warmer climate. Several pumping scenarios were combined with $2 \times \mathrm{CO}_{2}$ climate scenarios to assess the sensitivity of water resources impacts to human-induced stresses on the Edwards Balcones Fault Zone (BFZ) aquifer, Texas, USA. The $2 \times \mathrm{CO}_{2}$ climate change scenarios were linked to surface hydrology and used to drive aquifer dynamics with alternative numerical simulation models calibrated to the Edwards BFZ aquifer.

Yusoff et al. (2002) used two future scenarios from the HadCM2 model: a medium-high ( $\mathrm{MH})$ emissions scenario and a mediumlow (ML) emissions scenario of 'greenhouse' gases. Two future periods were considered: 2020-2035 and 2050-2065. Future recharge to the aquifer was estimated by adjusting the historic record of monthly precipitation and potential evapotranspiration by factors calculated from comparing control and future HadCM2-generated values. Impacts of climate change were evaluated by incorporating the monthly estimated recharge inputs within a groundwater flow model.

York et al. (2002) used a coupled land-atmosphere model (CLASP II) to investigate decadal timescale impacts of global climate change on a watershed in Kansas, USA. Although climate change was not explicitly considered in that study, the nesting of a physically-based groundwater flow model into a GCM showed promise for assessing climate change impacts on groundwater systems. Yu et al. (2006) described a new method of interactively coupling climate and hydrologic models, based on categories of fine-grid hydrologic cells within each climate cell. The method is designed for interactive coupling of climate and hydrologic models in past and future climate applications. The paper, however, is limited to model description and validation using observed meteorological data standing in for the climate model.

Allen et al. (2004) applied shifts to the temperature and precipitation normals via a stochastic weather generator. The shifts reflected extreme climate conditions (i.e., wet and warm, wet and cold, dry and warm, dry and cold) predicted by three GCMs for the south British Columbia mountains region, Canada up to the end of the 21st century (Taylor, 1997). The stochastic weather series were used as input to a recharge model. Ultimately, two extreme recharge conditions were used as specified flux boundary conditions to a steady state groundwater flow model. An independent sensitivity analysis was conducted to explore the effect of 
river stage elevation (using lower than baseflow and higher than peak flow stage).

Brouyère et al. (2004) selected a subset of three GCMs (ECHAM4, HadCM2, CGCM1) and computed monthly increments of precipitation and temperature for three future model periods for the Geer basin in Belgium. Using these increments, "local" climate change scenarios were constructed by combining the daily precipitation and temperature values of the baseline period with the appropriate monthly change rates, in order to obtain realistic daily data for the climate scenarios. In the scenarios, the quantity of rain increased during the winter time and decreased during the summer time, compared to present climatic conditions. Climate data series were input to an integrated hydrological model.

Scibek et al. (2007) applied the aquifer recharge estimates from Scibek and Allen (2006b) in combination with basin-scale runoff predicted from downscaled CGCM1 data. These results were converted to river discharge along river reaches within the valley aquifer. Future climate scenarios indicate a shift in river peak flow to an earlier date in a year; the shift for the 2040-2069 climate is larger than for the 2010-2039, although the overall hydrograph shape remains the same. In that particular aquifer system, the impacts on basin runoff that affect the timing and magnitude of the stream hydrograph were considered to be far more important than changes in groundwater recharge from precipitation under both current and future climate conditions. That study serves to illustrate the importance of considering impacts to both surface hydrology and groundwater conditions.

Jyrkama and Sykes (2007) used the 40 years of actual historical weather data as a reference, several scenarios were constructed to simulate the impact of climate change over a period of 40 years, corresponding to the general predictions made by the IPCC (2001) for southern Ontario, Canada. A range in absolute changes in temperature, relative changes in precipitation and solar radiation, as well as combinations of different scenarios were modeled. Climate data series were applied to a spatially-distributed model for groundwater recharge.

Serrat-Capdevila et al. (2007) used results from an ensemble of 17 global circulation models (GCMs) and four different IPCC climate change scenarios to assess the impacts of climate change on water resources of a semi-arid basin in southeastern Arizona and northern Sonora. Annual GCM precipitation data for the region were downscaled and used to derive spatially distributed recharge estimates in the San Pedro Basin. A three dimensional transient groundwater/surface-water flow model was used to simulate the hydrology of the current century, from 2000 to 2100, under different climate scenarios and model estimates.

van Roosmalen et al. (2007) used outputs from a regional climate model for the periods 1961-1990 and 2071-2100 (scenarios A2 and B2) to force a physically based, distributed hydrological model to simulate changes in groundwater head, recharge, and discharge in Denmark. Precipitation, temperature, and reference evapotranspiration increased for both scenarios, resulting in a significant increase in mean annual net precipitation, but with decreased values in the summer months. The magnitude of the hydrological response to the simulated climate change was found to be highly dependent on the geological setting of the model area. For the same region, van Roosmalen et al. (2009) explored how land use change and irrigation impacted groundwater recharge and surface-water hydrology.

Mileham et al. $(2008,2009)$ used a soil-water balance model to simulate surface runoff and deep drainage (groundwater recharge) under historical (Mileham et al., 2008) and projected climates (Mileham et al., 2009) in Uganda. Spatial interactions between the interpolated rainfall and model parameter distributions had significant effects on the average model outcomes. Estimation of projected climate with simple "delta factors" resulted in underestimated recharge relative to RCM projected climate that accounted for a change in the distribution of rainfall intensity.

Rivard et al. (2008) used the Canadian Regional Climate Model (CRCM4) to generate 30-year climate forecasts for input to a catchment hydrology model (CATHY) for a small $\left(8 \mathrm{~km}^{2}\right)$ catchment in Nova Scotia, Canada. The CRCM4 uses results from the Third Generation Coupled Global Climate Model (CGCM3) with a $45 \times 45 \mathrm{~km}^{2}$ mesh $(112 \times 88$ grid points $)$. Daily atmospheric forcing from CRCM4 for the 1961-1990 reference period was also used to generate 30-year series for comparison to observed data; 30 year periods were selected in order to obtain a statistically significant representation of climate variations and catchment hydrodynamic responses for past and future periods.

Toews and Allen (2009a) used three different GCMs (CGCM1 GHG+A1, CGCM3.1 A2, and HadCM3 A2) to determine the sensitivity of recharge to different climate models for the Oliver region of the south Okanagan, British Columbia. Temperature data were downscaled (Wilby et al., 2002); however, changes in precipitation and solar radiation were calculated directly from the raw GCM data as these variables could not be reliably downscaled. Climate data were then synthetically generated using LARS-WG for input to a recharge model. Three future time periods are considered to coincide with the availability of GCM data. Estimates of recharge, runoff and evapotranspiration were estimated. Toews and Allen (2009a) used the results from CGCM3.1 A2 to model impacts on groundwater levels through a groundwater flow model.

The appropriate level of model complexity for a given problem may remain subjective, but some level of process interaction within the plant-soil-groundwater-atmospheric system must be present. Tietjen et al. (2009) made a case for at least two soil layers in a soil-vegetation model that simulated soil-water dynamics under different climatic conditions. Others have applied relatively complex, spatially distributed subsurface models and coupled surface-groundwater models (van Roosmalen et al., 2007, 2009; Goderniaux et al., 2009).

Numerical model-based studies continue to improve, but for the most part, the approaches are similar to the ones described above. By analogy with climate models, hydrogeophysical models used to predict subsurface effects of climate change must incorporate appropriate processes and their interactions in space and time. Integration studies encompassing changes in human or socio-economic scenarios (apart from emissions scenarios), such as land use and water demand are generally lacking (Holman, 2006).

\section{Schemes for adapting to climate change}

As a definition, climate adaptation measures are developed to cope with the consequences of a changing climate and avoid future risks. Adaptation encompasses both national and regional strategies as well as practical measures taken at all political levels and by individuals.

In many parts of the world, groundwater is crucial to sustainable development through provision of low-cost, drought-reliable and high-quality water supplies. About $70 \%$ of drinking water in the European Union, $80 \%$ of rural water supply in sub-Saharan Africa and $60 \%$ of agricultural irrigation in India depend on groundwater (IAH, 2006). Many countries, therefore, have large groundwater-dependent economies. Groundwater also sustains ecosystems and landscapes in humid regions in supporting wetlands and riparian areas, and also supports unique aquatic ecosystems in more arid regions and in coastal environments. Unfortunately, the largely hidden nature of groundwater means that development is often uncontrolled and not incorporated into overall river basin management, resulting in over-exploitation and contamination. Thus, even without considering climate 
change, sustainable development of groundwater is a major challenge given that groundwater is a widely distributed resource responding at basin scale, but is affected by local users and polluters (municipalities, industrial enterprises and farmers) whose behaviours are greatly influenced by national policies determining land and water use. Hence, in general, governance systems, resource policies, innovation incentives, data collection and information provision need to relate to a wide range of scales, with different adaptive management approaches in rural and urban environments (IAH, 2006).

Climate change challenges the traditional assumption that past hydrological experience provides a good guide to future conditions (IPCC, 2007b). In times of surface-water shortages during droughts, a typical response is for groundwater resources to be abstracted as an emergency supply (Table 1). Under conditions of climate change, this response is likely to be unsustainable, especially in those areas expected to experience an increase in drought frequency and duration. Also, rising sea levels under climate change will further threaten coastal freshwater aquifers, especially those already experiencing salinisation due to over-exploitation. In this paper, and to address possible future adaptive responses to climate change, reference is made to the emerging literature on the mitigation and adaptation responses that apply to water resources in general, together with specific consideration of groundwater.

Adaptation approaches can be preventative or reactive and apply to natural and social systems. Ensuring the sustainability of

Table 1

Types of adaptation options for water supply and demand (IPCC, 2008).

\begin{tabular}{|c|c|}
\hline Supply-side & Demand-side \\
\hline $\begin{array}{l}\text { Increase storage capacity by building } \\
\text { reservoirs and dams }\end{array}$ & $\begin{array}{l}\text { Improve water-use efficiency by } \\
\text { recycling water }\end{array}$ \\
\hline Desalinate seawater & Reduce water demand for \\
\hline Expand rain-water storage & $\begin{array}{l}\text { irrigation by changing the } \\
\text { cropping calendar, crop mix, } \\
\text { irrigation method and area } \\
\text { planted }\end{array}$ \\
\hline $\begin{array}{l}\text { Remove invasive non-native vegetation } \\
\text { from riparian areas }\end{array}$ & $\begin{array}{l}\text { Promote traditional practices for } \\
\text { sustainable water use }\end{array}$ \\
\hline Prospect and extract groundwater & $\begin{array}{l}\text { Expand use of water markets to } \\
\text { reallocate water to highly valued } \\
\text { uses }\end{array}$ \\
\hline $\begin{array}{l}\text { Develop new wells and deepen existing } \\
\text { wells }\end{array}$ & $\begin{array}{l}\text { Expand use of economic } \\
\text { incentives including metering and }\end{array}$ \\
\hline $\begin{array}{l}\text { Maintain well condition and } \\
\text { performance }\end{array}$ & $\begin{array}{l}\text { pricing to encourage water } \\
\text { conservation }\end{array}$ \\
\hline $\begin{array}{l}\text { Develop aquifer storage and recovery } \\
\text { systems }\end{array}$ & $\begin{array}{l}\text { Introduce drip-feed irrigation } \\
\text { technology }\end{array}$ \\
\hline $\begin{array}{l}\text { Develop conjunctive use of surface water } \\
\text { and groundwater resources }\end{array}$ & License groundwater abstractions \\
\hline $\begin{array}{l}\text { Develop surface water storage reservoirs } \\
\text { filled by wet season pumping from } \\
\text { surface water and groundwater }\end{array}$ & $\begin{array}{l}\text { Meter and price groundwater } \\
\text { abstractions }\end{array}$ \\
\hline \multicolumn{2}{|l|}{$\begin{array}{l}\text { Develop artificial recharge schemes } \\
\text { using treated wastewater discharges }\end{array}$} \\
\hline \multicolumn{2}{|l|}{$\begin{array}{l}\text { Develop riverbank filtration schemes } \\
\text { with vertical and inclined bank-side } \\
\text { wells }\end{array}$} \\
\hline \multicolumn{2}{|l|}{$\begin{array}{l}\text { Develop groundwater management } \\
\text { plans that manipulate groundwater } \\
\text { storage, e.g. resting coastal wells } \\
\text { during times of low groundwater } \\
\text { levels }\end{array}$} \\
\hline \multicolumn{2}{|l|}{$\begin{array}{l}\text { Develop groundwater protection } \\
\text { strategies to avoid loss of } \\
\text { groundwater resources from surface } \\
\text { contamination }\end{array}$} \\
\hline $\begin{array}{l}\text { Manage soils to avoid land degradation } \\
\text { to maintain and enhance } \\
\text { groundwater recharge }\end{array}$ & \\
\hline
\end{tabular}

Water transfer and expanded water markets to reallocate water to highly valued uses. investments in, for example, groundwater resources planning and development, over the entire lifetime of a scheme and taking explicit account of changing climate, is referred to as climate proofing (CEC, 2007). At a minimum, and in the absence of reliable projections of future changes in hydrological variables, adaptation processes and methods can be implemented, such as improved water use efficiency and water demand management, offering no-regrets options to cope with climate change.

The Dutch are investing in "climate proofing" (Kabat et al., 2005) that uses hard infrastructure and softer measures, such as insurance schemes or evacuation planning, to reduce the risks of climate change and hydrologic variability to a quantifiable level that is acceptable by the society or economy. The Netherlands, like the rest of the world's coastal delta regions, are vulnerable to climate change and sea-level rise and associated groundwater quality (and quantity) related challenges. Rather than coping with extreme-climatic events, as people from all over the world have done over human history, "climate-proofing" is a proactive approach to develop precautionary measures to address the low-probability but high-magnitude hydroclimatologic events that are forecasted under climate change and variability (Kabat et al., 2005). Kabat et al. (2005) also noted that climate proofing should be driven by opportunities for technological, institutional, and societal innovations, rather than by the fear of climate-change induced threats. The "climate proofing" approach could be used by water-resource scientists, engineers, and managers to develop forward thinking, innovative solutions and precautionary measures for a range of probable hydroclimatic events under future climate change. The "death" of hydroclimatological stationarity (Milly et al., 2008) is the impetus that will drive the innovation and suitable precautionary measures to protect the sustainability of groundwater resources under a new hydroclimatic conceptual regime.

According to the IPCC (2007b), the array of potential adaptive responses available to human societies is very large, ranging from purely technological (e.g., deepening of existing boreholes), through behavioral (e.g., altered groundwater use) to managerial (e.g., altered farm irrigation practices), to policy (e.g., groundwater abstractions licensing regulations). The IPCC (2007b) argued that while most technologies and strategies are known and developed in some countries (e.g., demand-management through the conjunctive use of surface-water and groundwater resources), the effectiveness of various options to fully reduce risks for vulnerable water-stressed areas, particularly at higher levels of warming and related impacts, is not yet known. Shah (2009) noted that there is also an indirect feedback of pumping on climate change due to energy use and associated carbon emissions (already approximately $5 \%$ of India's total). This is one obvious example of the interactions between potential groundwater-atmosphere feedbacks and adaptation to global change that must be considered.

For water resources management, there are generally two types of decisions to be considered: those dealing with new investments and those dealing with the operation and maintenance of existing systems. In order to inform these decisions, information is needed about future water availability and demand, both of which are affected by climate change at the river-basin scale (Ballentine and Stakhiv, 1993). Table 1 summarises supply-side and demand-side adaptation options designed to ensure supplies of water and groundwater during average and drought conditions. As explained by the IPCC (2008), supply-side options generally involve increases in storage capacity or water abstraction. Demand-side adaptation options rely on the combined actions of individuals (industry users, farmers (especially irrigators) and individual consumers) and may be less reliable. Indeed, some options, for example those incurring increased pumping and treatment costs, may be inconsistent with climate change mitigation measures because they involve high energy consumption. 
One of the major challenges facing water resources managers is coping with climate change uncertainties in the face of real-world decision-making, particularly where expensive investment in infrastructure such as well-field design, construction and testing and laying of pipelines is required (Brekke et al., 2004). As discussed by Dessai and Hulme (2007), this challenge presents a number of new questions, for example to what amount of climate change uncertainty should we adapt? Are robust adaptation options socially, environmentally and economically acceptable and how do climate change uncertainties compare with other uncertainties such as changes in demand? The answers to these questions leading to robust adaptation decisions will require the development of probability distributions of specified outcomes (Wilby and Harris, 2006) and negotiation between decision-makers and stakeholders involved in the adaptation process (Dessai and Hulme, 2007). For lower income countries, availability of resources and building adaptive capacity are particularly important in order to meet water shortages and salinisation of fresh waters (IPCC, 2007b).

Examples of current adaptation to observed and anticipated climate change in the management of groundwater resources are few, with groundwater typically considered as part of an integrated water-supply system. Here, three examples serve to highlight the difference in approach in technically-advanced and developing country contexts. The ability of California's water supply system to adapt to long-term climate and demographic changes is examined by Tanaka et al. (2006) using a state-wide economic-engineering optimisation model of water supply management and considering two climate warming scenarios for the year 2100 . The results suggested that California's water supply system appears physically capable of adapting to significant changes in climate and population, albeit at significant cost. Such adaptations would entail large changes in the operation of California's large groundwater storage capacity, significant transfers of water among water users and some adoption of new technologies. In a further study, in the Sacramento Valley, California, Purkey et al. (2007) used four climate time series to simulate agricultural water management with adaptation in terms of improvements in irrigation efficiency and shifts in cropping patterns during dry periods leading to lower overall water demands in the agricultural sector with associated reductions in groundwater pumping and increases in surface-water allocations to other water use sectors. Land-use adaptation to projected climate change may include management changes within land-use classes (e.g., alternative crop rotations) or changes in land classification (e.g., converting annual cropping systems to perennial grasslands or forests). Soil and water conservation programs already encourage some of these types of landuse changes.

A similar technological approach to that demonstrated for California is presented for the Mediterranean region of Europe. This region is experiencing rapid social and environmental changes with increasing water scarcity problems that will worsen with climate change. Iglesias et al. (2007) found that these pressures are heterogeneous across the region or water use sectors and adaptation strategies to cope with water scarcity include technology, use of strategic groundwater and better management based on preparedness rather than a crisis approach. Iglesias et al. (2007) also advocated the importance of local management at the basin level but with the potential benefits dependent on the appropriate multi-institutional and multi-stakeholder coordination.

In contrast to the examples from North America and Europe, Ojo et al. (2003) discussed the downward trends in rainfall and groundwater levels, and increases in water deficits and drought events affecting water resources availability in West Africa. There, the response strategies needed to adapt to climate change emphasize the need for water supply-demand adaptations. Moreover, the mechanisms needed to implement adaptation measures include: building the capacity and manpower of water institutions in the region for hydro-climatological data collection and monitoring; the public participation and involvement of stakeholders; and the establishment of both national and regional co-operation.

Further to the challenges presented by climate change, water resources management has a clear association with many other policy areas such as energy, land use and nature conservation. In this context, groundwater is part of an emerging integrated water resources management approach that recognises society's views, reshapes planning processes, co-ordinates land and water resources management, recognises water quantity and quality linkages, manages surface-water and groundwater resources conjunctively and protects and restores natural systems while including a consideration of climate change. This integrated approach presents new challenges for groundwater. For example, better understanding is needed of leakage processes associated with carbon capture and storage if the potential degradation of groundwater quality is to be avoided. Also, insight is needed into the effects of large-scale plantations of commercial energy crops on groundwater recharge quantity and quality (IPCC, 2008).

In summary, groundwater resources stored in aquifers can be managed given reasonable scientific knowledge, adequate monitoring, sustained political commitment and provision of institutional arrangements. Although there is no single approach to relieving pressures on groundwater resources given the intrinsic variability of both groundwater systems and socio-economic situations, incremental improvements in resource management and protection can be achieved now and in the future under climate change. Future sustainable development of groundwater will only be possible by approaching adaptation through the effective engagement of individuals and stakeholders at community, local government and national policy levels.

\section{Summary and future directions}

The present synthesis addresses current interest, knowledge, programs, methods and research results to date regarding global change and subsurface water (groundwater). Interest and scientific investigations have grown rapidly in the last decade, as evinced by conferences, international programs and the rate of peer-reviewed journal publications.

The hydrology of the subsurface is coupled with surface hydrology and the atmosphere. Feedback between soil water and atmospheric processes has been explored over short time periods, but long-term (multidecadal or greater) feedback from groundwater, including deeper saturated zones, and climate constitutes a knowledge gap. Paleohydrology indicates that contemporary groundwater-climate systems are not in equilibrium, due to the long memory of deep groundwater with long flow paths and large storage.

Global change has implications for both water quantity and quality. Methods of observations from various disciplines are being applied to study patterns of past changes in groundwater chemistry, temperature and other hydrogeophysical properties and resources over a range of spatial scales. Satellite remote sensing offers a way of detecting trends over space and time, but over a limited time period so far. Gravity measurements over large areas may facilitate global water balance estimates (i.e., temporal changes in terrestrial water), but higher spatial resolution is needed to make such measurements more practically useful for regional groundwater management.

Most numerical simulation studies to date have focused on estimating impacts of projected climate change on groundwater. The level of process detail, dimensionality and space-time resolution 
varies among models, and the effects of projected climate change on hydrological fluxes (e.g., groundwater recharge) may vary with different combinations of soils/aquifer materials, vegetation, and climate zone. Spatial variability within a study region can be addressed with distributed process models, but the added complexity limits their application at least in the short term.

Estimation of projected climate remains probably the greatest source of uncertainty in evaluating future scenarios. Even if future emissions of greenhouse gases were known (and the general upward trend is clear), variability among GCMs (designed and run by different scientific organisations around the world) is large. Ensemble means are used widely, but questions remain about GCM selection for a particular region of the Earth. Downscaling of GCM output to a given scale of application (model input) has been approached physically and statistically with mixed results. This is an active area of research, including issues of statistical non-stationarity in historically measured climate variables.

There is a ubiquitous need for improved quantification of existing hydrogeological, agroecological systems toward estimating their responses to projected climate change. Long-term monitoring of terrestrial systems (groundwater, surface water, vegetation and land-use patterns) is essential for quantifying baseline properties. Scaling fluxes of water and its constituents up and down to the scales of interest for management and policy is an overarching theme for projecting groundwater responses and feedbacks with climate. Furthermore, information from one study area must be transferred across the globe to other areas where monitoring infrastructure and research resources are not available. Mapping of global analogues in terms of climatic and terrestrial properties seems to be a promising first-order approach.

Decisions are being made around the globe with very limited information on the potential impacts of climate change. State-ofthe-science "best guesses" will continue to be employed and updated for policy and decision making from global down to local scales. Issues of food and energy security, environmental protection, and social welfare all interact and depend upon improved understanding of terrestrial responses to climate change and feedback mechanisms.

Adaptation to global change will be needed. As the limits of groundwater sustainability are reached through development, it is likely that even small changes in recharge, discharge, or groundwater storage will have economic or environmental consequences (Mayer and Congdon, 2008). Current water-resource management practices cannot cope with current climate variability and thus may not be robust enough to cope with the impacts of future climate change (Bates et al., 2008).

The demand for groundwater is likely to increase in the future because of the need to offset the substantial declines in surfacewater availability from increasing precipitation variability and reduced summer low flows in snow-dominated basins (Kundzewicz et al., 2007). The current demands for surface water in many parts of the world will not be met under plausible future climate conditions, much less the demand under future population growth (Barnett et al., 2008). The potential increase in rates of extraction could exacerbate declining water tables, the loss of groundwater storage and decreasing water quality in many already stressed aquifer systems. Alternatively, artificial recharge and managed storage and recovery projects may become a more important component of many local water systems to bank excess renewable-water supplies and provide water for both normal years and those times when resource shortages may develop (Woodhouse, 2007). Hanson and Dettinger (2005) noted the importance of anthropogenic actions, especially groundwater pumping for agricultural activities, in developed groundwater systems and the urgent need to improve the ability of predicting human extractions and returns of water on the basis of climatic effects.
Quantification of biological, physical and social responses to global change is a daunting task that requires transdisciplinary systems approaches. Although the science of subsurface global change is in its infancy, its place in the greater terrestrial system is critical. Groundwater has been an historical buffer against climate variability, and our dependence on groundwater resources is likely to increase as water supplies are further stressed by population increase and projected increases in climatic variability over much of the globe. As researchers from a broad spectrum of disciplines and geographical locations converge to address global change issues, process knowledge will increase, systems will be better understood, and estimates of projected groundwater changes and their potential feedbacks on climate will be refined, including quantification of uncertainty and associated risks.

Finally, we assert that disciplinary sciences will benefit from the cross-fertilisation effect of transdisciplinary, whole-systems approaches and methodologies. Adaptation decision processes in the face of global change should be addressed even to improve management and decision making in an otherwise unchanging world. That is, natural and human-induced variability under historical conditions will be better quantified and managed using new scientific advances gained under the auspices of global change research, making such work a "win-win" proposition.

\section{Acknowledgments}

The authors are grateful to the UNESCO International Hydrological Programme GRAPHIC (Groundwater Resources Assessment under the Pressures of Humanity and Climate Change) project for facilitating workshops and discussions that formed the basis of this review paper. For logistical reasons, the size of the writing team was limited, but we fully appreciate dialogue with other key members of the GRAPHIC team, including (alphabetically by last name) Bret Bruce, Henrique Chaves, Gordon Grant, Ken Howard, Arie Issar, Neno Kukuric, Jose Luis Martin, Peter McMahon, Gualbert Oude Essink, Matthew Rodell, Richard Taylor, Ian White, and Yossi Yechieli. Two detailed journal reviews and comments from Prof. Emeritus Don Nielsen are sincerely appreciated.

\section{Appendix A. Supplementary material}

Supplementary data associated with this article can be found, in the online version, at doi:10.1016/j.jhydrol.2011.05.002.

\section{References}

Aguilera, H., Murillo, J., 2009. The effect of possible climate change on natural groundwater recharge based on a simple model: a study of four karstic aquifers in SE Spain. Environ. Geol. 57 (5), 963-974.

Allen, D.M., 2004. Sources of ground water salinity on islands using ${ }^{18} \mathrm{O},{ }^{2} \mathrm{H}$, and ${ }^{34} \mathrm{~S}$ Ground Water $42(1), 17-31$.

Allen, D.M., Cannon, A.J., Toews, M.W., Scibek, J., 2010. Variability in simulated recharge using different GCMs. Water Resour. Res. 46, W00F03. doi:10.1029/ 2009WR008932.

Allen, D.M., Mackie, D.C., Wei, M., 2004. Groundwater and climate change: a sensitivity analysis for the grand forks aquifer, southern British Columbia, Canada. Hydrogeol. J. 12 (3), 270-290.

Alley, W.M., 1993. Regional Ground-Water Quality. Van Nostrand Reinhold, New York, 634 pp.

Alley, W.M., 2001. Ground water and climate. Ground Water 39 (2), 161.

Alley, W.M., 2006. Tracking US groundwater: reserves for the future? Environment 48 (3), $10-25$.

Alley, W.M., 2007. Flow and storage in groundwater systems. Science 296, 1985 1990.

Alley, W.M., Reilly, T.E., Franke, O.L., 1999. Sustainability of Ground-Water Resources. US Geological Survey Circular, 1186, 79 pp.

Anderson, M., Kustas, W., 2008. Thermal remote sensing of drought and evapotranspiration. EOS 89 (26), 233-234.

Aureli, A., Taniguchi, M., 2006. Groundwater Assessment under the Pressures of Humanity and Climate Changes - GRAPHIC, GRAPHIC Series No. 1. United Nations Educational, Scientific, and Cultural Organization, Paris, pp. 19. <http:// unesdoc.unesco.org/images/0015/001507/150730e.pdf> 
Bajjali, W., Abu-Jaber, N., 2001. Climatological signals of the paleogroundwater in Jordan. J. Hydrol. 243 (1-2), 133-147.

Ballentine, T.M., Stakhiv, E.Z. (Eds.), 1993. Climate change and water resources management. In: Proceedings of the First National Conference, IWR Report 93R-17. US Army Corps of Engineers Institute of Water Resources.

Barco, J., Hogue, T.S., Girotto, M., Kendall, D., Putti, M., 2010. Climate signal propagation in southern California aquifers. Water Resour. Res. 46, W00F05 doi:10.1029/2009WR008376.

Barnett, T.P., Pierce, D.W., Hidalgo, H.G., Bonfils, C., Santer, B.D., Das, T., Bala, G., Wood, A.W., Nozawa, T., Mirin, A.A., Cayan, D.R., Dettinger, M.D., 2008. Humaninduced changes in the hydrology of western United States. Science 319 (5866), 1080-1083.

Barrocu, G., Dahab, K., 2010. Changing climate and saltwater intrusion in the Nile Delta, Egypt. In: Taniguchi, M., Holman, I.P. (Eds.), Groundwater Response to Changing Climate. International Association of Hydrogeologists Selected Paper. CRC Press, Taylor and Francis Group, London, UK, pp. 11-25.

Barthel, R., Sonneveld, B.G.J.S., Goetzinger, J., Keyzer, M.A., Pande, S., Printz, A., Gaiser, T., 2009. Integrated assessment of groundwater resources in the Oueme basin, Benin, West Africa. Phys. Chem. Earth 34 (4-5), 236-250.

Bates, B., Kundzewicz, Z.W., Wu, S., Palutikof, J.P., 2008. Climate Change and Water. Technical Paper VI of the Intergovernmental Panel on Climate Change. Intergovernmental Panel on Climate Change Secretariat, Geneva, 210 pp.

Bates, B.C., Charles, S.P., Sumner, N.R., Fleming, P.M., 1994. Climate change and its hydrological implications for South Australia. Trans. Roy. Soc. S. Aust. 118, 3543.

Bear, J., Cheng, H.D., 1999. Seawater Intrusion in Coastal Aquifers - Concepts, Methods and Practices. Kluwer Academic Publisher, Dordrecht, Boston, London, $625 \mathrm{pp}$.

Beltrami, H., 2002. Climate from borehole data: energy fluxes and temperatures since 1500. Geophys. Res. Lett. 29 (23), 26.

Beltrami, H., Mareschal, J.C., 1995. Resolution of ground temperature histories inverted from borehole temperature data. Global Planet. Change 11 (1-2), 57 70.

Bense, V.F., Ferguson, G., Kooi, H., 2009. Evolution of shallow groundwater flow systems in areas of degrading permafrost. Geophys. Res. Lett. 36, L22401.

Berg, M.A., Allen, D.M., 2007. Low flow variability in groundwater-fed streams. Can. Water Resour. J. 32 (3), 227-246.

Beuhler, M., 2003. Potential impacts of global warming on water resources in southern California. Water Sci. Technol. 47 (7-8), 165-168.

Beyerle, U., Rueedi, J., Leuenberger, M., Aeschbach-Hertig, W., Peeters, F., Kipfer, R. Dodo, A., 2003. Evidence for periods of wetter and cooler climate in the Sahe between 6 and 40 kyr BP derived from groundwater. Geophys. Res. Lett. 30 (4), 1173. doi:10.1029/2002GL016310.

Birch, F., 1948. The effects of pleistocene climatic variations upon geotherma gradients. Am. J. Sci. 246, 729-760.

Bloomfield, J.P., Williams, R.J., Gooddy, D.C., Cape, J.N., Guha, P., 2006. Impacts of climate change on the fate and behaviour of pesticides in surface and groundwater - a UK perspective. Sci. Total Environ. 369 (1-3), 163-177.

Bodri, L., Cermak, V., 2005. Borehole temperatures, climate change and the preobservational surface air temperature mean: allowance for hydraulic conditions. Global Planet. Change 45 (4), 265-276.

Bouraoui, F., Vachaud, G., Li, L.Z.X., Le Treut, H., Chen, T., 1999. Evaluation of the impact of climate changes on water storage and groundwater recharge at the watershed scale. Clim. Dynam. 15 (2), 153-161.

Bovolo, C.I., Parkin, G., Sophocleous, M., 2009. Groundwater resources, climate and vulnerability. Environ. Res. Lett. 4 (3), 035001.

Brekke, L.D., Miller, N.L., Bashford, K.E., Quinn, N.W.T., Dracup, J.A., 2004. Climate change impacts uncertainty for water resources in the San Joaquin River Basin, California. J. Am. Water Resour. Assoc. 40 (1), 149-164.

Brikowski, T.H., 2008. Doomed reservoirs in Kansas, USA? Climate change and groundwater mining on the Great Plains lead to unsustainable surface wate storage. J. Hydrol. 354 (1-4), 90-101.

Brouyere, S., Carabin, G., Dassargues, A., 2004. Climate change impacts on groundwater resources: modelled deficits in a chalky aquifer, Geer Basin, Belgium. Hydrogeol. J. 12 (2), 123-134.

Brown, L., 2001. Running on empty. Forum Appl. Res. Public Pol. 16, 1-3.

Bultot, F., Coppens, A., Dupriez, G.L., Gellens, D., Meulenberghs, F., 1988 Repercussions of a $\mathrm{CO} 2$ doubling on the water cycle and on the water balance - a case study for Belgium. J. Hydrol. 99 (3-4), 319-347.

Burkett, V.R., Zilkoski, D.B., Hart, D.A., 2002. Sea-level Rise and Subsidence: Implications for Flooding in New Orleans, Louisiana. US Geological Survey Subsidence Interest Group Conference. US Geological Survey, Galveston, Texas, pp. 63-71.

Burnett, W.C., Aggarwal, P.K., Aureli, A., Bokuniewicz, H., Cable, J.E., Charette, M.A. Kontar, E., Krupa, S., Kulkarni, K.M., Loveless, A., Moore, W.S., Oberdorfer, J.A., Oliveira, J., Ozyurt, N., Povinec, P., Privitera, A.M.G., Rajar, R., Ramessur, R.T. Scholten, J., Stieglitz, T., Taniguchi, M., Turner, J.V., 2006. Quantifying submarine groundwater discharge in the coastal zone via multiple methods. Sci. Total Environ. 367 (2-3), 498-543.

Cambi, C., Dragoni, W., 2000. Groundwater yield, climate changes and recharge variability: considerations arising from the modelling of a spring in the UmbriaMarche Apennines. Hydrogeologie 4, 11-25.

Candela, L., von Igel, W., Javier Elorza, F., Aronica, G., 2009. Impact assessment of combined climate and management scenarios on groundwater resources and associated wetland (Majorca, Spain). J. Hydrol. 376 (3-4), 510-527.
Cannon, A.J., 2008. Probabilistic multisite precipitation downscaling by an expanded Bernoulli-gamma density network. J. Hydrometeorol. 9 (6), 12841300.

Cannon, A.J., 2009. Negative ridge regression parameters for improving the covariance structure of multivariate linear downscaling models. Int. J. Climatol. 29 (5), 761-769.

Caruso, B.S., 2002. Temporal and spatial patterns of extreme low flows and effects on stream ecosystems in Otago, New Zealand. J. Hydrol. 257 (1-4), 115133.

Castro, M.C., Hall, C.M., Patriarche, D., Goblet, P., Ellis, B.R., 2007. A new noble gas paleoclimate record in Texas - basic assumptions revisited. Earth Planet Sci. Lett. 257 (1-2), 170-187.

Cayan, D.R., Kammerdiener, S.A., Dettinger, M.D., Caprio, J.M., Peterson, D.H., 2001. Changes in the onset of spring in the western United States. Bull. Am. Meteorol. Soc. 82, 399-415.

CEC, 2007. Adapting to Climate Change in Europe - Options for Eu Action. Green Paper from the Commission to the Council, the European Parliament, the European Economic and Social Committee and the Committee of the Regions, Commission of the European Communities, Brussels.

Čermák, V., 1971. Underground temperature and inferred climatic temperature of the past millennium. Paleogeogr. Paleoclim. Paleoecol. 10 (1), 1-19.

Čermák, V., Bodri, L., Šafanda, J., 1992. Underground temperature fields and changing climate: evidence from Cuba. Global Planet. Change 5 (4), 325-337.

Chapman, D.S., Chisholm, T.J., Harris, R.N., 1992. Combining borehole temperature and meteorologic data to constrain past climate change. Global Planet. Change 6 (2-4), 269-281.

Chen, Z., Grasby, S.E., Osadetz, K.G., 2002. Predicting average annual groundwater levels from climatic variables: an empirical model. J. Hydrol. 260 (1-4), 102 117.

Chen, Z., Grasby, S.E., Osadetz, K.G., 2004. Relation between climate variability and groundwater levels in the upper carbonate aquifer, southern Manitoba, Canada. J. Hydrol. 290 (1-2), 43-62.

Cheng, G., Wu, T., 2007. Responses of permafrost to climate change and their environmental significance, Qinghai-Tibet Plateau. J. Geophys. Res. 112, F02S03. doi:10.1029/2006JF000631.

Chiew, F.H.S., McMahon, T.A., 2002. Modelling the impacts of climate change on Australian streamflow. Hydrol. Process. 16 (6), 1235-1245.

Christensen, J.H., Hewitson, B., Busuioc, A., Chen, A., Gao, X., Held, I., Jones, R., Kolli, R.K., Kwon, W.-T., Laprise, R., Rueda, V.M., Mearns, L., Menéndez, C.G., Räisänen, J., Rinke, A., Sarr, A., Whetton, P., 2007. Regional climate projections. In: Solomon, S. et al. (Eds.), Climate Change 2007: The Physical Science Basis. Contribution of Working Group I to the Fourth Assessment Report of the Intergovernmental Panel on Climate Change. Cambridge University Press, Cambridge, United Kingdom, and New York, NY, USA.

Cimino, A., Cosentino, C., Oieni, A., Tranchina, L., 2008. A geophysical and geochemical approach for seawater intrusion assessment in the Acquedolci coastal aquifer (northern Sicily). Environ. Geol. 55 (7), 1473-1482.

Clark, I., Fritz, P., 1997. Environmental Isotopes in Hydrogeology. Lewis Publishers, Boca Raton, New York, 328 pp.

Cohen, D., Person, M., Daannen, R., Locke, S., Dahlstrom, D., Zabielski, V., Winter, T.C., Rosenberry, D.O., Wright, H., Ito, E., 2006. Groundwater-supported evapotranspiration within glaciated watersheds under conditions of climate change. J. Hydrol. 320 (3-4), 484-500.

Cook, P., Herczeg, A.L., 2000. Environmental Tracers in Subsurface Hydrology. Kluwer Academic Publ., Norwell, MA, USA, 529 pp.

Dams, J., Woldeamlak, S.T., Batelaan, O., 2007. Forecasting land-use change and its impact on the groundwater system of the Kleine Nete catchment, Belgium. Hydrol. Earth Syst. Sci. Discuss. (HESS-D) 4 (6), 4265-4295.

Davis, M.G., Harris, R.N., Chapman, D.S., 2010. Repeat temperature measurements in boreholes from northwestern Utah link ground and air temperature changes at the decadal time scale. J. Geophys. Res. 115 (5), 22.

de Jeu, R., Wagner, W., Holmes, T., Dolman, A., van de Giesen, N., Friesen, J., 2008. Global soil moisture patterns observed by space borne microwave radiometers and scatterometers. Surv. Geophys. 29 (4), 399-420.

de Vries, J.J., Simmers, I., 2002. Groundwater recharge: an overview of processes and challenges. Hydrogeol. J. 10 (1), 5-17.

Dehn, M., Burger, G., Buma, J., Gasparetto, P., 2000. Impact of climate change on slope stability using expanded downscaling. Eng. Geol. 55 (3), 193-204.

Dent, D., 2007. Environmental geophysics mapping salinity and water resources. Int. J. Appl. Earth Observ. Geoinfo. 9 (2), 130-136.

Dessai, S., Hulme, M., 2007. Assessing the robustness of adaptation decisions to climate change uncertainties: a case study on water resources management in the east of England. Global Environ. Change 17 (1), 59-72.

Destouni, G., Darracq, A., 2009. Nutrient cycling and $\mathrm{N}_{2} \mathrm{O}$ emissions in a changing climate: the subsurface water system role. Environ. Res. Lett. 4 (3), 035008.

Dettinger, M.D., Earman, S., 2007. Western ground water and climate changepivotal to supply sustainability or vulnerable in its own right? Ground Water 4 (1), 4-5.

Döll, P., 2009. Vulnerability to the impact of climate change on renewable groundwater resources: a global-scale assessment. Environ. Res. Lett. 4 (3), 035006.

Dragoni, W., Sukhija, B.S., 2008. Climate Change and Groundwater: A Short Review. Geological Society Special Publication, pp. 1-12.

Dugan, J.T., Sharpe, J.B., 1996. Water-level Changes in the High Plains AquiferPredevelopment to 1904. US Geological Survey. 
Dzhamalov, R.G., Zektser, I.S., Krichevets, G.N., Safronova, T.I., Sotnikova, L.F., Gromova, Y.V., 2008. Changes in groundwater runoff under the effect of climate and anthropogenic impact. Water Resour. 35 (1), 15-22.

Eckhardt, K., Ulbrich, U., 2003. Potential impacts of climate change on groundwater recharge and streamflow in a central European low mountain range. J. Hydrol. 284 (1-4), 244-252.

Edmunds, W.M., 2001. Palaeowaters in European Coastal Aquifers - The Goals and Main Conclusions of the Palaeaux Project, vol. 189. Geological Society Special Publication, pp. 1-16.

Edmunds, W.M., Milne, C.J. (Eds.), 2001. Palaeowaters in Coastal Europe: Evolution of Groundwater since the Late Pleistocene, vol. 189. Geological Society Special Publication, $332 \mathrm{pp}$

Edmunds, W.M., Tyler, S.W., 2002. Unsaturated zones as archives of past climates: toward a new proxy for continental regions. Hydrogeol. J. 10, 216-228.

Emori, S., Brown, S.J., 2005. Dynamic and thermodynamic changes in mean and extreme precipitation under changed climate. Geophys. Res. Lett. 32 (17), L17706. doi:10.1029/2005GL023272.

European Space Agency, 2009. The Tiger Initiative: 2005-2008 Report. 49 <http:// www.tiger.esa.int/pdf/tiger_report09_web.pdf>

Famiglietti, J.S., Lo, M., Ho, S.L., Bethune, J., Anderson, K.J., Syed, T.H., Swenson, S.C., de Linage, C.R., Rodell, M., 2011. Satellites measure recent rates of groundwater depletion in California's Central Valley. Geophys. Res. Lett. 38, L03403. doi:10.1029/2010GL046442.

Fan, Y., Duffy, C.J., Oliver, J.D.S., 1997. Density-driven groundwater flow in closed desert basins: field investigations and numerical experiments. J. Hydrol. 196 (14), 139-184.

Fan, Y., Miguez-Macho, G., Weaver, C.P., Walko, R., Robock, A., 2007. Incorporating water table dynamics in climate modeling: 1 . Water table observations and equilibrium water table simulations. J. Geophys. Res. 112, D10125.

Faure, H., Walter, R.C., Grant, D.R., 2002. The coastal oasis: ice age springs on emerged continental shelves. Global Planet. Change 33 (1-2), 47-56.

Ferguson, G., Woodbury, A.D., 2007. Urban heat island in the subsurface. Geophys. Res. Lett. 34, L23713. doi:10.1029/2007GL032324.

Ferguson, I.M., Maxwell, R.M., 2010. Role of groundwater in watershed response and land surface feedbacks under climate change. Water Resour. Res. 46, 3, doi:1029/2009WR008616

Flato, G.M., Boer, G.J., Lee, W.G., McFarlane, N.A., Ramsden, D., Reader, M.C., Weaver, A.J., 2000. The Canadian centre for climate modelling and analysis global coupled model and its climate. Clim. Dynam. $16(6), 451-467$.

French, H., Binley, A., 2004. Snowmelt infiltration: monitoring temporal and spatial variability using time-lapse electrical resistivity. J. Hydrol. 297 (1-4), 174-186.

Fukuda, Y., Yamamoto, K., Hasegawa, T., Nakaegawa, T., Nishijima, J., Taniguchi, M., 2009. Monitoring groundwater variation by satellite and implications for in-situ gravity measurements. Sci. Total Environ. 407 (9), 3173-3180.

Garbrecht, J.D., Rossel, F.E., 2002. Decade-scale precipitation increase in Great Plains at end of 20th century. ASCE J. Hydrol. Eng. 7 (1), 64-75.

Gasse, F., 2000. Hydrological changes in the African tropics since the last glacial maximum. Quat. Sci. Rev. 19 (1-5), 189-211.

Ghil, M., 2002. Natural climate variability. In: MacCracken, M.C., Perry, J.S. (Eds.), Encyclopedia of Global Environmental Change. John Wiley and Sons, Chichester.

Giertz, S., Diekkruger, B., Jaeger, A., Schopp, M., 2006. An interdisciplinary scenario analysis to assess the water availability and water consumption in the upper oueme catchment in Benin. Adv. Geosci. 9, 3-13.

Glassley, W.E., Nitao, J.J., Grant, C.W., Johnson, J.W., Steefel, C.I., Kercher, J.R., 2003. The impact of climate change on vadose zone pore waters and its implication for long-term monitoring. Comput. Geosci. 29 (3), 399-411.

Gleick, P.H., 1986. Methods for evaluating the regional hydrologic impacts of global climatic changes. J. Hydrol. 88 (1-2), 97-116.

Goderniaux, P., Brouyère, S., Fowler, H.J., Blenkinsop, S., Therrien, R., Orban, P., Dassargues, A., 2009. Large scale surface-subsurface hydrological model to assess climate change impacts on groundwater reserves. J. Hydrol. 373 (1-2), $122-138$.

González-Rouco, J.F., Beltrami, H., Zorita, E., Stevens, M.B., 2009. Borehole climatology: a discussion based on contributions from climate modeling. Clim. Past 5 (1), 97-127.

Gosling, S.M., Taylor, R.G., Arnell, N.W., Todd, M.C., 2010. A comparative analysis of projected impacts of climate change on river runoff from global and catchmentscale hydrological model. Hydrol. Earth Syst. Sci. Discuss. 7, 7191-7229.

Grasby, S.E., Betcher, R.N., 2002. Regional hydrogeochemistry of the carbonate rock aquifer, southern Manitoba. Can. J. Earth Sci. 39, 1053-1063.

Green, T.R., Bates, B.C., Charles, S.P., Fleming, P.M., 2007a. Physically based simulation of potential effects of carbon dioxide-altered climates on groundwater recharge. Vadose Zone J. 6 (3), 597-609.

Green, T.R., Taniguchi, M., Kooi, H., 2007b. Potential impacts of climate change and human activity on subsurface water resources. Vadose Zone J. 6 (3), 531-532.

Groves, D.G., Yates, D., Tebaldi, C., 2008. Developing and applying uncertain global climate change projections for regional water management planning. Water Resour. Res. 44 (12), W12413.

Guendouz, A., Moulla, A.S., et al., 2003. Hydrogeochemical and isotopic evolution of water in the complex terminal aquifer in the Algerian sahara. Hydrogeol. J. 11, 483-495.

Guérin, R., Descloitres, M., Coudrain, A., Talbi, A., Gallaire, R., 2001. Geophysical surveys for identifying saline groundwater in the semi-arid region of the central Altiplano, Bolivia. Hydrol. Process. 15 (17), 3287-3301.
Gurdak, J.J., 2008. Ground-Water Vulnerability: Nonpoint-Source Contamination, Climate Variability, and the High Plains Aquifer. VDM Verlag Publishing Saarbrucken, Germany.

Gurdak, J.J., Hanson, R.T., Green, T.R., 2009. Effects of Climate Variability and Change on Groundwater Resources of the United States. <http://pubs.usgs.gov/fs/2009/ $3074 />$

Gurdak, J.J., Hanson, R.T., McMahon, P.B., Bruce, B.W., McCray, J.E., Thyne, G.D. Reedy, R.C., 2007. Climate variability controls on unsaturated water and chemical movement, High Plains aquifer, USA. Vadose Zone J. 6 (3), 533-547.

Gurdak, J.J., Roe, C.D., 2010. Review: recharge rates and chemistry beneath playas of the High Plains aquifer, USA. Hydrogeol. J. 18 (8), 1747-1772.

Gurdak, J.J., Walvoord, M.A., McMahon, P.B., 2008. Susceptibility to enhanced chemical migration from depression-focused preferential flow, High Plains aquifer. Vadose Zone J. 7 (4), 1172-1184.

Gutowski, W.J., Vorosmarty, C.J., Person, M., Otles, Z., Fekete, B., York, J., 2002. A coupled land-atmosphere simulation program (CLASP): calibration and validation. J. Geophys. Res. 107 (D16, 4283), 1-17

Haldorsen, S., Heim, M., Dale, B., Landvik, J.Y., van der Ploeg, M., Leijnse, A. Salvigsen, O., Hagen, J.O., Banks, D., 2010. Sensitivity to long-term climate change of subpermafrost groundwater systems in Svalbard. Quat. Res. 73, 393402.

Hanson, R.T., Dettinger, M.D., 2005. Ground water/surface water responses to global climate simulations, Santa Clara-Calleguas basin, Ventura, California. J. Am. Water Resour. Assoc. 41 (3), 517-536.

Hanson, R.T., Dettinger, M.D., Newhouse, M.W., 2006. Relations between climatic variability and hydrologic time series from four alluvial basins across the southwestern United States. Hydrogeol. J. 14 (7), 1122-1146.

Hanson, R.T., Martin, P., Koczot, K.M., 2003. Simulation of Ground-Water/SurfaceWater Flow in the Santa Clara-Calleguas Ground-Water Basin, Ventura County, California. US Geological Survey.

Hanson, R.T., Newhouse, M.W., Dettinger, M.D., 2004. A methodology to assess relations between climatic variability and variations in hydrologic time series in the southwestern United States. J. Hydrol. 287 (1-4), 252-269.

Hendry, M.J., Woodbury, A.D., 2007. Clay aquitards as archives of Holocene paleoclimate: ${ }^{18} \mathrm{O}$ and thermal profiling. Ground Water 45 (6), 683-691.

Hengeveld, H.G., 2000. A Discussion of Recent Simulations with CGCM. Climate Change Digest. Environment Canada Special Edition CCD 00-01, 32 pp.

Herrera-Pantoja, M., Hiscock, K.M., 2008. The effects of climate change on potential groundwater recharge in Great Britain. Hydrol. Process. 22 (1), 73-86.

Hewitson, B.C. Crane, R.G., 2006. Consensus between GCM climate change projections with empirical downscaling: precipitation downscaling over South Africa. Int. J. Climatol. 26 (10), 1315-1337.

Hinsby, K., Edmunds, W.M., Loosli, H.H., Manzano, M., Condesso de Melo, M.T. Barbecot, F., 2001. The modern water interface: recognition, protection and development - advance of modern waters in European aquifer systems. In: Edmunds, W.M., Milne, C.J. (Eds.), Palaeowater in Coastal Europe: Evolution of Groundwater since the Late Pleistocene. Geol. Soc. Lond. Spec. Publ., pp. 271288.

Hiscock, K.M., Lloyd, J.W., 1992. Palaeohydrogeological reconstructions of the North Lincolnshire Chalk, UK, for the last 140000 years. J. Hydrol. 133 (3-4), 313-342.

Holman, I.P., 2006. Climate change impacts on groundwater recharge-uncertainty, shortcomings, and the way forward? Hydrogeol. J. 14 (5), 637-647.

Hsu, K.C., Wang, C.H., Chen, K.C., Chen, C.T., Ma, K.W., 2007. Climate-induced hydrological impacts on the groundwater system of the Pingtung Plain, Taiwan. Hydrogeol. J. 15 (5), 903-913.

Huang, S., Pollack, H.N., Po-Yu, S., 2000. Temperature trends over the past five centuries reconstructed from borehole temperatures. Nature 403, 756-758.

Huang, S., Taniguchi, M., Yamano, M., Wang, C.-H., 2009. Detecting urbanization effects on surface and subsurface thermal environment - a case study of Osaka. Sci. Total Environ. 407 (9), 3142-3152.

$\mathrm{IAH}$, 2006. Groundwater for Life and Livelihoods - the Framework for Sustainable Use. 4th World Water Forum Invitation and Briefing. <http://www.iah.org/ downloads/occpub/IAH_WWF_briefing.pdf >.

Iglesias, A., Garotte, L., Flores, F., Moneo, M., 2007. Challenges to manage the risk of water scarcity and climate change in the Mediterranean. Water Resour. Manage. 21, 775-788.

IGRAC, 2009. Transboundary Aquifers of the World. <http://www.igrac.net/ dynamics/modules/SFIL0100/view.php?fil_Id=121>.

Ingram, R.G.S., Hiscock, K.M., Dennis, P.F., 2007. Noble gas excess air applied to distinguish groundwater recharge conditions. Environ. Sci. Technol. 41 (6) 1949-1955.

IPCC, 2001. Climate change 2001: The scientific basis. Contribution of working group I to the third assessment report of the Intergovernmental panel on climate change. In: Houghton, J.T., et al. (Eds.), Cambridge University Press, Cambridge, United Kingdom, and New York, NY, USA, pp. 944.

IPCC, 2007a. Climate change 2007: the physical science basis. Contribution of working group I to the fourth assessment report of the intergovernmental pane on climate change. In: Solomon, S., et al. (Eds.), Cambridge University Press, Cambridge, UK, and New York, USA, pp. 996.

IPCC, 2007b. Climate change 2007: impacts, adaptation and vulnerability Contribution of working group II to the fourth assessment report of the intergovernmental panel on climate change. In: Parry, M.L., Canziani, O.F. Palutikof, J.P., Linden, P.J.v.d., Hanson, C.E. (Eds.), Cambridge University Press, Cambridge, UK, and New York, USA 
IPCC, 2008. Technical Paper on Climate Change and Water (Finalized at the 37th Session of the IPCC Bureau). <http://www.ipcc.ch/meetings/session28/ doc13.pdf>.

Jasper, K., Calanca, P., Fuhrer, J., 2006. Changes in summertime soil water patterns in complex terrain due to climatic change. J. Hydrol. 327 (3-4), 550-563.

Jorgensen, D.G., Yasin al-Tikiriti, W., 2003. A hydrologic and archeologic study of climate change in Al Ain, United Arab Emirates. Global Planet. Change 35 (1-2), 37-49.

Jungkunst, H.F., Flessa, H., Scherber, C., Fiedler, S., 2008. Groundwater level controls $\mathrm{CO}_{2}, \mathrm{~N}_{2} \mathrm{O}$ and $\mathrm{CH}_{4}$ fluxes of three different hydromorphic soil types of a temperate forest ecosystem. Soil Biol. Biochem. 40 (8), 2047-2054.

Jyrkama, M.I., Sykes, J.F., 2007. The impact of climate change on spatially varying groundwater recharge in the grand river watershed (Ontario). J. Hydrol. 338 (34), 237-250

Kabat, P., van Vierssen, W., Veraart, J., Vellinga, P., Aerts, J., 2005. Climate proofing the Netherlands. Nature 438 (7066), 283-284.

Kalma, J., McVicar, T., McCabe, M., 2008. Estimating land surface evaporation: a review of methods using remotely sensed surface temperature data. Surv. Geophys. 29 (4), 421-469.

Kalnay, E., Kanamitsu, M., Kistler, R., Collins, W., Deaven, D., Gandin, L., Iredell, M., Saha, S., White, G., Woollen, J., Zhu, Y., Chelliah, M., Ebisuzaki, W., Higgins, W. Janowiak, J., Mo, K.C., Ropelewski, C., Wang, J., Leetmaa, A., Reynolds, R., Jenne, R., Joseph, D., 1996. The NCEP/NCAR 40-year reanalysis project. Bull. Am. Meteorol. Soc. 77 (3), 437-471.

Keeling, C.D., Bacastow, R.B., Bainbridge, A.E., 1976. Atmospheric carbon dioxide variations at Mauna Loa Observatory, Hawaii. TELLUS 28 (6), 538-551.

Keeling, C.D., Brix, H., Gruber, N., 2004. Seasonal and long-term dynamics of the upper ocean carbon cycle at Station ALOHA near Hawaii. Global Biogeochem. Cycl. 18 (4), 1-26.

Kerr, R.A., 2000. A north Atlantic climate pacemaker for the centuries. Science 288 (5473), 1984-1986.

Kertesz, A., Mika, J., 1999. Aridification - climate change in south-eastern Europe Phys. Chem. Earth 24 (10), 913-920.

Khalil, M.A., Santos, F.A.M., Moustafa, S.M., Saad, U.M., 2009. Mapping water seepage from Lake Nasser, Egypt, using the VLF-EM method: a case study. J. Geophys. Eng. 6 (2), 101. doi:10.1088/1742-2132/6/2/001.

Khan, M.S., Coulibaly, P., Dibike, Y., 2006. Uncertainty analysis of statistical downscaling methods. J. Hydrol. 319 (1-4), 357-382.

Kingston, D.G., Taylor, R.G., 2010. Sources of uncertainty in climate change impacts on river discharge and groundwater in a headwater catchment of the Upper Nile Basin, Uganda. Hydrol. Earth Syst. Sci. Discuss. 14, 1297-1308.

Kipfer, R., Aeschbach-Hertig, W., Peeters, F., Stute, M., 2002. Noble gases in lakes and ground waters. Rev. Mineral. Geochem. 47, 615-700.

Kitabata, H., Nishizawa, K., Yoshida, Y., Maruyama, K., 2006. Permafrost thawing in circum-artic and highlands under climate change scenario projected by community climate system model (CCSM3). Sci. Online Lett. Atmos. 2, 5356.

Klein, R.J.T., Nicholls, R.J., 1999. Assessment of coastal vulnerability to climate change. Ambio 28 (2), 182-187.

Knorr, W., Prentice, I.C., House, J.I., Holland, E.A., 2005. Long-term sensitivity of soil carbon turnover to warming Nature 433 (7023), 298-301.

Kooi, H., 2008a. Groundwater palaeohydrology. In: Bierkens, M.F.P., Dolman, A.J., Troch, P.A. (Eds.), Climate and the Hydrological Cycle, vol. 8. IAHS Special Publication, pp. 235-254.

Kooi, H., 2008b. Spatial variability in subsurface warming over the last three decades: insight from repeated borehole temperature measurements in the Netherlands. Earth Planet. Sci. Lett. 270, 86-94.

Koukadaki, M., Karatzas, G., Papadopoulou, M., Vafidis, A., 2007. Identification of the saline zone in a coastal aquifer using electrical tomography data and simulation. Water Resour. Manage. 21 (11), 1881-1898.

Kovalevskii, V.S., 2007. Effect of climate changes on groundwater. Water Resour. 34 (2), 140-152.

Krause, P., Naujoks, M., Fink, M., Kroner, C., 2009. The impact of soil moisture changes on gravity residuals obtained with a superconducting gravimeter. J. Hydrol. 373 (1-2), 151-163.

Kreuzer, A.M., von Rohden, C., Friedrich, R., Chen, Z., Shi, J., Hajdas, I., Kipfer, R., Aeschbach-Hertig, W., 2009. A record of temperature and monsoon intensity over the past $40 \mathrm{kyr}$ from groundwater in the North China Plain. Chem. Geol. 259 (3-4), 168-180.

Kruger, A., Ulbrich, U., Speth, P., 2001. Groundwater recharge in NorthrhineWestfalia predicted by a statistical model for greenhouse gas scenarios. Phys. Chem. Earth 26 (11-12), 853-861.

Kukkonen, I.T., Čermák, V., Šafanda, J., 1994. Subsurface temperature-depth profiles, anomalies due to climatic ground surface temperature changes or groundwater flow effects. Global Planet. Change 9 (3-4), 221-232.

Kundzewicz, Z.W., Döll, P., 2009. Will groundwater ease freshwater stress under climate change? Hydrol. Sci. J. 54 (4), 665-675.

Kundzewicz, Z.W., Mata, L.J., Arnell, N.W., Doll, P., Kabat, P., Jimenez, B., Miller, K.A Oki, T., Sen, Z., Shiklomanov, I.A., 2007. Freshwater resources and their management. In: Parry, M.L., Canziani, O.F., Palutikof, J.P., van der Linden, P.J., Hanson, C.E. (Eds.), Climate Change 2007: Impacts, Adaptation and Vulnerability. Cambridge University Press, Cambridge, pp. 173-210.

Lambrakis, N., Kallergis, G., 2001. Reaction of subsurface coastal aquifers to climate and land use changes in Greece: modelling of groundwater refreshning patterns under natural recharge conditions. J. Hydrol. 245 (1-4), 19-31.
Laroque, M., Mangin, A., Razack, M., Banton, O., 1998. Contribution of correlation and spectral analyses to the regional study of a large karst aquifer (Charente, France). J. Hydrol. 205 (3-4), 217-231.

Le Treut, H., Somerville, R., Cubasch, U., Ding, Y., Mauritzen, C., Mokssit, A., Peterson, T. Prather, M., 2007. Historical overview of climate change In: Solomon, S., Oin, D., Manning, M., Chen, Z., Marquis, M., Averyt, K.B., Tignor, M., Miller, H.L. (Eds.), Climate Change 2007: The Physical Science Basis. Contribution of Working Group I to the Fourth Assessment Report of The Intergovernmental Panel on Climate Change. Cambridge University Press, Cambridge, United Kingdom, and New York, NY, USA.

Leblanc, M.J., Tregoning, P., Ramillien, G., Tweed, S.O., Fakes, A., 2009. Basin-scale, integrated observations of the early 21st century multiyear drought in southeast Australia. Water Resour. Res. 45 (4), W04408. doi:10.1029/ 2008 wr007333.

Lee, K.S., Chung, E.S., 2007. Hydrological effects of climate change, groundwater withdrawal, and land use in a small korean watershed. Hydrol. Process. 21 (22), 3046-3056.

Leith, R.M.M., Whitfield, P.H., 1998. Evidence of climate change effects on the hydrology of streams in south-central B.C. Can. Water Resour. J. 23 (3), 219230.

Lewis, T.J., Wang, K., 1998. Geothermal evidence for deforestation induced warming: implications for the climatic impact of land development. Geophys. Res. Lett. 25 (4), 535-538.

Liu, Y.Y., van Dijk, A.I.J.M., de Jeu, R.A.M., Holmes, T.R.H., 2009. An analysis of spatiotemporal variations of soil and vegetation moisture from a 29-year satellitederived data set over mainland Australia. Water Resour. Res. 45 (7), W07405.

Loaiciga, H.A., 2003. Climate change and ground water. Ann. Assoc. Am. Geographers 93 (1), 30-41.

Loaiciga, H.A., 2009. Long-term climatic change and sustainable ground water resources management. Environ. Res. Lett. 4 (3), 035004

Loaiciga, H.A., Maidment, D.R., Valdes, J.B., 2000. Climate-change impacts in a regional karst aquifer, Texas, USA. J. Hydrol. 227 (1-4), 173-194.

Loaiciga, H.A., Valdes, J.B., Vogel, R., Garvey, J., Schwarz, H., 1996. Global warming and the hydrologic cycle. J. Hydrol. 174 (1-2), 83-127.

Loosli, H.H., Aeschbach-Hertig, W., Barbecot, F., Blaser, P., Darling, W.G., Dever, L., Edmunds, W.M., Kipfer, R., Purtschert, R., Walraevens, K., 2001. Isotopic methods and their hydrogeochemical context in the investigation of palaeowaters. In: Edmunds, W.M., Milne, C.J. (Eds.), Palaeowater in Coastal Europe: Evolution of Groundwater since the Late Pleistocene, vol. 189. Geol. Soc. Lond. Spec. Publ, pp. 193-212.

Lorenz, E.N., 1963. Deterministic nonperiodic flow. J. Atmos. Sci. 20, 130-141.

Lorenz, E.N., 1975. Climate predictability. In: The Physical Basis of Climate and Climate Modelling. WMO GARP Publ. Ser. No. 16, pp. 132-136.

Ludwig, F., Kabat, P., van Schaik, H., van der Valk, M., 2010. Climate Change Adaptation in the Water Sector. Earthscan Publishing, London, 274 pp.

Mantua, N.J., Hare, S.R., 2002. The Pacific decadal oscillation. J. Oceanogr. 58 (1), 3544.

Martin-Rosales, W., Pulido-Bosch, A., Vallejos, A., Gisbert, J., Andreu, J.M., SanchezMartos, F., 2007. Hydrological implications of desertification in southeastern Spain. Hydrol. Sci. J. 52 (6), 1146-1161.

Maxwell, R.M., Miller, N.L., 2005. Development of a coupled land surface and groundwater model. J. Hydrometeorol. 6 (3), 233-247.

Mayer, T.D., Congdon, R.D., 2008. Evaluating climate variability and pumping effects in statistical analyses. Ground Water 46 (2), 212-227.

McCabe, G.J., Palecki, M.A., Betancourt, J.L., 2004. Pacific and Atlantic ocean influences on multidecadal drought frequency in the United States. Proc. Natl. Acad. Sci. USA 101 (12), 4136-4141.

McMahon, P.B., Dennehy, K.F., Bruce, B.W., Bohlke, J.K., Michel, R.L., Gurdak, J.J., Hurlbut, D.B., 2006. Storage and transit time of chemicals in thick unsaturated zones under rangeland and irrigated cropland, High Plains, United States. Water Resour. Res. 42, W03314.

McMahon, P.B., Dennehy, K.F., Bruce, B.W., Gurdak, J.J., Qi, S.L., 2007. Water-quality Assessment of the High Plains Aquifer, 1999-2004. US Geological Survey.

Mearns, L.O., Hulme, M., Carter, T.R., Leemans, R., Lal, M., Whetton, P., 2007. Climate scenario development. In: Solomon, S., Qin, D., Manning, M., Chen, Z., Marquis, M., Averyt, K.B., Tignor, M., Miller, H.L. (Eds.), Climate Change 2007: The Physical Science Basis. Contribution of Working Group I to the Fourth Assessment Report of the Intergovernmental Panel on Climate Change. Cambridge University Press, Cambridge, United Kingdom, and New York, NY, USA, pp. 739-768.

Meehl, G.A., Stocker, T.F., Collins, W.D., Friedlingstein, P., Gaye, A.T., Gregory, J.M., Kitoh, A., Knutti, R., Murphy, J.M., Noda, A., Raper, S.C.B., Watterson, I.G., Weaver, A.J., Zhao, Z.-C., 2007. Global climate projections. In: Solomon, S., Qin, D., Manning, M., Chen, Z., Marquis, M., Averyt, K.B., Tignor, M., Miller, H.L. (Eds.), Climate Change 2007: The Physical Science Basis. Contribution of Working Group I to the Fourth Assessment Report of the Intergovernmental Panel on Climate Change. Cambridge University Press, Cambridge, United Kingdom, and New York, NY, USA

Mileham, L., Taylor, R., Thompson, J., Todd, M., Tindimugaya, C., 2008. Impact of rainfall distribution on the parameterisation of a soil-moisture balance model of groundwater recharge in equatorial Africa. J. Hydrol. 359 (1-2), 46-58.

Mileham, L., Taylor, R.G., Todd, M., Tindimugaya, C., Thompson, J., 2009. The impact of climate change on groundwater recharge and runoff in a humid, equatorial catchment: sensitivity of projections to rainfall intensity. Hydrol. Sci. J. 54 (4), 727-738. 
Miller, N.L., Dale, L.L., Brush, C.F., Vicuna, S.D., Kadir, T.N., Dogrul, E.C., Chung, F.I., 2009. Drought resilience of the California Central Valley surface-ground-waterconveyance system. J. Am. Water Resour. Assoc. 45 (4), 857-866.

Milly, P.C.D., Betancourt, J.L., Falkenmark, M., Hirsch, R.M., Kundzewicz, Z.W., Lettenmaier, D.P., Stouffer, R.J., 2008. Stationarity is dead: whither water management? Science 319, 573-574.

Milly, P.C.D., Dunne, K.A., Vecchia, A.V., 2005. Global pattern of trends in streamflow and water availability in a changing climate. Nature 438, 347-350.

Miyakoshi, A., Taniguchi, M., Okubo, Y., Uemura, T., 2005. Evaluations of subsurface flow for reconstructions of climate change using borehole temperature and isotope data in Kamchatka. Phys. Earth Planet Int. 152 (4), 335-342.

Monnin, E., Indermuhle, A., Dallenbach, A., Fluckiger, J., Stauffer, B., Stocker, T.F. Raynaud, D., Barnola, J.-M., 2001. Atmospheric CO2 concentrations over the last glacial termination. Science 291 (5501), 112-114.

Mote, P.W., Hamlet, A.F., Clark, M.P., Lettenmaier, D.P., 2005. Declining mountain snowpack in western North America. Am. Meteorol. Soc. 86 (1), 39-49.

Moustadraf, J., Razack, M., Sinan, M., 2008. Evaluation of the impacts of climate changes on the coastal chaouia aquifer, Morocco, using numerical modeling. Hydrogeol. J. 16 (7), 1411-1426.

Mudelsee, M., 2001. The phase relations among atmospheric CO2 content, temperature and global ice volume over the past 420 ka. Quaternary Sci. Rev. 20 (4), 583-589.

Nakićenović, N., Swart, R., 2000. Special Report on Emissions Scenarios. A Special Report of Working Group III of the Intergovernmental Panel on Climate Change. Cambridge, UK, and New York, NY, USA.

Neelin, J.D., Muennich, M., Su, H., Meyerson, J.E., Holloway, C.E., 2006. Tropical drying trends in global warming models and observations. Proc. Natl. Acad. Sci. USA 103 (16), 6110-6115.

Ngongondo, C.S., 2006. An analysis of long-term rainfall variability, trends and groundwater availability in the Mulunguzi river catchment area, Zomba Mountain, Southern Malawia. Quat. Int. 148, 45-50.

Noguer, M., 1994. Using statistical techniques to deduce local climate distributions. An application for model validation. Meteor. Apps. 1, 277-287.

Novicky, O., Kasparek, L., Uhlik, J., 2010. Vulnerability of groundwater resources in different hydrogeology conditions to climate change. In: Taniguchi, M., Holman, I.P. (Eds.), Groundwater Response to Changing Climate. International Association of Hydrogeologists Selected Paper. CRC Press, Taylor and Francis Group, London, UK, pp. 1-10.

Ojo, O., Oni, F., Ogunkunle, O., 2003. Implications of climate variability and climate change on water resources availability and water resources management in West Africa. In: Franks, S., Bloschl, S., Kumagai, M., Musiake, K., Rosbjerg, D. (Eds.), Water Resources Systems - Water Availability and Global Change. International Association of Hydrological Sciences, Wallingford, UK, pp. 37-47.

Okkonen, J., Jyrkama, M., Klove, B., 2009. A conceptual approach for assessing the impact of climate change on groundwater and related surface waters in cold regions (Finland). Hydrogeol. J. 18 (2), 429-439.

Okkonen, J., Klove, B., 2010. A conceptual and statistical approach for the analysis of climate impact on ground water table fluctuation patterns in cold conditions. J. Hydrol., 388. doi:10.1016/j.jhydrol.2010.02.015.

Osborn, T.J., Briffa, K.R., Tett, S.F.B., Jones, P.D., Trigo, R.M., 1999. Evaluation of the north atlantic oscillation as simulated by a coupled climate model. Clim. Dynam. 15, 685-702.

Oude Essink, G.H.P., 1996. Impact of Sea Level Rise on Groundwater Flow Regimes, A Sensitivity Analysis for the Netherlands. Delft University of Technology, Delft, $411 \mathrm{pp}$.

Oude Essink, G.H.P., 2001. Salt water intrusion in a three-dimensional groundwater system in the Netherlands: a numerical study. Transp. Porous Media 43, 137158.

Oude Essink, G.H.P., 2004. Modeling three-dimensional density dependent groundwater flow at the island of Texel, The Netherlands. In: Cheng, A.H.D. Ouazar, D. (Eds.), Coastal Aquifer Management: Monitoring, Modeling, and Case Studies. Lewis Publisher, New York, pp. 77-94

Oude Essink, G.H.P., van Baaren, E.S., de Louw, P.G.B., 2010. Effects of climate change on coastal groundwater systems: a modeling study in the Netherlands. Water Resour. Res. 46, W00F04. doi:10.1029/2009WR008719.

Ouysse, S., Laftouhi, N.E., Tajeddine, K., 2010. Impacts of climate variability on the water resources in the Draa basin (Morocco): analysis of the rainfall regime and groundwater recharge. In: Taniguchi, M., Holman, I.P. (Eds.), Groundwater Response to Changing Climate, International Association of Hydrogeologists Selected Paper. CRC Press, Taylor and Francis Group, London, UK, pp. 27-48.

Payne, J.T., Wood, A.W., Hamlet, A.F., Palmer, R.N., Lettenmaier, D.P., 2004 Mitigating the effects of climate change on the water resources of the Columbia River Basin. Clim. Change 62, 233-256.

Peterson, R.N., Burnett, W.C., Glenn, C., Johnson, A., 2009. Quantification of pointsource groundwater discharges to the ocean from the shoreline of the Big Island, Hawaii. Limnol. Oceanogr. 54 (3), 890-904.

Petit, J.R., Jouzel, J., Raynaud, D., Barkov, N.I., Barnola, J.M., Basile, I., Bender, M., Chappellaz, J., Davis, M., Delaygue, G., Delmotte, M., Kotlyakov, V.M., Legrand, M., Lipenkov, V.Y., Lorius, C., Pepin, L., Ritz, C., Saltzman, E., Stievenard, M., 1999. Climate and atmospheric history of the past 420,000 years from the Vostok ice core, Antarctica. Nature 399 (6735), 429-436.

Phillips, F.M., 1994. Environmental tracers for water in desert soils of the American Southwest. Soil Sci. Soc. Am. J. 58, 15-24.

Pielke Sr., R.A., 2001. Influence of the spatial distribution of vegetation and soils on the prediction of cumulus convective rainfall. Rev. Geophys. 39 (2), 151-177.
Pierson, W.L., Nittim, R., Chadwick, M.J., Bishop, K.A., Horton, P.R., 2001. Assessment of changes to saltwater/freshwater habitat from reductions in flow to the Richmond river estuary, Australia. Water Sci. Technol. 43 (9), 89-97.

Plummer, L.N., 1993. Stable isotope enrichment in paleowaters of the southeast Atlantic coastal plain, United States. Sci. Total Environ. 262, 2016-2020.

Pool, D.R., Eychaner, J.H., 1995. Measurement of aquifer-storage change and specific yield using gravity surveys. Ground Water 33 (3), 425-432.

Porcelli, D., Ballentine, C.J., Wieler, R., 2002. Noble Gases in Geochemistry and Cosmochemistry (Reviews in Mineralogy and Geochemistry 47). Geochemical Society and Mineralogical Society of America, Washington, USA.

Postel, S., 2001. Growing more food with less water. Sci. Am. 284 (2), 46-51.

Puri, S., Aureli, A., 2005. Transboundary aquifers: a global program to assess, evaluate, and develop policy. Ground Water 43 (5), 661-668.

Purkey, D.R., Joyce, B., Vicuna, S., Hanemann, M.W., Dale, L.L., Yates, D., Dracup, J.A., 2007. Robust analysis of future climate change impacts on water for agriculture and other sectors: a case study in the Sacramento Valley. Clim. Change 87, S109-S122 (Supplement).

Ramillien, G., Famiglietti, J.S., Wahr, J., 2008. Detection of continental hydrology and glaciology signals from GRACE: a review. Surv. Geophys. 29, 361-374.

Randall, D.A., Wood, R.A., Bony, S., Colman, R., Fichefet, T., Fyfe, J., Kattsov, V. Pitman, A., Shukla, J., Srinivasan, J., Stouffer, R.J., Sumi, A., Taylor, K.E., 2007. Climate models and their evaluation. In: Solomon, S., Qin, D., Manning, M. Chen, Z., Marquis, M., Averyt, K.B., Tignor, M., Miller, H.L. (Eds.), Climate Change 2007: The Physical Science Basis. Contribution of Working Group I to the Fourth Assessment Report of the Intergovernmental Panel on Climate Change. Cambridge University Press, Cambridge, United Kingdom, and New York, NY, USA, pp. 589-662.

Ranjan, P., Kazama, S., Sawamoto, M., 2006a. Effects of climate change on coastal fresh groundwater resources. Global Environ. Change 16 (4), 388-399.

Ranjan, S.P., Kazama, S., Sawamoto, M., 2006b. Effects of climate and land use changes on groundwater resources in coastal aquifers. J. Environ. Manage. 80 (1), 25-35.

Reilly, T.E., Dennehy, K.F., Alley, W.M., Cunningham, W.L., 2008. Ground-water Availability in the United States, vol. 1323. US Geological Survey, 70 pp.

Rivard, C., Paniconi, C., Gauthier, M.J., François, G., Sulis, M., Camporese, M., Larocque, M., Chaumont, D., 2008. A modeling study of climate change impacts on recharge and surface-groundwater interactions for the Thomas brook catchment (Annapolis Valley, Nova Scotia). In: Proceedings of GeoEdmonton, Canadian Geotechnical Society - International Association of Hydrogeologists Canadian National Chapter Joint Annual Conference, Edmonton, Canada.

Rodell, M., Chen, J., Kato, H., Famiglietti, J., Nigro, J., Wilson, C., 2007. Estimating ground water storage changes in the Mississippi river basin using GRACE Hydrogeol. J.. doi:10.1007/s10040-006-0103-7.

Rodell, M., Famiglietti, J.S., 2002. The potential for satellite-based monitoring of groundwater storage changes using GRACE: the high plains aquifer, central US J. Hydrol. 263 (1-4), 245-256.

Rodell, M., Velicogna, I., Famiglietti, J.S., 2009. Satellite-based estimates of groundwater depletion in India. Nature, 460. doi:10.1038/nature108238.

Rosenberg, N.J., Epstein, D.J., Wang, D., Vail, L., Srinivasan, R., Arnold, J.G., 1999. Possible impacts of global warming on the hydrology of the Ogallala Aquifer region. Clim. Change 42 (4), 677-692.

Rowell, D., Jones, R., 2006. Causes and uncertainty of future summer drying over Europe. Clim. Dynam. 27 (2), 281-299.

Roy, S., Harris, R.N., Rao, R.U.M., Chapman, D.S., 2002. Climate change in India inferred from geothermal observations. J. Geophys. Res. 107 (7), 5.

Ruud, N., Harter, T., Naugle, A., 2004. Estimation of groundwater pumping as closure to the water balance of a semi-arid, irrigated agricultural basin. J. Hydrol. 297 (1-4), 51-73.

Sahagian, D.L., Schwartz, F.W., Jacobs, D.K., 1994. Direct anthropogenic contributions to sea level rise in the twentieth century. Nature 367, 54-57.

Sandstrom, K., 1995. Modeling the effects of rainfall variability on groundwater recharge in semi-arid Tanzania. Nordic Hydrol. 26, 313-330.

Scanlon, B.R., Healy, R.W., Cook, P.G., 2002. Choosing appropriate techniques for quantifying groundwater recharge. Hydrogeol. J. 10 (1), 18-29.

Scanlon, B.R., Keese, K.E., Flint, A.L., Flint, L.E., Gaye, C.B., Edmunds, W.M., Simmers, I., 2006. Global synthesis of groundwater recharge in semiarid and arid regions Hydrol. Process. 20, 3335-3370.

Schnur, R., Lettenmaier, D.P., 1998. A case study of statistical downscaling in Australia using weather classification by recursive partitioning. J. Hydrol. 212213, 362-379.

Scibek, J., Allen, D.M., 2006a. Comparing modelled responses of two highpermeability, unconfined aquifers to predicted climate change. Global Planet. Change 50 (1-2), 50-62.

Scibek, J., Allen, D.M., 2006b. Modeled impacts of predicted climate change on recharge and groundwater levels. Water Resour. Res. 42 (11), W11405. doi:10.1029/2005WR004742.

Scibek, J., Allen, D.M., Cannon, A.J., Whitfield, P.H., 2007. Groundwater-surface water interaction under scenarios of climate change using a high-resolution transient groundwater model. J. Hydrol. 333 (2-4), 165-181.

Semenov, M.A., Barrow, E.M., 1997. Use of a stochasic weather generator in the development of climate change scenarios. Clim. Change 35 (4), 397-414.

Semenov, M.A., Brooks, R.J., Barrow, E.M., Richardson, C.W., 1998. Comparison of the WGEN and LARS-WG stochastic weather generators for diverse climates. Clim. Res. 10 (2), 95-107. 
Seneviratne, S.I., Corti, T., Davin, E.L., Hirschi, M., Jaeger, E.B., Lehner, I., Orlowsky, B. Teuling, A.J., 2010. Investigating soil moisture-climate interactions in changing climate: a review. Earth-Sci. Rev. 99 (3-4), 125-161.

Serrat-Capdevila, A., Valdes, J.B., Perez, J.G., Baird, K., Mata, L.J., Maddock Iii, T., 2007. Modeling climate change impacts - and uncertainty - on the hydrology of a riparian system: The San Pedro Basin (Arizona/Sonora). J. Hydrol. 347 (1-2), 48 66.

Shah, T., 2009. Climate change and groundwater: India opportunities for mitigation and adaptation. Environ. Res. Lett. 4 (3), 035005.

Sharda, V.N., Kurothe, R.S., Sena, D.R., Pande, V.C., Tiwari, S.P., 2006. Estimation of groundwater recharge from water storage structures in a semi-arid climate of India. J. Hydrol. 329 (1-2), 224-243.

Sharif, M.M., Singh, V.P., 1999. Effect of climate change on sea water intrusion in coastal aquifers. Hydrol. Process. 13 (8), 1277-1287.

Sharma, M.L., 1989. Impact of Climate Change on Groundwater Recharge Conference on Climate and Water. Academy of Finland, Helsinki, Finland, pp. 511-519.

Sherif, M.M., Singh, V.P., 1999. Effect of climate change on sea water intrusion in coastal aquifers. Hydrol. Process. 13 (8), 1277-1287.

Singleton, M.J., Moran, J.E., 2010. Dissolved noble gas and isotopic tracers reveal vulnerability of groundwater in a small, high elevation catchment to predicted climate change. Water Resour. Res, 46, W00F06, doi:10.1029/2009WR008718.

Skinner, A.C., 2008. Groundwater: still out of sight but less out of mind. Quart. J. Eng. Geol. Hydrogeol. 41 (1), 5-19.

Slomp, C.P., Van Cappellen, P., 2004. Nutrient inputs to the coastal ocean through submarine groundwater discharge: controls and potential impact. J. Hydrol. 295 (1-4), 64-86.

Small, E.E., 2005. Climatic controls on diffuse groundwater recharge in semiarid environments of the southwestern United States. Water Resour. Res. 41, W04012.

Smerdon, J.E., Beltrami, H., Creelman, C., Stevens, M.B., 2009. Characterizing land surface processes: a quantitative analysis using air-ground thermal orbits. J. Geophys. Res. 114 (D15), D15102.

Smerdon, J.E., Pollack, H.N., Cermak, V., Enz, J.W., Kresl, M., Safanda, J., Wehmiller, J.F., 2004. Air-ground temperature coupling and subsurface propagation of annual temperature signals. J. Geophys. Res. 109 (21).

Soldati, M., Corsini, A., Pasuto, A., 2004. Landslides and climate change in the Italian Dolomites since the late glacial. Catena 55 (2), 141-161.

Sophocleous, M., 2004. Climate change: why should water professionals care? Ground Water 42 (5), 637.

Speidel, D.H., Agnew, A.F., 1988. The world water budget. In: Speidel, D.H., Ruedisili, L.C., Agnew, A.F. (Eds.), Perspectives on Water: Uses and Abuses. Oxford University Press, New York, pp. 27-36.

St. Jacques, J.M., Sauchyn, D.J., 2009. Increasing winter baseflow and mean annual streamflow from possible permafrost thawing in the Northwest Territories, Canada. Geophys. Res. Lett. 36, L01401.

Stewart, I.T., Cayan, D.R., Dettinger, M.D., 2004. Changes in snowmelt runoff timing in western North America under a 'business as usual' climate change scenario. Clim. Change 62, 217-232.

Stoll, S., Hendricks Franssen, H.J., Butts, M., Kinzelbach, W., 2011. Analysis of the impact of climate change on groundwater related hydrological fluxes: a multimodel approach including different downscaling methods. Hydrol. Earth Syst. Sci. 15 (1), 21-38.

Strassberg, G., Scanlon, B.R., Rodell, M., 2007. Comparison of seasonal terrestrial water storage variations from GRACE with groundwater-level measurements from the high plains aquifer (USA). Geophys. Res. Lett. 34, L14402. doi:10.1029/ 2007GL030139.

Strzepek, K.M., Yates, D.N., 1997. Climate change impacts on the hydrologic resources of Europe: a simplified continental scale analysis. Clim. Change 36 (12), 79-92.

Stute, M., Schlosser, P., 1993. Principles and applications of the noble gas paleothermometer. In: Swart, P.K., Lohmann, K.C., McKenzie, J., Savin, S. (Eds.), Climate Change in Continental Isotopic Records. American Geophysical Union, Geophysical Monograph 78, Washington, DC, pp. 89-100.

Sukhija, B.S., Reddy, D.V., Nagabhushanam, P., 1998. Isotopic fingerprints of paleoclimates during the last 30,000 years in deep confined groundwaters of southern India. Quat. Res. 50 (3), 252-260.

Suski, B., Ladner, F., Baron, L., Vuataz, F.D., Philippossian, F., Holliger, K., 2008 Detection and characterization of hydraulically active fractures in a carbonate aquifer: results from self-potential, temperature and fluid electrical conductivity logging in the Combioula hydrothermal system in the southwestern Swiss alps. Hydrogeol. J. 16 (7), 1319-1328.

Swenson, S., Famiglietti, J., Basara, J., Wahr, J., 2008. Estimating profile soil moisture and groundwater variations using GRACE and Oklahoma Mesonet soil moisture data. Water Resour. Res. 44, W01413. doi:10.1029/ 2007WR006057.

Swenson, S., Yeh, P.J.F., Wahr, J., Famiglietti, J., 2006. A comparison of terrestrial water storage variations from GRACE with in situ measurements from Illinois Geophys. Res. Lett. 33 (16).

Syed, T.H., Famiglietti, J.S., Rodell, M., Chen, J., Wilson, C.R., 2008. Analysis of terrestrial water storage changes from GRACE and GLDAS. Water Resour. Res. 44 (2), W02433.

Tague, C., Grant, G., Farrell, M., Choate, J., Jefferson, A., 2008. Deep groundwater mediates streamflow response to climate warming in the Oregon Cascades. Clim. Change 86 (1-2), 189-210.
Tague, C., Grant, G.E., 2009. Groundwater dynamics mediate low-flow response to global warming in snow-dominated alpine regions. Water Resour. Res. 45 (7), W07421.

Tanaka, S.K., Zhu, T.J., Lund, J.R., Howitt, R.E., Jenkins, M.W., Pulido, M.A., Tauber, M., Ritzema, R.S., Ferreira, I.C., 2006. Climate warming and water management adaptation for California. Clim. Change 76, 361-387.

Taniguchi, M., 2000. Evaluation of the saltwater-groundwater interface from borehole temperature in a coastal region. Geophys. Res. Lett. 27 (5), 713-716.

Taniguchi, M., 2002. Estimations of the past groundwater recharge rate from deep borehole temperature data. Catena 48 (1-2), 39-51.

Taniguchi, M., Burnett, W.C., Ness, G.D., 2008. Integrated research on subsurface environments in Asian urban areas. Sci. Total Environ. 404 (2-3), 377-392.

Taniguchi, M., Shimada, J., Fukuda, Y., Yamano, M., Onodera, S.-I., Kaneko, S., Yoshikoshi, A. 2009. Anthropogenic effects on the subsurface thermal and groundwater environments in Osaka, Japan and Bangkok, Thailand. Sci. Total Environ. 407 (9), 3153-3164.

Taniguchi, M., Uemura, T.J.K., Jago-on, K., 2007. Combined effects of heat island and global warming on subsurface temperature. Vadose Zone J. 6 (3), 591596.

Taniguchi, M., Williamson, D.R., Peck, A.J., 1999. Disturbances of temperature-depth profiles due to surface climate-change and subsurface water flow: (2) an effect of step increase in surface temperature caused by forest clearing in southwest of Western Australia. Water Resour. Res. 35, 1519-1529.

Tapley, B.D., Bettadpur, S., Ries, J.C., Thompson, P.F., Watkins, M.M., 2004. GRACE measurements of mass variability in the earth system. Science 305, 503-505.

Taylor, B., 1997. Climate change scenarios for British Columbia and yukon. In: Taylor, E., Taylor, B. (Eds.), Responding to Global Climate Change in British Columbia and Yukon. Volume I of the Canada Country Study: Climate Impacts and Adaptation. Environment Canada and BC Ministry of Environment, Lands and Parks.

Taylor, K.E., 2001. Summarizing multiple aspects of model performance in a single diagram. J. Geophys. Res. 106, 7183-7192.

Thomsen, R., 1989. The Effects of Climate Variability and Change on Groundwater in Europe, Conference on Climate and Water. Academy of Finland, Helsinki, Finland, pp. 486-500.

Thoning, K.W., Tans, P.P., Komhyr, W.D., 1989. Atmospheric carbon dioxide at Mauna Loa Observatory. 2. Analysis of the NOAA GMCC data, 1974-1985. J. Geophys. Res. 94 (D6), 8549-8565.

Tietjen, B., Zehe, E., Jeltsch, F., 2009. Simulating plant water availability in dry lands under climate change: a generic model of two soil layers. Water Resour. Res. 45 (1), W01418.

Toews, M.W., Allen, D.M., 2009a. Simulated response of groundwater to predicted recharge in a semi-arid region using a scenario of modelled climate change. Environ. Res. Lett. 4 (3), 035003.

Toews, M.W., Allen, D.M., 2009b. Evaluating different GCMs for predicting spatial recharge in an irrigated arid region. J. Hydrol. 374 (3-4), 265-281.

Uchida, Y., Hayashi, T., 2005. Effects of hydrogeological and climate change on the subsurface thermal regime in the Sendai Plain. Phys. Earth Planet Int. 152 (4), 292-304.

UNESCO, 2008. Groundwater Resources Assessment under the Pressures of Humanity and Climate Change (GRAPHIC): A Framework Document. GRAPHIC Series Number 2. United Nations Educational, Scientific, and Cultural Organization (UNESCO), Paris, $31 \mathrm{pp}$.

Vaccaro, J.J., 1992. Sensitivity of groundwater recharge estimates to climate variability and change, Columbia Plateau, Washington. J. Geophys. Res. 97 (D3), 2821-2833.

van der Gun, J.A.M., 2010. Climate change and alluvial aquifers in arid regions: examples from Yemen. In: Ludwig, F., Kabat, P., Schaik, H.v., Valk, M.v.d. (Eds.), Climate Change Adaptation in the Water Sector. Earthscan Publishing, London, pp. 159-176.

Van Dijck, S.J.E., Laouina, A., Carvalho, A.V., Loos, S., Schipper, A.M., Van der Kwast, H., Nafaa, R., Antari, M., Rocha, A., Borrego, C., Ritsema, C.J., 2006. Desertification in northern Morocco due to effects of climate change on groundwater recharge. In: Kepner, W.G., Rubio, J.L., Mouat, D.A., Pedrazzini, F. (Eds.), Desertification in the Mediterranean region: A Security Issue. Springer, Dordrecht, The Netherlands, pp. 549-577.

van Roosmalen, L., Christensen, B.S.B., Sonnenborg, T.O., 2007. Regional differences in climate change impacts on groundwater and stream discharge in Denmark. Vadose Zone J. 6 (3), 554-571.

van Roosmalen, L., Sonnenborg, T.O., Jensen, K.H., 2009. Impact of climate and land use change on the hydrology of a large-scale agricultural catchment. Water Resour. Res. 45 (7), W00A15.

Vandenbohede, A., Luyten, K., Lebbe, L., 2008. Effects of global change on heterogeneous coastal aquifers: a case study in Belgium. J. Coast. Res. 24 (2 Suppl. B), 160-170.

Veijalainen, N., Lotsari, E., Alho, P., Vehviläinen, B., Käyhkö, J., 2010. National scale assessment of climate change impacts on flooding in Finland. J. Hydrol. 391 (34), 333-350.

Viviroli, D., Archer, D.R., Buytaert, W., Fowler, H.J., Greenwood, G.B., Hamlet, A.F., Huang, Y., Koboltschnig, G., Litaor, M.I., Lopez-Moreno, J.I., Lorentz, S., Schadler, B., Schreier, H., Schwaiger, K., Vuille, M., Woods, R., 2011. Climate change and mountain water resources: overview and recommendations for research, management and policy. Hydrol. Earth Syst. Sci. Discuss. 15, 471-504. 
von Storch, H., Zorita, E., Cubasch, U., 1993. Downscaling of global climate change estimates to regional scale: an application to Iberian rainfall in winter time. J. Clim. 6, 1161-1171.

Wahr, J., Swenson, S., Velicogna, I., 2006. The accuracy of GRACE mass estimates. Geophys. Res. Lett. 33, L06401. doi:10.1029/2005GL025305.

Walvoord, M.A., Striegl, R.G., 2007. Increased groundwater to stream discharge from permafrost thawing in the yukon river basin: potential impacts on lateral export of carbon and nitrogen. Geophys. Res. Lett. 34, L12402.

Wang, G., 2005. Agricultural drought in a future climate: results from 15 global climate models participating in the IPCC 4th assessment. Clim. Dynam. 25 (7), 739-753.

Wang, T., Istanbulluoglu, E., Lenters, J., Scott, D., 2009. On the role of groundwater and soil texture in the regional water balance: an investigation of the Nebraska Sand Hills, USA. Water Resour. Res. 45 (10), W10413.

Warner, S.D., 2007. Climate change, sustainability, and ground water remediation: the connection. Ground Water Monit. Remed. 27 (4), 50-52.

White, I., Falkland, T., Metutera, T., Metai, E., Overmars, M., Perez, P., Dray, A., Falkland, A.C., 2007. Climatic and human influences on groundwater in low atolls. Vadose Zone J. 6 (3), 581-590.

Wilby, R.L., Dawson, C.W., Barrow, E.M., 2002. A decision support tool for the assessment of regional climate change impacts. Environ. Model. Softw. 17 (2), $145-157$.

Wilby, R.L., Harris, I., 2006. A framework for assessing uncertainties in climate change: low-flow scenarios for the river thames, UK. Water Resour. Res. 42, W02419. doi:10.1029/2005WR00406.

Wilby, R.L., Wigley, T.M.L., 1997. Downscaling general circulation model output: a review of methods and limitations. Prog. Phys. Geogr. 21, 530-548.

Wilks, D.S., Wilby, R.L., 1999. The weather generation game: a review of stochastic weather models. Prog. Phys. Geogr. 23, 329-357.

Windom, H.L., Moore, W.S., Niencheski, L.F.H., Jahnke, R.A., 2006. Submarine groundwater discharge: a large, previously unrecognized source of dissolved iron to the south Atlantic ocean. Mar. Chem. 102, 252-266.

Winter, T.C., 1983. The interaction of lakes with variably saturated porous media. Water Resour. Res. 19 (5), 1203-1218.

Winter, T.C., 1999. Relation of streams, lakes, and wetlands to groundwater flow systems. Hydrogeol. J. 7 (1), 28-45.

Woldeamlak, S.T., Batelaan, O., De Smedt, F., 2007. Effects of climate change on the groundwater system in the Grote-Nete catchment, Belgium. Hydrogeol. J. 15 (5), 891-901.

Woodhouse, B., 2007. Climate change through the eyes of water managers. Southwest Hydrol. 6 (1), 22-23.

Xu, C.-Y., 1999. From GCM's to river flow: a review of downscaling methods and hydrologic modelling approaches. Prog. Phys. Geogr. 23 (2), 229-249.
Yamamoto, K., Hasegawa, T., Fukuda, Y., Nakaegawa, T., Taniguchi, M., 2008 Improvement of jlg terrestrial water storage model using GRACE satellite gravity data. In: Taniguchi, M. et al. (Eds.), From Headwater to the Ocean. CRC Press, Taylor and Francis Group, London, pp. 369-374.

Yamano, M. Goto, S. Miyakoshi, A. Hamamoto, H., Lubis, R.F., Monyrath, V. Taniguchi, M., 2009. Reconstruction of the thermal environment evolution in urban areas from underground temperature distribution. Sci. Total Environ. 407 (9), 3120-3128.

Yang, C., Chandler, R.E., Isham, V.S., Annoni, C., Wheater, H.S., 2005. Simulation and downscaling models for potential evaporation. J. Hydrol. 302 (1-4), 239-254.

Yates, D., Gangopadhyay, S., Rajagopalan, B., Strzepek, K., 2003. A technique for generating regional climate scenarios using a nearest-neighbor algorithm. Water Resour. Res. 39 (7), 1199. doi:10.1029/2002WR001769.

Yechieli, Y., Shalev, E., Wollman, S., Kiro, Y., Kafri, U., 2010. Response of the Mediterranean and Dead Sea coastal aquifers to sea level variations. Wate Resour. Res. 46, W12550. doi:10.1029/2009WR008708.

Yeh, P.J.-F., Swenson, S.C., Famiglietti, J.S., Rodell, M., 2006. Remote sensing of groundwater storage changes in illinois using the gravity recovery and climate experiment (GRACE). Water Resour. Res. 42, W12203. doi:10.1029/ 2006WR005374.

York, J.P., Person, M., Gutowski, W.J., Winter, T.C., 2002. Putting aquifers into atmospheric simulation models: An example from the Mill Creek Watershed, northeastern Kansas. Adv. Water Resour. 25 (2), 221-238.

Yu, Z., Pollard, D., Cheng, L., 2006. On continental-scale hydrologic simulations with a coupled hydrologic model. J. Hydrol. 331 (1-2), 110-124.

Yusoff, I. Hiscock, K.M. Conway, D. 2002. Simulation of the impacts of climate change on groundwater resources in eastern England. In: Hiscock, K.M., Rivett M.O., Davison, R.M. (Eds.), Sustainable Groundwater Development. Geological Survey of London, London, pp. 325-344.

Zaitchik, B.F., Rodell, M., Reichle, R.H., 2008. Assimilation of GRACE terrestrial water storage data into a land surface model. J. Hydrometeorol. 9, 535-548.

Zektser, I.S., Loaiciga, H.A., 1993. Groundwater fluxes in the global hydrologic cycle: Past, present and future. J. Hydrol. 144 (1-4), 405-427.

Zorita, E., von Storch, H., 1999. The analog method - a simple statistica downscaling technique: comparison with more complicated methods. J. Clim. $12,2474-2489$

Zouhri, L., Carlier, E., Ben Kabbour, B., Toto, E., Gorini, C., Louche, B., 2008. Groundwater interaction in the coastal environment: hydrochemical, electrical and seismic approaches. Bull. Eng. Geol. Environ. 67 (1), 123-128.

Zuppi, G.M. Sacchi, E, 2004. Hydrogeology as a climate recorder: Sahara-Sahel (North Africa) and the Po Plain (northern Italy). Global Planet. Change 40 (1-2), 79-91. 